UNIVERSIDADE DE SÃO PAULO

FACULDADE DE FILOSOFIA, CIÊNCIAS E LETRAS DE RIBEIRÃO PRETO

Departamento de Psicologia

Programa de Pós-graduação em Psicologia

\title{
Organização e dinâmica psíquica na obesidade infantil
}

\section{Carmem Gil Coury}



FACULDADE DE FILOSOFIA, CIÊNCIAS E LETRAS DE RIBEIRÃO PRETO

Departamento de Psicologia

Programa de Pós-graduação em Psicologia

\section{Organização e dinâmica psíquica na obesidade infantil}

\section{Carmem Gil Coury}

Dissertação apresentada à Faculdade de Filosofia, Ciências e Letras de Ribeirão Preto da Universidade de São Paulo, como parte das exigências para a obtenção do título de Mestre em Ciências, Área: Psicologia.

Orientadora: Profa. Dra. Sonia Regina Pasian

Ribeirão Preto (SP)

- 2016 - 
Autorizo a reprodução e divulgação total ou parcial deste trabalho por qualquer meio convencional ou eletrônico, para fins de estudo e pesquisa, desde que citada a fonte.

\section{Coury, Carmem Gil}

Organização e dinâmica psíquica na obesidade infantil. Ribeirão Preto, 2016.

170p. : Il. ; $30 \mathrm{~cm}$.

Dissertação de Mestrado, apresentada à Faculdade de Filosofia Ciências e Letras de Ribeirão Preto/USP. Área de concentração : Psicologia.

1. Obesidade infantil. 2. Avaliação psicológica. 3. Métodos projetivos. 4. Rorschach. 5. Desenho da Figura Humana. 6. Personalidade.

Apoio: Capes. 



\section{FOLHA DE APROVAÇÃO}

\section{Carmem Gil Coury}

Título: Organização e dinâmica psíquica na obesidade infantil

Dissertação apresentada a Faculdade de Filosofia, Ciências e Letras de Ribeirão Preto da Universidade de São Paulo para a obtenção do titulo de mestre em Ciências.

Área de Concentração: Psicologia.

Aprovado em:

\section{Banca Examinadora}

Profa. Dra.:

Instituição:

Assinatura:

Profa. Dra.:

Instituição:

Assinatura:

Profa. Dra.:

Instituição:

Assinatura: 

Às crianças e suas expressões. E aos adultos que se dedicam a ouvi-las. 



\section{Agradecimentos}

Ao Ivan, meu parceiro de vida, por acreditar em mim mesmo quando eu duvidava. Obrigada por ser sempre minha fonte de conforto e inspiração e me ajudar a manter-me firme em meu caminho. Não há palavras para agradecer sua companhia e seu amor.

A meus pais Helenice e José, que tendo trilhado estes caminhos tão belamente em suas vidas, me encorajaram e estimularam a mim também me descobrir neles. Agradeço o carinho e paciência que me ofereceram sempre que por qualquer motivo eu lhes tenha necessitado.

Ao Francisco, meu irmão, que com seu bom humor carinhoso me ajudou a deixar o caminho mais leve. Obrigada por me mostrar outras formas de viver e trabalhar.

À Prof ${ }^{\mathrm{a}}$. Dr ${ }^{\mathrm{a}}$. Sonia Regina Pasian, por mais que me orientar, me acolher na casa que fez do CPP. E por ter paciência com os tempos e ritmos desta orientanda. Agradeço o zelo e cuidado persistentes em cada etapa desta construção e pelos inestimáveis conhecimentos que tão generosamente pôde partilhar comigo.

À Dra. Beatriz TronconBusatto, que pôde me ouvir e acolher em seu consultório, auxiliando de maneira inestimável o meu desenvolvimento pessoal, ajudando-me a me tornar uma pesquisadora mais flexível e amorosa.

À Stefani, minha amiga querida que partilhou as passadas desde o início deste percurso. Agradeço sua presença viva nos momentos de angústia e nas identificações que pudemos vivenciar nestes anos.

À Andressa e Paula, amigas queridas, pela torcida e confiança, por me ouvirem incansavelmente nos momentos de maior necessidade e por me receberem sempre com amizade e carinho.

À Fabiana, valioso presente deste Mestrado, pela bondade e generosidade sempre presentes em suas palavras e por tornar o percurso acadêmico tão mais prazeroso.

À ErikaTiemi Kato Okino, por sua paciência e companhia e por dividir comigo seus pensamentos e experiência tão valiosos.

Ao Rodolfo, por seu companheirismo e energia, que tanto me auxiliaram a prosseguir e por todo o seu auxílio durante a coleta dos dados. 
Aos amigos Ana Luisa Guimarães e Nichollas Martins Arecco, por seu importante auxílio e amizade durante a construção deste trabalho.

Aos colegas do Centro de Pesquisas e Psicodiagnóstico (CPP), pela convivência e pela troca de experiências e conhecimentos em vários momentos da construção deste trabalho e de minha formação pessoal, sobretudo ao Jorge por sua generosidade em partilhar seus conhecimentos em estatística.

À Prof ${ }^{a}$. Dr ${ }^{\mathrm{a}}$. Sonia Regina Loureiro e à Prof ${ }^{\mathrm{a}}$. Dr ${ }^{\mathrm{a}}$. Deise Matos do Amparo por suas cuidadosas contribuições à construção deste trabalho oferecidas no Exame de Qualificação.

Às Instituições de Cuidado à Saúde e à Educação das crianças que possibilitaram a realização do estudo.

Ao CAPES e ao Programa de Pós-Graduação em Psicologia da FFCLRP/USP, pelo apoio e subsídios financeiros necessários a concretização e divulgação científica deste trabalho.

Às crianças e suas famílias, que puderam fornecer sua valiosa ajuda à realização deste trabalho. Agradeço por partilharem comigo suas vivências e sentimentos, que me enriquecerem enormemente. 
“Todos estão loucos, neste mundo? Porque a cabeça da gente é uma só, e as coisas que há e que estão para haver são demais de muitas, muito maiores diferentes, e a gente tem de necessitar de aumentar a cabeça, para o total. Todos os sucedidos acontecendo, o sentir forte da gente - o que produz os ventos. Só se pode viver perto de outro, e conhecer outra pessoa, sem perigo de ódio, se a gente tem amor."

(João Guimarães Rosa) 



\section{RESUMO}

Coury, C. G. (2016). Organização e dinâmica psíquica na obesidade infantil. Dissertação de Mestrado, Faculdade de Filosofia, Ciências e Letras de Ribeirão Preto, Universidade de São Paulo, Ribeirão Preto.

Instrumentos de avaliação psicológica constituem-se em métodos sistemáticos de investigação e de compreensão de componentes estruturais e funcionais do comportamento humano, com diversificados objetivos e estratégias técnicas, respeitando-se especificidades das etapas do desenvolvimento. Em processos de avaliação psicológica de características da personalidade, os métodos projetivos, como o Método de Rorschach e o Desenho da Figura Humana, são recursos amplamente utilizados, contribuindo para a compreensão e elaboração de intervenções terapêuticas em variados campos de aplicação, como na área da obesidade infantil. Nesse contexto, este trabalho teve por objetivo identificar e comparar características psicológicas de crianças com obesidade em relação a eutróficas, a partir de métodos projetivos de investigação da personalidade. Foram examinadas 60 crianças de sete a 11 anos de idade, sendo 30 crianças diagnosticadas como obesas e em tratamento específico para o transtorno (Grupo 1 - G1) e 30 crianças com peso normal (Grupo 2 - G2), sem atraso acadêmico, sem limites cognitivos e sem histórico de outras doenças físicas. Os participantes de G1 foram recrutados em instituições de saúde voltadas ao tratamento da obesidade infantil e G2 foi constituído a partir de parceria estabelecida com instituição de ensino bem como a partir de contatos informais da pesquisadora e de seu grupo de pesquisa (técnica da "bola de neve"), buscando-se balanceamento dos grupos por sexo e idade. Os seguintes instrumentos de avaliação psicológica foram aplicados individualmente nas crianças: Teste das Matrizes Progressivas Coloridas de Raven (critério de seleção de participantes, incluindo-se na amostra apenas crianças com resultados intelectuais médios ou superiores), o Desenho da Figura Humana e o Método de Rorschach (Escola Francesa). Os pais das crianças participantes responderam ao Questionário de Capacidades e Dificuldades (SDQ) para caracterização da amostra. Os resultados foram examinados conforme padronização específica dos respectivos manuais técnicos dos instrumentos, realizando-se análises descritivas e inferenciais, a fim de examinar possíveis associações entre variáveis clínicas e demográficas e indicadores de características de personalidade das crianças. Foram efetuadas análises correlacionais entre resultados no DFH e no Rorschach, considerando também a classificação nutricional da criança. Os achados permitem compreender características do funcionamento psíquico envolvidas na obesidade infantil, de modo a favorecer estratégias futuras de intervenção terapêutica com crianças. (CAPES)

Palavras-chave: Obesidade infantil; Avaliação psicológica; Métodos projetivos; Rorschach; Desenho da Figura Humana; Personalidade. 



\begin{abstract}
$\underline{\text { ABSTRACT }}$
Coury, C. G. (2016). Psychological organization and psychic dynamics in childhood obesity. Dissertation (Master Degree), Faculdade de Filosofia, Ciências e Letras de Ribeirão Preto, University of São Paulo, Ribeirão Preto.

Psychological assessment instruments consist in methods of systematic research and of understanding the structural and functional components of human behavior, with diverse goals and technical strategies, respecting the specificities of the development. Projective techniques such as the Rorschach Method and the Human Figure Drawing are widely used resources in psychological evaluation processes of personality characteristics, contributing to the understanding and development of therapeutic interventions in various application fields, such as in the childhood obesity area. In this context, this study aimed to identify and compare psychological characteristics of children with obesity compared with those of normal weight, using projective methods of personality assessment. In this study were examined 60 children aged seven to 11 years old, 30 children diagnosed as obese and under specific treatment for the disorder (Group 1 - G1) and 30 children with normal weight (Group 2 - G2), with no academic delay, without cognitive limitation and with no history of other physical ailments. G1 participants were recruited from health institutions devoted to treatment of childhood obesity and G2 was formed by a partnership established with a teaching institution and a research group, intending to balance some characteristics of the two groups (sex and age). The following psychological assessment instruments were applied individually in children: Raven's Coloured Progressive Matrices Test (constituted on selection criteria of participants, being included only the children sample with average intellectual results or higher), the Human Figure Drawing (DFH) and the Rorschach Method (French School). The parents of children answered the Strengths and Difficulties Questionnaire (SDQ) to characterize the sample. The results were examined according to specific standardization of the respective technical manuals of the instruments. Descriptive and inferential analyses were performed in order to examine possible associations between clinical and demographic variables and indicators of personality characteristics of the children. Correlation analyzes were made of the main results in DFH and Rorschach in accordance with the child's nutritional classification. The findings illuminate possible features of psychic functioning involved in childhood obesity process in order to facilitate future strategies for therapeutic intervention with children. (CAPES)
\end{abstract}

Key words: Childhood obesity; Psychological Assessment; Projective Techniques; Rorschach; Human Figure Drawing; Personality. 



\section{LISTA DE TABELAS}

Tabela 1: Distribuição (em frequência simples) dos artigos excluídos em função dos critérios utilizados no levantamento da literatura científica realizada em 2014.

Tabela 2: Distribuição dos participantes do estudo em função do sexo e idade.

Tabela 3: Distribuição (em frequência simples e em porcentagem) do desempenho intelectual das crianças em função do grupo do estudo - Grupo 1 (Clínico) e Grupo 2 (Comparação).......72

Tabela 4: Distribuição (em frequência simples e porcentagem) dos participantes do estudo em função do sexo e do ano escolar.

Tabela 5: Distribuição (em frequência simples e porcentagem) dos participantes em função da classificação no SDQ (versão pais)

Tabela 6: Resultados médios (pontos brutos e percentis) do DFH e comparação estatística em função dos grupos de crianças.

Tabela 7: Distribuição dos casos e sua comparação estatística em função do número de indicadores emocionais presentes no DFH dos dois grupos de crianças.

Tabela 8: Caracterização e comparação estatística de resultados médios na produtividade e ritmo no Rorschach em função dos grupos de crianças.

Tabela 9: Caracterização e comparação estatística de resultados médios (em porcentagem) nos modos de apreensão no Rorschach em função dos grupos de crianças.

Tabela 10: Caracterização e comparação estatística de resultados médios nos determinantes das respostas no Rorschach em função dos grupos de crianças

Tabela 11 Caracterização e comparação estatística de resultados médios nos conteúdos, banalidades, reatividade cromática e fórmula de angústia do Rorschach, em função dos grupos de crianças.

Tabela 12: Distribuição e comparação estatística das crianças de G1 e G2 de acordo com variáveis selecionadas do Método de Rorschach.

Tabela 13: Distribuição e comparação estatística das crianças de G1 e G2 de acordo com funcionamento lógico pelo Método de Rorschach, em função do número de indicadores emocionais no DFH. 
Tabela 14: Distribuição e comparação estatística das crianças de G1 e G2 de acordo com funcionamento afetivo pelo Método de Rorschach, em função do número de indicadores emocionais no DFH.

Tabela 15: Distribuição e comparação estatística das crianças de G1 e G2 de acordo com os relacionamentos interpessoais pelo Método de Rorschach, em função do número de indicadores emocionais no DFH.

Tabela 16: Resultados descritivos nos instrumentos na amostra total $(n=60)$ e sua comparação estatística segundo o sexo.

Tabela 17: Resultados descritivos, comparação estatística das principais variáveis de cada instrumento avaliativo, e correlações com IMC no grupo masculino (15 com obesidade e 15 eutróficos).

Tabela 18: Resultados descritivos, comparação estatística das principais variáveis de cada instrumento avaliativo, e correlações com IMC no grupo feminino (15 com obesidade e 15 eutróficas) 


\section{SUMÁRIO}

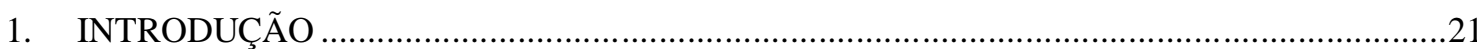

1.1. Avaliação Psicológica e métodos projetivos ..............................................................23

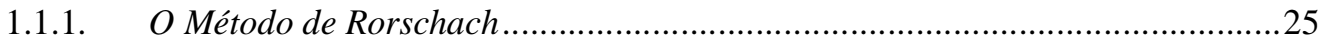

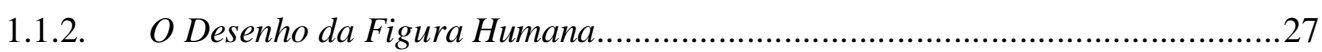

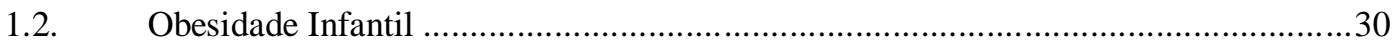

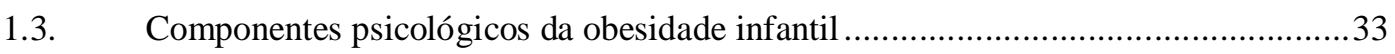

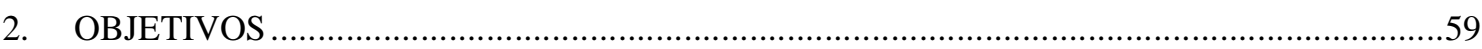

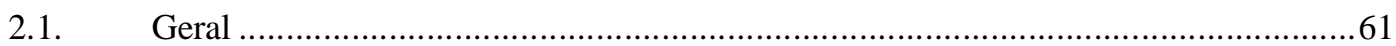

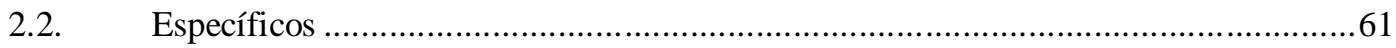

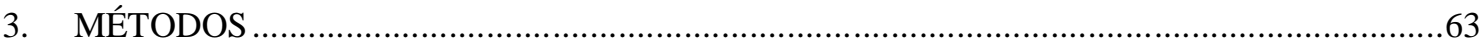

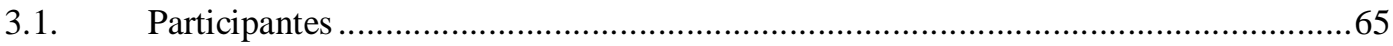

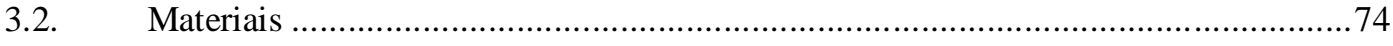

3.2.1. Carta de apresentação da pesquisa .....................................................................74

3.2.2. Termo de Consentimento Livre Esclarecido (TCLE) .............................................74

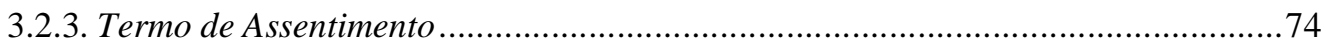

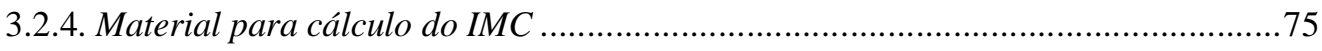

3.2.5. Teste das Matrizes Progressivas Coloridas de Raven ........................................... 75

3.2.6. Questionário de Capacidades e Dificuldades $(S D Q)$.............................................75

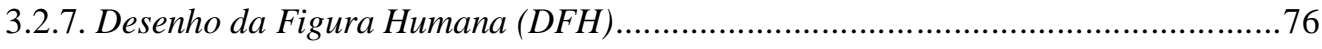

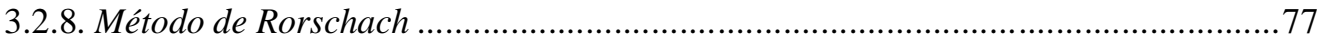

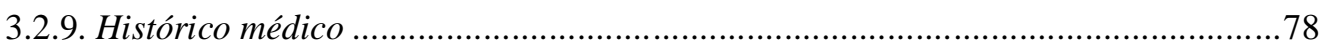

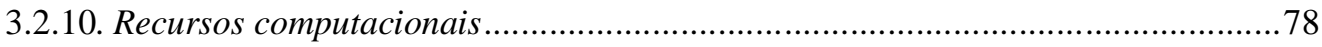

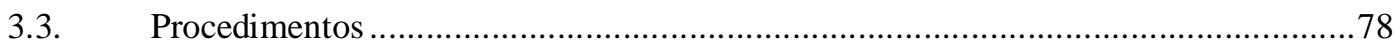

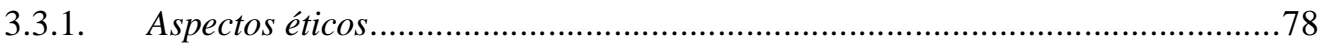

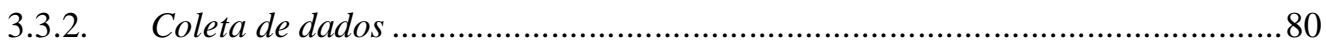

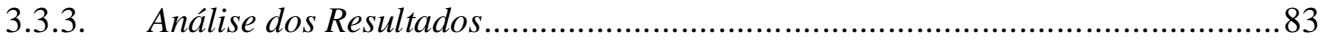

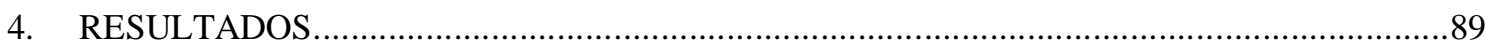


4.1. Resultados descritivos e comparação de valores médios ...........................................91

4.1.1. Questionário de Capacidades e Habilidades $(S D Q)$........................................91

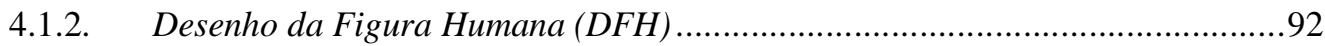

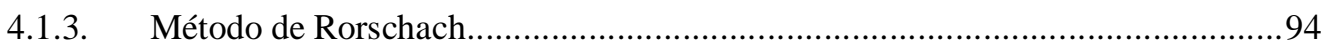

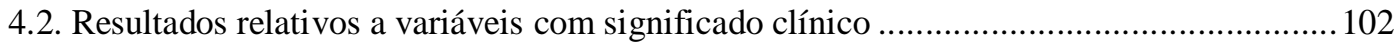

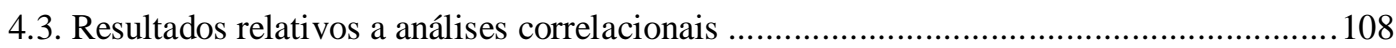

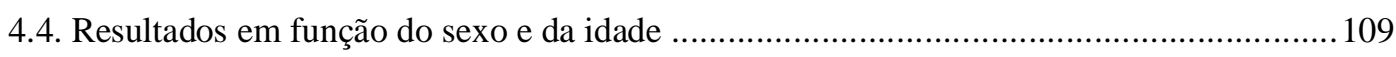

4.5. Análise comparativa do Rorschach com grupo normativo ................................................... 121

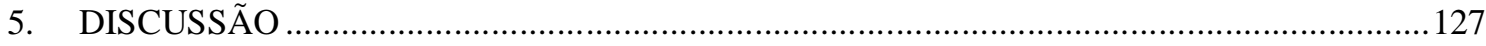

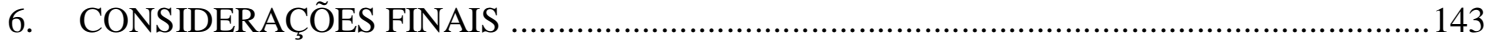

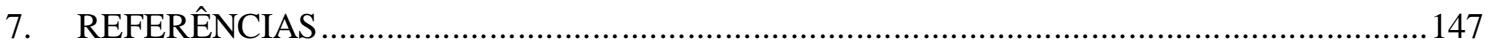

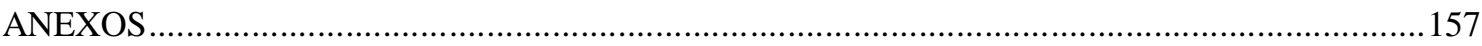

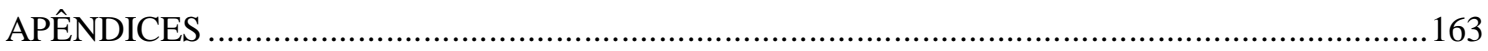




\section{INTRODUÇÃO}




\subsection{Avaliação Psicológica e métodos projetivos}

Avaliação psicológica refere-se a uma área do conhecimento psicológico, constituindo processo de investigação científica relativo a condições psicológicas de indivíduo/grupo, a partir da utilização de conjunto de procedimentos técnico-científicos, teoricamente fundamentados, e que consideram condições clínicas pregressas e atuais desse indivíduo/grupo (Cruz, 2004). Segundo Urbina (2007), um dos recursos para processos de avaliação psicológica são os testes psicológicos, que se constituem enquanto procedimentos sistemáticos para se obter amostras significativas de comportamentos relevantes ao funcionamento cognitivo ou afetivo, e da avaliação destas por meio de padrões definidos. Desse modo, para que uma avaliação psicológica seja considerada válida e útil, deve ser baseada em testes ou procedimentos meticulosamente programados de forma a serem uniformes, devendo seguir objetivos claros e justos, bem como serem passíveis de demonstração empírica. Da mesma forma, os padrões para avaliação das amostras obtidas devem ser baseados em dados empíricos, buscando compor adequado referencial para as análises interpretativas dos indicadores obtidos.

A avaliação psicológica objetiva, em última instância, buscar um conjunto de informações necessárias à tomada de decisões sobre o indivíduo/grupo avaliado. Tais decisões situam-se nos mais variados contextos, tais como organizacional, jurídico, clínico/saúde, entre outros (Fensterseifer \& Werlang, 2008). No presente estudo, enfocar-se-á sua utilização em contextos de saúde e tratamento, concordando com Capitão, Scortegagna e Baptista (2005) ao afirmarem que a Psicologia atua como importante fator para a compreensão do adoecimento e, da mesma forma, das maneiras 
de se permanecer saudável. Como argumentam Baum e Posluszny (1999), a união entre a Psicologia e as Ciências Médicas propiciou notável desenvolvimento de ambas as áreas, expandindo o conhecimento e a compreensão de transtornos em suas facetas psicológicas, físicas e comportamentais, buscando sua integração. Pensamentos, sentimentos e comportamentos afetam o bem-estar e a saúde, devendo ser considerados em conjunto nos serviços destinados ao cuidado de pessoas.

As considerações de Capitão, Scortegagna e Baptista (2005) enfatizam a necessidade de abordagens multidisciplinares integradas no cuidado à saúde, sendo esta considerada não como ausência de doença, mas como um estado multidimensional que engloba condições física, psicológica e social do indivíduo/grupo. Assim, do ponto de vista psicológico, as práticas de avaliação psicológica (enquanto processos de investigação e compreensão do funcionamento e organização do psiquismo individual) podem funcionar como importantes ferramentas de auxílio no trabalho interdisciplinar em várias frentes: tomadas de decisão referentes a diagnósticos, a tipos de intervenção necessária, bem como sobre prognósticos.

No contexto clínico, o processo de avaliação psicológica com o objetivo de psicodiagnóstico parte de pressupostos semelhantes, ao priorizar um enfoque compreensivo das múltiplas informações geradas em um caso clínico, tomando aquilo que é relevante e significativo na personalidade a fim de facilitar a indicação de recursos terapêuticos e prever possíveis respostas aos mesmos (Cunha, 2007). Nesse sentido, Araújo (2007) ao descrever as diversas abordagens teóricas utilizadas no diagnostico e avaliação psicológica aponta que uma enriquecedora concepção de personalidade seria a que pressupõe a existência de aspectos conscientes e inconscientes em sua dinâmica e estrutura, cujo funcionamento encontra-se bem descrito pela teoria psicanalítica. $\mathrm{O}$ objetivo do psicodiagnóstico, frente a isso, seria descrever e compreender a 
personalidade do indivíduo, buscando-se identificar seus elementos constitutivos e, principalmente, a explicação da dinâmica dos elementos existentes, integrados em um quadro global (Ocampo \& Arzeno, 1994).

Dentre as técnicas de avaliação de personalidade, destacam-se os métodos projetivos que, sob o referencial de base psicodinâmica, possibilitam o reconhecimento de fenômenos projetivos ao considerar que a percepção externa que um indivíduo tem de certo estímulo é determinada e influenciada por seu mundo interno. Assim, este se torna passível de ser conhecido a partir de suas expressões em produções incitadas por estímulos pré-estabelecidos, em geral pouco estruturados (Anzieu, 1986; Fensterseifer \& Werlang, 2008). Apesar da diversidade de instrumentos existentes, figuram entre métodos projetivos muito utilizados, no Brasil e no mundo, o Método de Rorschach e o Desenho da Figura Humana (DFH) (Herzberg \& Mattar, 2008), sendo ambos aplicáveis a diferentes grupos etários, étnicos e socioeconômicos. Esses instrumentais serão brevemente abordados a seguir.

\subsubsection{O Método de Rorschach}

O Método de Rorschach, desenvolvido pelo psiquiatra suíço Herman Rorschach e publicado em 1921, constitui-se por pranchas contendo borrões de tinta imprecisos, cuja interpretação é proposta ao respondente. As respostas resultantes dessa tarefa devem ser consideradas como indicadores da personalidade do indivíduo, acessada a partir de suas projeções. Dessa forma, os estímulos pouco estruturados dificultam que o indivíduo se utilize de respostas estereotipadas, geradas por estímulos ambientais comuns, facilitando a expressão livre da individualidade de sua personalidade (Yazigi, 2010). Essa liberdade de respostas geradas permite que o indivíduo expresse aspectos mais primitivos de seu psiquismo, pouco acessíveis, reprimidos e inconscientes, além 
dos aspectos da personalidade conscientes e observáveis no comportamento (JardimMaran, Pasian \& Okino, 2015).

O Método de Rorschach é baseado na percepção e comunicação verbal elementar, mostrando-se sensível e eficiente na captação de elementos do psiquismo humano (Rausch de Traubenberg, 1998). Pelo tipo de material e atividade pode ser aplicado a diferentes faixas etárias, sendo que reflexões teóricas envolvidas no processo interpretativo permitem situar o indivíduo em seu contexto de desenvolvimento, relativizando suas respostas em relação a seus pares e às características de cada etapa do crescimento.

Enquanto um dos métodos mais utilizados no mundo para avaliação da personalidade (Azoulay et al., 2007), o Rorschach foi um dos primeiros métodos com esta finalidade a receber análises e procedimentos técnicos que visassem estabelecer sua cientificidade, expandindo sua credibilidade no cenário internacional (Fenstersifer \& Werlang, 2008). A literatura contemporânea, como descrevem Pasian e Loureiro (2010), apresenta evidências claras de validade e da precisão técnica do Método de Rorschach. Entretanto, para ser possível descrever a personalidade individual, é preciso poder contextualizar seus traços específicos dentro do grupo ao qual pertence, bem como a época e o contexto sócio cultural que os circunscrevem, o que tende a ser retratado nos estudos normativos (Jardim-Maran, Pasian \& Okino, 2015).

Este cuidado técnico relativo a padrões normativos baseados em dados estatísticos cuida para que, além da teoria de personalidade que embasa as interpretações do Rorschach, possa também existir cuidado com o significado destes resultados em termos adaptativos no ambiente cultural do indivíduo (Weiner, 2000). Assim, suas respostas ao método ficam contextualizadas na distribuição de um grupo considerado como de referência (Pasian \& Loureiro, 2010). A possibilidade de 
aprofundada compreensão do dinamismo e estruturação psíquica do indivíduo, bem como sua adaptação no contexto sócio cultural, permitem que se possa realizar, com maior precisão e validade, inferências sobre o comportamento e encaminhamentos para intervenções mais adequadas às demandas.

\subsubsection{O Desenho da Figura Humana}

Da mesma forma, outro importante recurso de acesso a processos psicológicos latentes intervenientes no funcionamento global da personalidade, incluindo os modos de pensar sentir ou agir (Villemor-Amaral \& Pasqualini-Casado, 2006), são as técnicas gráficas de avaliação psicológica. Destaque se faz ao Desenho da Figura Humana (DFH), que se aproveita de uma forma de comunicação humana primordial (grafismo/desenho) para levantar elementos para a análise e avaliação da personalidade (Weschler, 2003).

Hutz e Bandeira (1995) descrevem que desde 1926 o DFH é utilizado para acessar o desenvolvimento da inteligência, por meio dos critérios de Goodenough (1951), posteriormente revisados por Harris em 1963. Como coloca Arteche (2006), a compreensão do desenho enquanto expressão de aspectos desenvolvimentais pressupõe um ciclo infantil típico, observável também a partir da produção gráfica. Ainda que existam controvérsias quanto à linearidade, bem como às fases do desenvolvimento, a maioria dos autores reconhece estágios típicos deste processo. No Brasil, o DFH é utilizado para a avaliação de aspectos cognitivos pelos sistemas avaliativos de Weschsler (2003) e Sisto (2006), aprovados pelo Conselho Federal de Psicologia (uso restrito a psicólogos).

Outra linha de investigação dos desenhos infantis foi iniciada por Machover em 1949, recorrendo ao DFH para avaliar a personalidade (Rosa \& Alves, 2014). Neste 
sentido, como aponta Hammer (1991), o desenho é entendido como método projetivo de avaliação psicológica na medida em que aspectos do inconsciente são expressos no grafismo, indicando aquilo que a criança sente, em lugar do que a criança vê. Assim, as produções pictóricas permitiriam à criança colocar no papel suas preocupações, angústias, desejos, problemas e satisfações, bem como apontar às estruturas básicas que delineiam sua personalidade.

Em 1968, uma terceira linha investigativa sobre desenhos de crianças, integrando o DFH como técnica projetiva na investigação da personalidade e também como avaliação cognitiva, foi desenvolvida por Elisabeth Koppitz a partir de sua experiência clínica. Para esta pesquisadora (Koppitz, 1966), o desenho infantil refletiria uma espécie de fotografia do estágio maturacional, bem como do estado emocional da criança em um dado momento. Koppitz desenvolveu um sistema avaliativo do DFH constituído por itens evolutivos baseados nas propostas de Goodenough-Harris, cuja presença aumenta na medida em que a criança envelhece e se desenvolve; e indicadores emocionais, embasados no pensamento de Machover e Hammer, que teriam sua ocorrência independentemente da idade da criança, e seriam indicadores de dificuldades e preocupações emocionais destas (Kobayashi, 2015). Segundo Koppitz (1966), a presença de dois ou mais indicadores emocionais seria altamente sugestiva da presença de problemas emocionais e relações interpessoais problemáticas.

Segundo Saur, Pasian e Loureiro, (2010) a abordagem de Koppitz tem se mostrado válida e útil para processos de avaliação psicológica, permitindo informações referentes à imagem corporal do indivíduo, entre outros componentes da personalidade. Desta forma, várias possibilidades interpretativas dos indicadores do $\mathrm{DFH}$ foram desenvolvidas ao longo de décadas de estudos, cabendo ao avaliador optar pelo sistema avaliativo que atenda aos seus objetivos em cada situação (Saur, Pasian \& Loureiro, 
2010). Como apontam Lilienfeld, Wood e Garb (2000), os métodos avaliativos envolvendo DFH têm a vantagem de apresentarem aplicações rápidas e pouco dispendiosas, adotando, de forma geral, um sistema de classificação e análise específico para as produções dos indivíduos.

Apesar da grande utilização do DFH pelos profissionais em sua prática clínica, Hutz e Bandeira (1995) apontam para o baixo número de estudos que se ocuparam sistematicamente da validação do uso deste teste com crianças brasileiras. Ainda, mais recentemente, Arteche (2006) complementa que as instrumentações projetivas quando avaliadas em suas propriedades psicométricas não apontam resultados satisfatórios, sobretudo em sua validade e fidedignidade. No Brasil, essa pesquisadora se apoia nas considerações de Safran (1996) para afirmar que estudos que visam avaliar a validade do DFH devem empregá-lo em conjunto a um instrumento controle ou a um método projetivo com maiores evidências de validade, como o Método de Rorschach, proposta implementada no presente trabalho.

Dentro da imensa variabilidade de contextos de aplicação dos métodos projetivos de avaliação psicológica, é relevante apontar sua grande contribuição para as práticas em Saúde, sobretudo Saúde Mental. Ao circunscrever esse amplo tema nas discussões da Saúde Pública, em âmbito mundial, focalizaremos as possibilidades de contribuição dos processos projetivos de avaliação psicológica para compreender e pensar sobre intervenções junto à crescente incidência da obesidade e do sobrepeso. Destaca-se, em especial, o aumento dos índices de obesidade infantil (World Health Organization - WHO, 2012), a seguir explorada em seus aspectos mais gerais e, em seguida, em algumas particularidades psicológicas. 


\subsection{Obesidade Infantil}

Obesidade e sobrepeso são definidos pela WHO (2012), como "acúmulo de gordura anormal ou excessivo que pode prejudicar a saúde”. Estudos têm mostrado alta correlação entre obesidade na infância e sua ocorrência na idade adulta, bem como o desenvolvimento de síndromes metabólicas nesta fase (Sun, Liang, Huang, Daniels, Arslanian, Liu, Grave \& Siervogel, 2008; Guo, Wu, Chumlea \& Roche, 2001). Nesse sentido, diversos trabalhos apontam para a importância do tratamento e prevenção da obesidade ainda na infância, favorecendo a manutenção de hábitos e cuidados saudáveis durante toda a vida (Hesketh \& Campbell, 2010).

Usualmente, a classificação nutricional para adultos é realizada pelo Índice de Massa Corporal (IMC), calculado a partir da divisão do valor do peso do indivíduo, em quilogramas, pelo valor de sua altura, em metros, ao quadrado. O resultado é então classificado, segundo WHO (2012) nas categorias: baixo peso (IMC $<18,5 \mathrm{~kg} / \mathrm{m}^{2}$ ), eutrofia $\left(18,5 \mathrm{~kg} / \mathrm{m}^{2} \leq \mathrm{IMC}<25 \mathrm{~kg} / \mathrm{m}^{2}\right)$, sobrepeso $\left(25 \mathrm{~kg} / \mathrm{m}^{2} \leq \mathrm{IMC}<30 \mathrm{~kg} / \mathrm{m}^{2}\right)$ e obesidade $\left(\mathrm{IMC} \geq 30 \mathrm{~kg} / \mathrm{m}^{2}\right.$ ). Existem, entretanto, diversos outros índices e métodos para avaliação e acesso da gordura corporal e classificação nutricional, com variações de acordo com idade e finalidade avaliativa, como medidas de pregas cutâneas e de circunferência abdominal. Na infância, a avaliação nutricional com base em faixas préestabelecidas de IMC, como é feito para a idade adulta, é inadequada devido aos problemas gerados pela comparação da altura da criança com aquela esperada para sua idade, o que é altamente variável (Melo, 2011).

Alternativamente, outras formas de classificação nutricional existentes permitem melhor compreensão e avaliação do estado nutricional em crianças. O Ministério da Saúde adota as recomendações da Organização Mundial da Saúde (OMS) em relação à 
utilização de curvas de referência para essa avaliação, segundo as quais crianças menores de cinco anos devem seguir a referência internacional da OMS de 2006. Já em relação a crianças com cinco anos ou mais, bem como adolescentes, é recomendado o uso da referência internacional da OMS lançada em 2007 (Sociedade Brasileira de Pediatria - Avaliação nutricional da criança e do adolescente: Manual de Orientação, 2009). Nestes referenciais, a classificação do IMC é variável segundo a faixa de crescimento específica a idade e sexo da criança, diferentemente da classificação nutricional de adultos que se baseia em faixas de IMC pré-estabelecidas.

De acordo com dados da WHO (2012), a obesidade classifica-se em quinto lugar entre os maiores riscos para mortes globais, sendo que 2,8 milhões de adultos morrem a cada ano por problemas decorrentes desse fenômeno. Além disso, a obesidade predispõe o indivíduo a inúmeras comorbidades (diabetes, problemas cardíacos, certos tipos de câncer, entre outros), afetando todas as etnias e camadas socioeconômicas. Da mesma forma, a obesidade infantil também é apontada como um dos mais sérios desafios à saúde, sendo que, em 2010, o número de crianças obesas ou com sobrepeso superava a faixa de 42 milhões, mundialmente.

No Brasil, apesar do histórico envolvendo a desnutrição, principalmente na região nordeste do país, a tendência tem sido a mesma observada em termos internacionais, no sentido da inversão nutricional a favor da prevalência da obesidade (Ferreira \& Magalhães, 2006). Avaliações antropométricas realizadas pelo Instituto Brasileiro de Geografia e Estatística (IBGE) em famílias selecionadas de todo o Brasil, em regiões urbanas e rurais no período entre 2008 e 2009, mostraram excesso de peso em $33,5 \%$ das crianças entre cinco a nove anos, sendo que 16,6\% dos meninos também eram obesos; entre as meninas, a obesidade apareceu em 11,8\%. A prevalência de excesso de peso variou entre $25 \%$ a $30 \%$ nas Regiões Norte e Nordeste (correspondendo 
a um valor mais que cinco vezes superior ao déficit de peso) e de $32 \%$ a $40 \%$ nas Regiões Sudeste, Sul e Centro-Oeste (mais do que 10 vezes a prevalência do déficit de peso). $\mathrm{O}$ excesso de peso tendeu a ser mais frequente em áreas urbanas, em particular nas Regiões Norte, Nordeste e Centro-Oeste do Brasil. A prevalência da obesidade mostrou distribuição geográfica semelhante à observada para o excesso de peso, em menores magnitudes.

Frente ao preocupante contexto descrito, inúmeros estudos buscam compreender a obesidade infantil em suas múltiplas facetas, de forma a desenvolver estratégias interventivas mais eficientes para cuidar desse fenômeno e suas consequências. Os resultados têm mostrado a complexidade do quadro, acompanhado de diversas variáveis de difícil identificação, acarretando achados contraditórios na literatura científica. Entretanto, como aponta a revisão de literatura de De Niet \& Naiman, (2011), parece haver concordância no tocante a multideterminação da obesidade, pautada por fatores inerentes ao indivíduo (como herança genética e aspectos psicológicos), bem como aspectos ambientais (externos ao indivíduo). São, assim, múltiplos os determinantes do quadro de obesidade, destacando-se a forte associação a comportamentos alimentares e estilos de vida.

Os fatores externos, tais como a influência dos pares e do comportamento alimentar parental, especialmente o materno, bem como transtornos psicopatológicos maternos e estresse prolongado na infância, parecem estar associados ao sobrepeso da criança (Puder \& Munsch, 2010). Ainda que tais fatores assumam grande importância na determinação da obesidade infantil, ainda não são suficientes para explicá-la de modo global.

Em relação às características psicológicas estudadas, na literatura científica ganham destaque os fatores referentes à expressão internalizada e externalizada de 
dificuldades emocionais (Puder \& Munsch, 2010). Em relação ao primeiro grupo, são descritos problemas relacionados à depressão, ansiedade, somatizações, baixa autoestima, insatisfação com o corpo e dificuldades de socialização. Quanto a expressões de externalização de vivências psíquicas, são referenciadas dificuldades em função do controle da impulsividade, geralmente relacionadas a comportamentos alimentares compulsivos em crianças, bem como hiperatividade e até mesmo agressividade, apesar de tais resultados não se mostrarem conclusivos em revisões de literatura sobre o tema (Braet, 2005; De Niet \& Naiman, 2011; Incledon, Wake \& Hay, 2011; Puder \& Munsch, 2010).

Evidenciam-se importantes avanços na compreensão da obesidade infantil, ainda que existam controvérsias entre achados. Grande parte dos estudos nesse tema focalizou, até o momento, questões psicopatológicas e suas possíveis relações causais, como pode ser visto em detalhes no próximo tópico. Assim, muito ainda precisa ser feito no sentido de explorar e descrever a organização e funcionamento psíquico desses indivíduos. Tais investigações possuem importante potencial na compreensão desse quadro clínico, possibilitando o desenvolvimento de intervenções baseadas em recursos psíquicos desses indivíduos, otimizando seu desenvolvimento.

\subsection{Componentes psicológicos da obesidade infantil}

Com objetivo de organizar e sistematizar informações referentes aos elementos psicológicos associados à obesidade infantil, foram realizados dois levantamentos da literatura científica dessa área, em momentos distintos durante desenvolvimento do presente estudo, respectivamente em março de 2013 e após um ano (abril de 2014). O

primeiro levantamento objetivou analisar os principais achados que relacionassem a 
obesidade a fatores psicológicos, enfocando-se estudos que utilizaram o Método de Rorschach. Decidiu-se incluir nas buscas a terminologia "Imagem Corporal" visando auxiliar na compreensão dos aspectos da percepção do corpo, visto que se trata de um transtorno que afeta largamente esta dimensão individual. Para tanto, optou-se pela utilização das palavras-chave: "Childhood obesity"; "Body image”; "Psychological Assessment" e "Rorschach", em combinações pareadas. Foram selecionadas para a realização da busca três importantes bases de dados bibliográficos, a saber: PsycINFO, Biblioteca Virtual em Saúde (BVS) e PubMed, acessadas em 20/02/2013, com preferência por trabalhos publicados nos últimos 10 anos (2003-2013). Dessa forma, realizaram-se um total de 21 consultas cujos resultados mostraram um total de 1.573 artigos, sendo 942 publicados entre 2003-2013. Deste montante, foram selecionados para análise os trabalhos que tratassem de características psicológicas de crianças com obesidade, ou revisões de literatura que fornecessem informações mais gerais sobre o tema, porém também envolvendo algum instrumento de avaliação psicológica.

Aplicados esses critérios de seleção de trabalhos foram identificados 107 estudos publicados. Esse total de pesquisas foi examinado em seus respectivos resumos, de modo a admitir no levantamento da literatura científica os trabalhos que tratassem efetivamente de obesidade infantil e métodos projetivos de avaliação psicológica.

A partir desses procedimentos iniciais, 19 artigos foram considerados pertinentes para a proposta do atual trabalho, sendo apenas um deles anterior a 2003, selecionado por sua vinculação ao tema em estudo. A análise pormenorizada desses 19 artigos científicos revelou a seguinte distribuição: nove trabalhos realizaram revisão (sistematizada ou não) da literatura científica referente às temáticas abordadas; um estudo de coorte; oito estudos transversais quantitativos; e um estudo transversal qualitativo. 
Antes de seguir com a descrição de seus principais achados a partir de sua data de publicação, um primeiro destaque se faz para a diversidade de hipóteses e evidências empíricas relativas aos indicadores psicológicos vinculados à obesidade em crianças. Assim, as revisões bibliográficas que discutem a depressão (Braet, 2005; De Niet \& Naiman, 2011; Fabricatore \& Wadden, 2004; Harriger \& Thompson, 2012; Incledon, Wake \& Hay, 2011; Puder \& Munsch, 2010; Wardle \& Cooke, 2005) e autoestima (Cornette, 2008; De Niet \& Naiman, 2011; Incledon, Wake \& Hay, 2011; Harriger \& Thompson, 2012; Wardle \& Cooke, 2005) apontam para hipóteses divergentes no tocante a fatores psíquicos associados à obesidade infantil. Alguns estudos apontam a depressão como o problema psicopatológico mais prevalente em crianças obesas (Harriger \& Thompson, 2012), enquanto outros não apontam existência de qualquer associação entre as variáveis (De Niet \& Naiman, 2011; Incledon, Wake \& Hay, 2011). Por sua vez, Incledon, Wake e Hay (2011), além de Wardle e Cooke (2005), sinalizam, em suas revisões, associação um pouco diferente, no sentido de que a presença de sintomas depressivos sinaliza possível aumento do IMC, hipótese sustentada empiricamente.

Da mesma forma, estudos aqui analisados, referentes à relação entre autoestima e obesidade infantil, também não relataram resultados consensuais entre si. A revisão bibliográfica de Harriger e Thompson (2012) relata estudos que afirmam ser o nível de gordura corporal preditivo de baixa autoestima em anos posteriores. Já, segundo as revisões de Incledon, Wake e Hay (2011) e Cornette (2008), baixa autoestima parece predizer a incidência de obesidade em crianças e adolescentes. De forma interessante, Wardle e Cooke (2005) concluem, com base em seu levantamento da literatura científica, que níveis de insatisfação corporal tendem a ser mais altos em amostras de 
crianças e adolescentes obesos (em relação aos indivíduos eutróficos), sendo insignificante a diferença entre eles para índices de depressão e baixa autoestima.

Embora realizado na década de 1990, o estudo de Dreyfus (1993) foi incorporado no presente levantamento de literatura científica, visto seu caráter integrador e impacto para a área. O trabalho parte da concepção da obesidade enquanto síndrome multifatorial, exigindo abordagem multidisciplinar e vários instrumentos avaliativos para sua adequada compreensão. Utilizou entrevistas, técnicas gráficas e o Método de Rorschach enquanto instrumentos de coleta de dados, apontando a necessidade de ampla investigação de características de personalidade, em construção nessa etapa do desenvolvimento. Seus resultados apontam que a obesidade infantil seria uma forma de expressão da organização psicológica, exigindo intervenções específicas para o adequado cuidado desses casos clínicos.

Com objetivo de examinar variáveis envolvidas no desajustamento psicológico de crianças e adolescentes com obesidade, Zeller, Saelens, Roehrig, Kirk e Daniels (2004) avaliaram 121 voluntários clínicos (45 meninos e 75 meninas), de 11 a 17 anos, bem como o grau em que fatores maternos, demográficos e da juventude estavam correlacionados ao ajustamento psicológico dos participantes do estudo, avaliados pelo instrumento Behavior Assessment System for Children (BASC), que inclui medidas de autorrelato e escala respondida por pais. Os resultados apontam maior percepção de desajustamento psicológico proveniente das descrições maternas do que dos próprios jovens. Os autores discutem que as correlações do estudo reafirmam a associação entre o autorrelato do jovem sobre ajustamento psicológico com o nível de sofrimento psicológico materno, destacando essa variável para a compreensão do desenvolvimento infanto-juvenil. 
Hilbert, Winfried, Tuschen-Caffier, Zwaan e Czaja (2009) enfocaram a alimentação compulsiva em 59 crianças de oito a treze anos, recorrendo à metodologia de entrevistas, a fim de investigar pensamentos e sentimentos vivenciados por crianças com obesidade antes e depois de eventos de alimentação com características de descontrole. Apontam que episódios de alimentação descontrolada, com ingestão calórica significativamente elevada em relação a alimentações cotidianas, tendem a ser precedidos e sucedidos por cognições a respeito de comida/alimentação e relacionados à imagem corporal, com mínimas evidências de estados de humor negativos antecedendo a perda de controle. Concluem afirmando a necessidade de investigação aprofundada entre dificuldades de regulação do afeto e comportamento alimentar em crianças.

Com base em estudo qualitativo, Mériaux, Berg e Hellström (2010) descreveram experiências cotidianas de vida, corpo e bem-estar de crianças com sobrepeso, entrevistando 16 voluntários de 10 a 12 anos. Seus dados apontam adequada imagem corporal nas crianças, embora preocupadas com o corpo e conscientes de estilos de vida saudáveis, ainda que não planejassem colocá-los em prática.

Certos trabalhos indicam ainda relação entre sobrepeso e problemas de socialização, como atitudes agressivas e antissociais, além de maior índice de apresentação de Transtorno do Déficit de Atenção e Hiperatividade (TDAH) (Puder \& Munsch, 2010). A revisão de estudos qualitativos com crianças inglesas, realizada por Rees, Oliver, Woodman e Thomas (2011), apresenta conteúdos de falas de crianças com sobrepeso. Evidenciam autopercepções de mudanças negativas no próprio comportamento, com relatos de experiências de bullying como estopim para atitudes de retaliação e agressividade repentina, levando muitas vezes a punições na escola. Nesse sentido, ao discutir a incidência de baixa autoestima, Harriger e Thompson (2012) retomam discussões que indicam não ser a condição de peso, em si, que influenciaria a 
autoestima, mas sim fatores sociais, relacionados ao peso, que poderiam estabelecer essas possíveis associações.

Apesar da grande disparidade de resultados entre possível associação da obesidade e componentes psicológicos, importantes variáveis intervenientes foram identificadas. Trabalhos que enfocaram diferenças entre gênero/sexo (Cornette, 2008; De Niet \& Naiman, 2011; Fabricatore \& Wadden, 2004; Incledon, Wake \& Hay, 2011; Harriger \& Thompson, 2012; Wardle \& Cooke, 2005) apontam existência de maior suscetibilidade de meninas à baixa autoestima, bem como a sintomas depressivos e insatisfação corporal. A revisão de Rees, Oliver, Woodman e Thomas (2011), enfocando as próprias percepções de crianças, aponta para pressões da mídia e dos ideais sociais de beleza feminina como fontes das próprias percepções infantis, sugerindo que as crianças tendem a formar forte ligação entre magreza e feminilidade, o que precisa ser examinado em novas investigações.

Em relação à idade, a autoestima, mas não a depressão, estabeleceria maior associação com a obesidade na adolescência. Segundo Incledon, Wake e Hay (2011), a obesidade não seria preditora de baixa autoestima na infância, podendo, contudo, existir mudanças em anos posteriores. A autoimagem e autoestima sofreriam, segundo os autores, maior impacto de variações de peso corporal durante a adolescência.

Em termos de evidências empíricas com delineamento de coorte, White, Nicholls, Christie, Cole e Viner (2012) buscaram estudar aspectos da hiperatividade e capacidade de atenção na infância e o risco para obesidade ao longo da vida (coorte britânico de 1970). Os 16.567 participantes do estudo foram acompanhados em diferentes momentos da vida: com cinco anos, 10 anos, 16 anos, 26 anos, 29-30 anos e $34 \operatorname{anos}(n=9.316)$, utilizando-se escalas adaptadas e respondidas por pais e professores sobre os aspectos estudados, e as mães tiveram seu bem-estar psicológico avaliado. Os 
resultados indicam consistente relação entre crianças com problemas psicológicos em geral, particularmente hiperatividade e problemas de atenção, com a obesidade na vida adulta. Os autores discutem seus resultados com base na associação já estabelecida na literatura científica entre impulsividade e comportamento alimentar compulsivo, acarretando aumento do IMC.

A partir do levantamento aqui realizado há que se comentar que o delineamento transversal e quantitativo foi mais frequente na literatura científica da área. Esses estudos utilizaram prioritariamente faixas de IMC para sobrepeso ou obesidade como critério de inclusão nas amostras, bem como escalas de figuras de silhuetas humanas para o acesso à imagem corporal ou o uso de inventários para exame dos quadros clínicos estudados.

Notou-se, da mesma forma, a priorização de instrumentos objetivos para avaliação de sintomatologia depressiva, em especial o Inventário de Depressão Infantil (CDI), utilizado nos trabalhos de Calderón, Forns e Varea (2010), com 281 adolescentes clínicos entre 11 e 17 anos; Li, Ma, Schouten, Hu, Cui, Wang e Kok (2007), com 3.886 crianças chinesas de nove e dez anos; Shin e Shin (2008), contando com 413 crianças do quinto e sexto ano escolar; e também em Young-Hyman, Tanofsky-Kraff, Keil, Cohen, Peyrot e Yanovski (2006). Outra variável enfocada nesses estudos foi o nível de ansiedade infantil, avaliado também por instrumentos objetivos, como o Inventário de Ansiedade Estado-Traço (STAI) e sua forma infantil, Inventário de Ansiedade EstadoTraço para Crianças (STAIC), utilizado nos trabalhos de Calderón, Forns e Varea (2010) e Young-Hyman, Tanofsky-Kraff, Keil, Cohen, Peyrot e Yanovski (2006), respectivamente. Ainda, o trabalho de McCullough, Muldoon e Dempster (2009), com 211 crianças escolares, examinou a possível associação entre autoestima e obesidade infantil a partir da Escala de Autopercepção de Harter. 
Como apontado nas citadas revisões da literatura científica, os resultados empíricos confirmaram fatores intervenientes na relação entre obesidade e sintomatologia depressiva/ansiedade e autoestima, porém com variadas ênfases nos pesos dessas variáveis. Foram destacados como relevantes para tendência à obesidade infantil: indicadores de comportamentos alimentares compulsivos, presença de insatisfação corporal, bullying e provocações sociais referentes ao peso corporal, além de claras diferenças em função do sexo.

Cerca de um ano mais tarde (abril de 2014), realizou-se novo levantamento da literatura científica sobre o tema da obesidade infantil, de modo a acompanhar os estudos dessa área. Efetuou-se a opção pelas seguintes bases de dados: LILACS (visando representar de maneira mais direta publicações nacionais, literatura Latino-Americana e do Caribe em Ciências da Saúde,); PubMed e PsycInfo (base de dados da Associação Psicológica Americana - APA, escolhida por representar de maneira mais contundente a produção internacional de estudos da área da Psicologia). Optou-se, neste levantamento, pelas seguintes palavras-chave, consideradas apropriadas ao objetivo da busca: "childhood obesity" (obesidade infantil); "personality" (personalidade); "psychological assessment" (avaliação psicológica) "body image" (imagem corporal); "psychological aspects" (aspectos psicológicos); e "projective techniques" (técnicas projetivas). A busca em cada base determinou que alterações específicas fossem efetuadas nas combinações entre as palavras, visando acessar de modo mais apropriado cada base de dados.

Optou-se por incluir apenas artigos científicos, que representam a produção científica divulgada nos periódicos indexados às bases bibliográficas pesquisadas. Estes artigos deveriam referir-se primordialmente à temática psíquica da obesidade infantil, ou seja, estudar aspectos do psiquismo da criança de zero a 12 anos de idade e com 
obesidade, além de estar disponível nos idiomas português, inglês, espanhol e francês. Foram excluídos os trabalhos repetidos entre as bases bibliográficas; estudos que envolvessem validações/avaliações de instrumentos ou programas específicos de intervenção; e trabalhos que enfocassem exclusivamente a percepção ou peso parentais.

O resultado deste segundo levantamento de literatura científica, realizado em abril de 2014, totalizou 805 trabalhos. Entretanto, vários textos foram excluídos por encontrarem-se repetidos entre as bases ou de acordo com os critérios de exclusão/inclusão estabelecidos, como pode ser visto na Tabela 1.

Tabela 1: Distribuição (em frequência simples) dos artigos excluídos em função dos critérios utilizados no levantamento da literatura científica realizada em 2014.

\begin{tabular}{lc}
\hline Critério de exclusão & Número excluídos \\
\hline Repetidos & 96 \\
Abordar transtornos alimentares (e não a obesidade) & 22 \\
Não abordar a temática psíquica & 222 \\
Estudos com casos de comorbidades físicas e mentais na criança & 22 \\
Estudos com grupos específicos (traumas, diferenças raciais) & 18 \\
Não ser artigo científico & 35 \\
Avaliações/validações de instrumentos específicos & 22 \\
Avaliações de programas interventivos para perda de peso & 78 \\
Não estarem publicados em inglês/português/espanhol/francês & 17 \\
Fatores relacionados exclusivamente a percepções/peso parentais & 26 \\
Não abordar obesidade/obesidade infantil & 46 \\
Não descrever faixa-etária infantil (0-12 anos) & 139 \\
\hline
\end{tabular}


O total de artigos efetivamente excluídos nesse segundo levantamento corresponde a 726 manuscritos, visto que alguns trabalhos preencheram mais de um fator de exclusão. Com relação aos estudos excluídos devido à língua de publicação, encontraram-se seis trabalhos em italiano, quatro estudos em alemão, dois em polaco, um trabalho em norueguês, um em chinês, um trabalho em árabe, um em húngaro e um estudo em russo.

Assim, foram selecionados para análise 79 trabalhos considerados pertinentes aos objetivos dessa revisão da literatura científica, optando-se por descrevê-los em função de algumas variáveis a fim de facilitar sua compreensão e posterior discussão. Para tanto, foi necessário realizar a busca do trabalho na íntegra, o que resultou em 60 trabalhos disponíveis. Para os 19 estudos não resgatados de modo integral, as informações presentes no resumo disponibilizado pelos autores foram consideradas, de modo a caracterizar o conjunto de artigos científicos identificados nesse segundo momento.

Em termos de distribuição das publicações científicas realizadas por ano, observou-se que no período de 1973 a 1994 houve um ou dois artigos anuais, taxa que se elevou nos anos de 1995 a 2000 (três a quatro trabalhos anuais), decrescendo depois ao patamar inicial (anos 2001 a 2004). Em 2005 foram identificados nove artigos sobre o tema em foco, taxa que sofreu alguma variação desde então, porém desde 2009 há oito a dez trabalhos publicados por ano, até 2013. Ou seja, há tendência a maior divulgação científica sobre o tema da obesidade infantil nos últimos anos.

O acesso ao país de origem da publicação foi disponibilizado somente nos trabalhos resgatados de modo integral, totalizando 60 artigos. Os EUA figuram na 
primeira posição com 22 trabalhos, seguido pelo Brasil (com nove artigos publicados), Reino Unido (seis estudos), Canadá (quatro trabalhos) e Austrália (três artigos). A partir daí figuram (com dois artigos publicados sobre o tema) os seguintes países: Noruega, Espanha, Portugal, Alemanha, Coréia do Sul e Bélgica. Seguem, por fim, os países com um trabalho publicado no período examinado: França, Suíça, Suécia e Itália.

Ainda, com relação aos delineamentos das pesquisas, optou-se por classificá-los em: a) estudos descritivos (trabalhos empíricos de observação de uma amostra e sua caracterização, 26\%); b) estudos descritivos comparativos (trabalhos empíricos com grupos distintos pré-determinados cujos resultados foram comparados, 45\%); c) estudos teóricos ou de revisão sistemática da literatura (22\%); d) estudos longitudinais (7\%).

Optou-se também pela análise do construto psicológico abordado nos estudos, destacando que um mesmo trabalho poderia abordar vários elementos. Dessa forma, os construtos foram pontuados de forma independente (número de vezes que cada aspecto psicológico foi abordado), e não referentes ao número total de manuscritos pesquisados. A Figura 1 descreve os dados de 76 artigos, sendo que três artigos (não resgatados de forma integral) não disponibilizaram informações suficientes para a categorização dos construtos em estudo. 


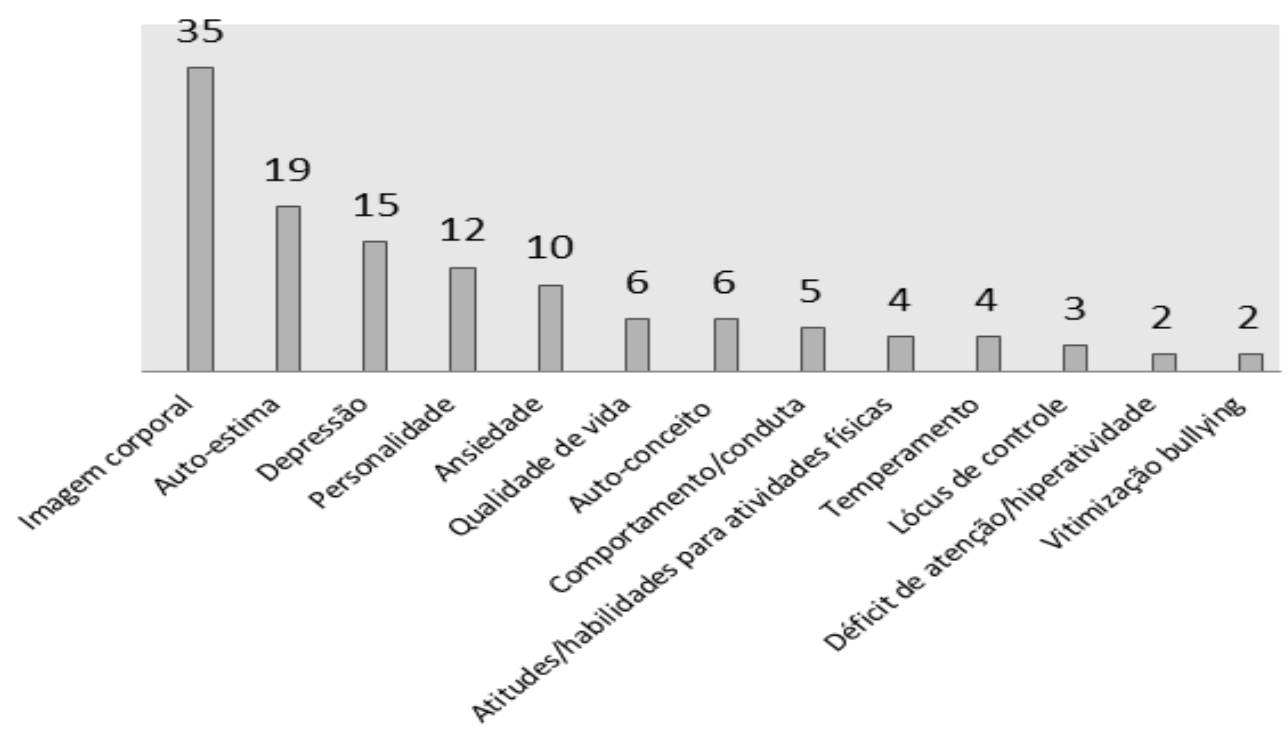

Figura 1: Distribuição (frequência simples) dos construtos psicológicos abordados em 76 artigos da revisão da literatura científica.

Observa-se que, além do construto "imagem corporal" e "personalidade", que foram propositadamente inseridos na busca bibliográfica, os elementos "autoestima", “depressão", “ansiedade", "qualidade de vida”, “autoconceito", “comportamento/conduta" e “atitudes/habilidades para atividades físicas”, "temperamento", "lócus de controle", “déficit de atenção/hiperatividade" e "vitimização/bullying" também aparecem como aspectos avaliados nas crianças e seus pais. Foi possível notar, ao longo do período pesquisado, que o tema da Imagem Corporal é constante nos estudos, bem como características de personalidade. Ao longo dos anos, houve interesse mais específico em alguns construtos, a saber: autoestima, ansiedade e depressão, menos frequentes até a década de 1980.

Outro elemento de interesse para o presente trabalho voltou-se aos instrumentos de avaliação psicológica utilizados nesses estudos. O resultado desta análise baseou-se em 60 trabalhos, visto que 14 estudos não utilizaram instrumentos específicos de avaliação, bem como outros cinco estudos não disponibilizaram esta informação em 
seus resumos. Um mesmo estudo pode utilizar mais de um instrumento avaliativo, de forma que os dados se referem à frequência com que estes foram utilizados, independentemente no número total de manuscritos examinados. Os principais instrumentos de avaliação identificados nos estudos foram: escalas de autorrelato (28\%); escalas de silhuetas (19\%); questionários (19\%); inventários (18\%); instrumentos projetivos (8\%); checklists (5\%); entrevistas $(2 \%)$ e observações $(1 \%)$. Optou-se por separar escalas de autorrelato diversas de escalas de imagem corporal (compostas de figuras de silhuetas humanas com diferentes índices de massa corporal) para possibilitar maior discernimento na análise.

Finalmente, para o âmbito do presente estudo, julgou-se pertinente especificar o método projetivo utilizado nos 10 estudos que fizeram uso desse recurso técnico. Em ordem de maior utilização encontrou-se o Desenho de Figura Humana (DFH) em sete estudos, o Método de Rorschach em dois trabalhos, o Holtzman Inkblot Technique (um estudo) e o Teste de Apercepção Infantil (CAT, um estudo). Em um desses trabalhos o Desenho da Figura Humana (DFH) e o CAT foram utilizados conjuntamente.

A partir das análises descritivas dos dados encontrados nessa revisão da literatura científica, pode-se apontar o gradual aumento das pesquisas na área, cujo primeiro trabalho selecionado foi publicado em 1973. A elevação do número de investigações científicas sobre o tema da obesidade infantil pode estar relacionada à crescente preocupação dos órgãos de Saúde Pública com esse quadro clínico e suas implicações, segundo a Organização Mundial da Saúde (WHO, 2014). Também é cada vez mais aceita a multidisciplinaridade e multidimensionalidade envolvida na compreensão da obesidade infantil e de processos interventivos eficazes (Carvalho, Cataneo, Galindo \& Malfará, 2005; Gonçalves, Silva \& Antunes, 2012). Esta 
perspectiva permite o investimento em outros aspectos da saúde da criança além do clínico-nutricional, como o âmbito psicológico.

Com relação à origem das publicações, percebe-se que a grande maioria dos trabalhos foi realizado na América do Norte, sobretudo nos Estados Unidos. Em seguida, destaca-se o Brasil, mas é preciso considerar que a escolha das bases de dados relativiza tal resultado. Com menor destaque, porém alta qualidade metodológica, aparecem a Austrália, países europeus e a Coréia do Sul. O alto índice de trabalhos concentrados nos Estados Unidos pode refletir a preocupação particular deste país com a elevada incidência da obesidade. Segundo Ogden, Carroll, Kit e Flegal (2014), desde a década de 1970 o índice de obesidade mais que dobrou nos Estados Unidos, sendo que hoje $68,5 \%$ dos adultos com mais de 20 anos apresentam peso elevado, dos quais $34,9 \%$ estão obesos. O mesmo estudo encontrou que, dentre as crianças americanas (dois a 19 anos), 31,8\% estão acima do peso, sendo que destas 16,9\% preenchem critérios para obesidade.

É importante ressaltar, no entanto, que existem dados contrastantes com relação aos índices de obesidade e sobrepeso de diferentes países, como apontado em pesquisa realizada pelo órgão de Saúde Pública do Reino Unido (2012), englobando achados de diversas instituições internacionais, comparando a prevalência da obesidade em adultos. Os extremos da comparação mostram que, no ano de 2010, os Estados Unidos apresentavam índice de 35,9\% de obesidade, enquanto o Japão apresentava 3,5\% de prevalência desse quadro clínico e, a Coréia do Sul, 4,1\%. Este apontamento é indicativo da importância das ressalvas culturais inerentes ao país onde se realiza o estudo sobre a obesidade.

Outro aspecto que se destaca a partir do presente levantamento da literatura científica é relativo ao delineamento das pesquisas. Devido ao caráter clínico do objeto 
de estudo, grande parte dos trabalhos é empírico-descritiva ou descritivo-comparativa, ou seja, visa descrever características psicológicas de um grupo de indivíduos e compará-las a posteriori. Exemplo desse tipo de pesquisa é o trabalho de Li, Ma, Schouten, Hu, Cui, Wang e Kok (2007), onde um grupo representativo de crianças chinesas foi caracterizado em função do peso corporal e de componentes psicológicos. Outro exemplo de estudo realizado com frequência na área é o delineamento de comparação de características de dois grupos pré-selecionados (por exemplo, um grupo de obesos e outro de não obesos, como realizado no estudo de Luiz, Gorayeb \& Liberatore Júnior, 2010). Apesar de tais metodologias mostrarem-se adequadas ao contexto, não se pode deixar de apontar limitações nesses trabalhos, uma vez que, ao descreverem covariações, não conseguem determinar relações de causa e efeito entre os aspectos estudados e a obesidade. Esta peculiaridade propicia alguns vieses interpretativos a serem devidamente ponderados a respeito desse tipo de achados, antes de conclusões sobre o tema em foco. Estudos longitudinais, por sua vez, evitariam este tipo de problema, mas tendem a ser pouco utilizados, possivelmente por seu alto custo financeiro e temporal.

Além do aumento das publicações ao longo das últimas décadas, pode-se observar também diversificação e flexibilização dos construtos enfocados, alargando o leque das hipóteses de variáveis envolvidas no processo da obesidade. Esta mudança possibilita investigar múltiplos fatores que determinam, influenciam ou alteram o curso da obesidade.

Em relação aos construtos psicológicos focalizados, a imagem corporal se apresenta como objeto de pesquisa constante desde o início da produção científica do campo, o que pode explicar a grande variedade de instrumentos e escalas destinados a esta investigação. A preocupação com a autoestima das crianças e sua relação com o 
transtorno aparece um pouco depois, mas assume também significativo espaço nos trabalhos realizados. Como aponta Cobreros (2008), a obesidade constitui-se em doença crônica visível e, por isso, alvo de estigmas que estariam de alguma forma associados à elevada autoexigência e baixa autoestima em crianças portadoras dessa síndrome.

Além disso, observa-se o surgimento e rápido crescimento de estudos enfocando aspectos psicopatológicos associados à obesidade, que se apresentam em publicações mais recentes (a partir dos anos 2000), sendo estes representados prioritariamente pelos sintomas depressivos e de ansiedade, e que, da mesma maneira que a autoestima, já conquistaram considerável número de estudos. Entretanto, os resultados das associações entre tais sintomas e a obesidade mostram-se complexos e muitas vezes contraditórios. Tais discordâncias puderam ser constatadas tanto dentro dos resultados das próprias revisões, como também entre diferentes trabalhos aqui analisados (Cornette, 2008; Incledon, Wake \& Hay Me, 2011; Puder \& Munsch, 2010), o que também foi detectado no primeiro levantamento da literatura científica realizado nesse trabalho. Nesse sentido, tem-se hipotetizado que a relação destes aspectos psicopatológicos com a obesidade pode estar sendo mediada por outras variáveis, tais como baixa autoestima, bullying, insatisfação com o corpo, gênero, entre outros (Cornette, 2008; De Niet \& Naiman, 2011; Incledon, Wake \& Hay, 2011; Harriger \& Thompson, 2012; Wardle \& Cooke, 2005).

Considerou-se importante aos propósitos deste trabalho analisar os tipos de instrumentos mais utilizados para acessar os construtos psicológicos, uma vez que cada instrumental permite informações peculiares. Notou-se uso prioritário de escalas e questionários, possivelmente pela objetividade e clareza dos resultados oferecidos por estes instrumentos. Já a metodologia projetiva, entrevistas e observações, que fornecem dados de natureza descritiva e a partir de princípios psicodinâmicos, tiveram uso menos 
frequente entre os trabalhos identificados no levantamento da literatura científica. Dentre estes últimos, o Desenho da Figura Humana (DFH) foi o método projetivo com maior uso, seguido pelo método de Rorschach, o teste de manchas de Holtzman e o Teste de Apercepção Temática Infantil (versão animal - CAT-A). Ou seja, envolvem poucos instrumentos projetivos, configurando-se como campo relativamente pouco explorado quando comparado com os demais métodos de avaliação ao psiquismo infantil.

Ao focalizar a análise em artigos voltados ao tema da obesidade e possíveis associações com características de personalidade, identificam-se nove trabalhos integralmente recuperados, com distintas linhas teóricas e delineamentos. Destes, sete são estudos empíricos e dois são trabalhos teóricos, sinteticamente explorados a seguir, conforme sua cronologia.

Dentre os trabalhos empíricos, os estudos de Carvalho (2001) e Cardoso e Carvalho (2007) realizaram ampla avaliação psicológica, não só de características de personalidade, mas também construtos como ansiedade, autoconceito, índices emocionais e cognitivos (a partir do Desenho de Figura Humana). Em Carvalho (2001), a ansiedade e lócus de controle foram acessados por meio de escalas, além de avaliação quantitativa e qualitativa do DFH visando averiguar problemas emocionais. Comparou seus resultados a um grupo controle, não encontrando diferenças significativas. Já Cardoso e Carvalho (2007) utilizaram instrumento avaliativo da ansiedade-traço e da ansiedade-estado, escala para lócus de controle e DFH. Identificaram em seus participantes produção compatível com os parâmetros médios do grupo de referência, sem particularidades nas crianças com obesidade.

Ao adotar abordagem psicanalítica para sua pesquisa, Cobreros (2008) utilizou o "Questionario de Personalidad para Niños" como instrumento de coleta de dados, 
permitindo classificação pautada em extremos: reservado/aberto; baixa inteligência/alta inteligência; afetado por sentimentos/emocionalmente estável; calmo/excitável; submisso/dominante; $\quad$ sóbrio/entusiasta; $\quad$ despreocupado/consciente; coibido/empreendedor; sensibilidade dura/sensibilidade branda; seguro/irresoluto; simples/astuto; sereno/apreensivo; pouco/muito integrado; relaxado/tenso. Além disso, possibilita identificação dos seguintes fatores de segunda ordem: ansiedade alta/baixa; introversão/extroversão; calma/excitabilidade-dureza. Foram incluídos na amostra desse estudo, três grupos de crianças: com obesidade, eutróficas e com diabetes. Consegue, então, comparar traços de personalidade comuns em ambos os quadros clínicos crônicos em relação ao grupo eutrófico saudável, identificando algumas especificidades. No grupo obeso os pesquisadores encontraram sinais de adaptação pessoal, porém com maior insatisfação consigo e menor autoestima. Não foram observados traços específicos de personalidade no grupo com obesidade. As diferenças encontradas distanciam os grupos de crianças com patologias crônicas (diabéticos e obesos) do grupo de crianças saudáveis eutróficas. Neste sentido, o grupo com quadros clínicos apresentava pólo mais negativo na variável inteligência, indicando intelectualidade deficitária e pensamento concreto, com aprendizagem e compreensão lentas. Os fatores de sensibilidade, integração e excitabilidade também demonstraram diferença significativa, sendo que as crianças com obesidade ou com diabetes sinalizaram caráter mais dependente, impressionável, submisso, prudente, sentimental, autodisciplinado, socialmente escrupuloso, pouco expressivo e elevado controle emocional. Já o grupo saudável eutrófico mostrou-se mais independente, autoconfiante, entusiasta, vital, obstinado, perspicaz, calculista e descuidado das regras sociais. Frente aos achados, os autores refletem sobre a possibilidade de padrões de personalidade próprios de crianças com enfermidades crônicas em lugar de padrões específicos de cada patologia. 
O trabalho de Mishima e Barbieri (2009) aborda a personalidade, assim como o estudo de Cobreros (2008), a partir do referencial psicanalítico. Entretanto, utilizam-se dos métodos projetivos CAT-A e DFH para acessar a dinâmica psíquica, aqui entendida sob o referencial de Winnicot como o processo de interação entre o mundo interno do indivíduo e o mundo externo. Por se tratar de estudo de caso, os resultados trazem dados minuciosos e hipotéticos a respeito da organização psíquica específica da criança examinada, elementos de difícil generalização e comparação com os demais achados da atual revisão da literatura científica.

O estudo de Hartmann, Czaja, Rief e Hilbert (2010) trabalha com o modelo de personalidade biossocial de Cloninger, segundo a qual temperamento e caráter são distintos. Temperamento envolve aspectos estáveis da personalidade, biologicamente determinados, enquanto o caráter, por sua vez, seria desenvolvido a partir da interação entre o temperamento e o ambiente. $\mathrm{O}$ instrumento utilizado nesse estudo foi um inventário respondido pelos pais das crianças participantes, visando acessar quatro dimensões do temperamento (busca pelo novo; evitação de danos; dependência de recompensa e persistência) e três dimensões do caráter (auto direcionamento; cooperativismo; auto transcendência). Além disso, as crianças responderam a um inventário sobre impulsividade, comportamentos de risco e empatia, considerados pelos autores como complementares ao estudo da personalidade. Os resultados sugerem padrão específico de traços de personalidade para crianças com episódios de alimentação compulsiva (LOC - Lost Of Control over eating). O grupo com LOC apresentou menor auto direcionamento e cooperativismo do que o grupo de comparação. Da mesma forma, crianças com LOC foram significativamente mais impulsivas. As dimensões da personalidade foram significativamente correlacionadas com maior índice de psicopatologias em geral, mas não a transtornos alimentares ou a 
presença de LOC. Os pesquisadores hipotetizam a existência de um padrão distinto de comportamento alimentar em crianças com LOC, vinculado a seus traços de personalidade, porém sugerem estudos longitudinais para examinar se certos padrões de personalidade nesta população contribuem para diferenças em possíveis manifestações psicopatológicas em momentos posteriores da vida da criança.

Os instrumentos usados nos estudos desenvolvidos por Romo, Coëffec e Guilmin-Crepon (2012) e Vollrath, Hampson e Juliusson (2012) têm por base a teoria dos cinco grandes fatores da personalidade (modelo Big Five), sendo eles neuroticismo ou instabilidade emocional, extroversão, amabilidade ou benevolência, escrupulosidade ou conscienciosidade, e abertura para a experiência ou imaginação. Tal modelo permite aos autores discutir seus objetivos em função das vantagens e desvantagens que os traços de personalidade apresentados pelos participantes facilitam ou dificultam a motivação à mudança de hábitos (Romo, Coëffec \& Guilmin-Crepon, 2012) ou uma propensão ao tipo de consumo alimentar (Vollrath, Hampson \& Juliusson, 2012). É interessante apontar que, em ambos os trabalhos, estes inventários são preenchidos pelos pais das crianças, ainda que em Romo, Coëffec e Guilmin-Crepon (2012) tenha sido aplicado um instrumento avaliativo também nas crianças. Os resultados do estudo supracitado não encontraram relação entre traços de personalidade dos pais e sobrepeso dos filhos. Já a avaliação de personalidade das crianças é discutida com cautela, com indicadores de aumento do neuroticismo podendo testemunhar aumento da sensibilidade a afetos negativos em crianças com obesidade. Da mesma forma, a elevação da extroversão, abertura, e conscienciosidade seriam fatores positivos à intervenção terapêutica em quadros de obesidade infantil.

A pesquisa desenvolvida por Vollrath, Hampson e Juliusson (2012) comparou índices dos cinco grandes fatores de personalidade com hábitos alimentares de crianças, 
controlando idade e escolaridade materna. Descrevem que crianças menos benevolentes consumiam mais bebidas doces, e meninas menos conscienciosas e mais neuróticas ingeriam menos bebidas adocicadas. Meninos e meninas mais benevolentes e imaginativos consumiam mais frutas e vegetais, assim como meninos mais extrovertidos, conscienciosos e menos neuróticos. Ao controlar a educação materna, os autores encontraram que meninos e meninas menos extrovertidos e meninas menos benevolentes e conscienciosas e mais neuróticas tinham maior propensão a estarem com sobrepeso ou com obesidade. Os autores concluem que os traços de personalidade das crianças exercem importante e ainda pouco compreendido papel nas dietas alimentares e sugerem novos estudos para auxiliar esta compreensão.

Finalmente, os estudos desenvolvidos por Braet (2005) e De Niet e Naiman (2011) constituem-se como trabalhos teóricos, descrevendo aspectos psicológicos gerais concernentes à obesidade infantil, apresentando subtópicos que abordam brevemente a personalidade. De Niet e Naiman (2011) descrevem a personalidade em traços, enfocando, sobretudo, os achados referentes a impulsividade e busca por diversão em casos de obesidade. Na mesma linha, Braet (2005) descreve a personalidade como fator que desempenha forte papel no desenvolvimento ou manutenção da obesidade. Destaca também escores mais altos em questionários para impulsividade e fatores de “externalização" (descrito como maior responsividade a estímulos externos, como cheiros e imagens, em detrimento de sensações internas como saciedade) como traços de personalidade em casos de obesidade em crianças, ainda que aponte a inexistência de consenso teórico e empírico sobre o tema.

A partir dos estudos identificados no levantamento da literatura científica sobre a obesidade infantil foi possível notar uma definição polissêmica para o construto 
personalidade, influenciada pela perspectiva teórica de cada investigador. Depreendeuse estudos que consideraram aspectos isolados da personalidade, como traço de ansiedade, lócus de controle (Carvalho, 2001; Cardoso \& Carvalho, 2007), ao lado de trabalhos que buscaram descrição global do indivíduo a partir de traços principais de sua personalidade (Cobreros, 2008; Hartmann, Czaja, Rief \& Hilbert, 2010; Romo, Coëffec \& Guilmin-Crepon, 2012; Vollrath, Hampson \& Juliusson, 2012) e um trabalho cuja caracterização do psiquismo foi descrito pela dinâmica de suas relações, não se caracterizando por traços específicos (Mishima \& Barbieri, 2009).

Após esse trabalho, buscou-se identificar pesquisas com o tema da obesidade infantil e que tivessem trabalhado com técnicas gráficas de investigação psicológica, sobretudo o Desenho de Figura Humana (DFH). Desse modo, foram detectados três estudos adicionais que utilizaram o DFH como ferramenta para acessar a personalidade de crianças com obesidade e serão apresentados em ordem cronológica.

Azevedo (2003) propôs-se a investigar, a partir da abordagem psicossomática (que considera a obesidade como sintoma e expressão inconsciente de transtornos emocionais), a personalidade de 30 crianças com obesidade e 30 crianças de peso normal, de sete a 13 anos de idade. Sistematizou a presença dos Indicadores Emocionais (IE) de Koppitz (1966) na produção dos DFH desses participantes. A autora encontrou significativo maior número de IEs e escores mais altos nas crianças com obesidade, corroborando a visão de Koppitz de que o aumento desses indicadores está associado ao comprometimento emocional da criança. Os IEs evidenciariam sinais de conflito no psiquismo e, como tal, revelaram evidências de ansiedade. Nesse sentido, as crianças com obesidade apresentaram mais indicadores de dificuldades emocionais do que as de peso normal. 
Os indicadores "Figura Inclinada", "Omissão do Nariz" e "Braços Curtos" apareceram com maior frequência no grupo com obesidade. Tais indicadores, segundo Koppitz (1966), seriam mais frequentes em desenhos de crianças com transtornos psicossomáticos. A omissão do nariz está associada à conduta tímida e retraída, com ausência de agressividade manifesta e reduzido interesse social. Já a presença de braços curtos é relacionada à tendência ao retraimento, ao fechamento sobre si e à inibição de impulsos; enquanto o desenho inclinado é associado a insegurança, instabilidade. As pesquisadoras comentam que, segundo Koppitz (1966), crianças menos impulsivas ou reprimidas poderiam redirecionar sua agressividade para si próprias, tendendo a desenvolver sintomas psicossomáticos quando frustradas e ressentidas, diferentemente de crianças agressivas, as quais revelariam menor controle de impulsos, voltando-os para fora.

Uma investigação mais recente nessa área foi desenvolvida com objetivo de investigar a relação entre a sintomatologia depressiva e a obesidade em crianças (Kitamura, Delvan, Schlösser \& Lançoni-Jr., 2013). Para tanto oito crianças entre sete e 11 anos, diagnosticadas com obesidade, responderam ao Inventário de Depressão Infantil (CDI) e realizaram o DFH, avaliado pelos Itens Evolutivos e Indicadores Emocionais de Koppitz, enquanto os pais responderam a um questionário e a anamnese. Como resultados os pesquisadores encontraram ausência de sintomatologia depressiva nas crianças avaliadas. Entretanto, sete das oito crianças avaliadas apresentaram mais que dois IEs, sugerindo problemática emocional. Os indicadores mais presentes entre as crianças foram "braços curtos" e "assimetria grosseira dos membros". Este último indicador, como descrevem os autores, estaria possivelmente associado à falta de coordenação e pobreza de controle muscular fino, mas também poderia refletir o sentimento da criança de não estar bem coordenada e sem adequado equilíbrio interno. 
Ainda pautado na produção infantil a partir do DFH, o estudo de Haldelzalts e Ben-Artzy-Cohen (2014) objetivou estudar as características altura, largura e inclusões/omissões de detalhes dos desenhos e sua relação com a imagem corporal medida por escala de autorrelato (Escala de Imagem Corporal de Gray) e comportamentos de dieta e IMC. Avaliaram 54 estudantes de Psicologia do sexo feminino, de 20 a 27 anos de idade, subdivididas de acordo com seu relato sobre dietas alimentares (27 mulheres relataram nunca terem feito dieta alimentar, 27 mulheres com relato de dieta alguma vez na vida, das quais 13 reportaram terem estado em dietas tanto no passado como no presente, e 14 mulheres reportaram estar em dieta no presente). Os resultados apontam que os desenhos das mulheres em dieta para perda de peso foram menores que as demais, porém não de maneira significativa. Entretanto, as dimensões mensuradas do DFH mostraram significativa e positiva correlação com os resultados da escala de autorrelato, na medida em que figuras maiores estavam associadas a melhor imagem corporal. Não foram encontradas diferenças estatisticamente significativas entre os grupos de mulheres no tocante a inclusões / omissões no DFH.

Pode-se notar que o DFH foi e ainda se constitui como relevante instrumento avaliativo para captação de características relativas ao psiquismo, quer em crianças ou em adultos, atravessando décadas e diferentes perspectivas teóricas. Como atesta a literatura científica, pode ser bastante útil e econômico para se compreender características internas dos indivíduos, sobretudo em quadros clínicos, como no caso da obesidade.

Frente aos achados de revisão da literatura científica a respeito da obesidade em crianças e seus componentes psicológicos realizadas neste trabalho, detectam-se poucos estudos com visão integradora do psiquismo, que o entenda como multifacetado e que busque relacionar diversos construtos, com predomínio de pesquisas que recorreram a 
instrumentos de acesso objetivo a variáveis específicas, tais como ansiedade e depressão. Entretanto, como bem apontam Villemor-Amaral e Pasqualini-Casado (2006), tais tipos de instrumento de avaliação psicológica possuem alcance delimitado, diferenciado daquele possível a partir de medidas projetivas. Instrumentos de autorrelato (como entrevistas estruturadas, inventários ou escalas), no geral, buscam indicadores objetivos sobre construtos psicológicos, enquanto medidas projetivas (como método de Rorschach e alguns sistemas avaliativos do Desenho da Figura Humana DFH) apreendem aspectos distintos de um mesmo estado motivacional, traço ou necessidade. Esses últimos relacionam-se à investigação de comportamentos e tendências espontâneas, subjetivas e motivadas por necessidades não aparentes e mais propícias a manifestarem-se em determinados contextos, em lugar das respostas intencionais e contextualizadas em um propósito, que são alcançadas por instrumentos objetivos de pesquisa.

Dessa forma, a avaliação psicológica mostra-se como importante alternativa de acesso ao funcionamento psicológico, permitindo investigação sistemática de componentes internos vinculados às expressões comportamentais. Destaque especial faz-se aqui ao já citado Método de Rorschach (Rausch de Traubenberg, 1998) e ao sistema avaliativo de Koppitz para o Desenho da Figura Humana (Koppitz, 1966), configurando em recursos profícuos para investigação da personalidade, apontado por Dreyfus (1993) como necessário para adequada compreensão da obesidade em crianças. Há que se enfatizar, contudo, uma linha investigativa mais específica, dada a amplitude e complexidade do construto personalidade. Essa vertente se justifica na medida em que, apesar o estudo da obesidade (sobretudo em crianças) ter crescido na literatura científica, ainda é pouco explorado pela vertente investigativa de instrumentos projetivos, foco do presente trabalho. Almeja-se, desse modo, buscar evidências 
empíricas a respeito de indicadores psicodinâmicos subjacentes em crianças com obesidade.

Tem-se como hipóteses para o presente estudo que a presença de obesidade em crianças pode ser acompanhada por indicadores de dificuldades no autocontrole e na contenção de impulsos (impulsividade), bem como por sinais de pensamento de tipo concreto, podendo produzir variáveis prejudiciais ao desenvolvimento infantil. Essas variáveis foram selecionadas frente aos resultados identificados nos estudos recuperados para a compreensão da temática da obesidade infantil. 
2. OBJETIVOS 


\subsection{Geral}

O presente estudo tem por objetivo identificar e comparar características psicológicas e da organização psíquica de crianças com obesidade em relação a eutróficas, a partir de métodos projetivos de investigação da personalidade, sendo esses, o Método de Rorschach e o Desenho da Figura Humana (Koppitz, 1966).

\subsection{Específicos}

2.2.1. Caracterizar padrão geral de respostas no Método de Rorschach e Desenho da Figura Humana (Koppitz, 1966) de crianças com obesidade em relação a crianças eutróficas, bem como indicadores de saúde mental a partir do Questionário de Capacidades e Dificuldades (SDQ).

2.2.2. Comparar achados referentes ao funcionamento afetivo e cognitivo e indicadores de saúde mental de crianças com obesidade, a partir de seus resultados no Teste de Rorschach, no Desenho da Figura Humana (Koppitz, 1966) e no Questionário de Capacidades e Dificuldades (SDQ), em relação ao grupo de comparação (crianças eutróficas).

2.2.3. Comparar resultados em principais variáveis do Método de Rorschach, Desenho da Figura Humana (Koppitz, 1966) a partir de indicadores clínicos desses instrumentos.

2.2.4. Comparar resultados em principais variáveis do Método de Rorschach, Desenho da Figura Humana (Koppitz, 1966) e do Questionário de Capacidades e Dificuldades (SDQ) de crianças em função do sexo e idade.

2.2.5. Testar a correlação do índice de massa corporal (IMC) como os principais resultados obtidos a partir do Método de Rorschach, Desenho da Figura Humana 
(Koppitz, 1966) e do Questionário de Capacidades e Dificuldades (SDQ), independentemente de grupos de classificação nutricional pré-estabelecidos.

2.2.6. Analisar, de modo comparativo, dados de principais variáveis do Método de Rorschach, Desenho da Figura Humana (Koppitz, 1966) e do Questionário de Capacidades e Dificuldades (SDQ) de crianças em função da presença (ou não) de obesidade com referenciais normativos de sua faixa etária. 
3. MÉTODOS 
A presente investigação científica caracteriza-se como um estudo transversal, descritivo e comparativo de grupos de crianças do ensino fundamental, pautada em uma perspectiva quantitativa e interpretativa de resultados advindos de instrumentos de avaliação psicológica.

\subsection{Participantes}

Participaram do presente estudo 60 crianças de sete a 11 anos, regularmente matriculadas na série escolar do ensino fundamental compatível com sua idade cronológica (portanto, sem atraso acadêmico), residentes em Ribeirão Preto e região (interior do Estado de São Paulo). Essa amostra foi dividida em dois grupos, equitativamente distribuídos em relação à idade e sexo dos participantes, a saber:

- Grupo 1 (G1 - grupo clínico), composto por 30 crianças diagnosticadas com obesidade conforme critérios e avaliação médica específicos, referenciados nos parâmetros da Organização Mundial de Saúde (2007), em tratamento nutricional há no máximo um ano na Clínica-escola de Nutrição da Universidade de Ribeirão Preto (UNAERP) ou no Núcleo de Gestão Ambulatorial - NGA no. 59 (Ambulatório Regional de Especialidades) de Ribeirão Preto (SP). Apenas uma criança foi identificada a partir de clínica particular de Nutrição, visto que os usuários dos referidos serviços já haviam sido todos contatados durante o período de dezembro de 2013 a setembro de 2014, ainda faltando dois casos para completar a amostra pretendida, buscada, então, dessa forma ativa entre os contatos da pesquisadora com nutricionistas que colaboraram com o estudo.

- Grupo 2 (G2 - grupo de comparação), composto por 30 crianças eutróficas pareadas em função do sexo, ano e origem escolar dos participantes que compuseram o Grupo 1. 
Essas crianças foram identificadas a partir de parceria da pesquisadora com escola de ensino fundamental da cidade de Cravinhos (SP), selecionada por conveniência e viabilidade para execução do estudo, na medida em que permitiu o acesso aos dados cadastrais e o contato com os alunos e seus pais ou responsáveis, tornando possível o balanceamento das características demográficas com os casos do Grupo 1.

Foram excluídos do estudo os voluntários com nível intelectual rebaixado, conforme resultado no Teste das Matrizes Progressivas Coloridas de Raven (Angelini, Alves, Custódio, Duarte \& Duarte, 1999). Assim, ficaram na amostra os estudantes com resultado igual ou superior ao percentil 25 , sinalizando potencial médio ou superior em termos intelectuais. Optou-se por este critério visto que o fator cognitivo poderia funcionar como uma variável de confusão na comparação entre os grupos delineados no presente estudo, visando assim homogeneizar a amostra.

Outro critério de exclusão de participantes foi a existência de comorbidades (como diabetes, síndromes ou outros quadros clínicos), bem como alterações corporais (como amputações, queimaduras visíveis, entre outros) ou senso-perceptivas que poderiam interferir nos resultados, sobretudo relativos ao DFH. Esses dados foram retirados do prontuário médico ou acadêmico do voluntário, bem como no primeiro contato direto com os estudantes.

A maioria dos casos do grupo clínico seguiam tratamento nutricional na Clínicaescola de Nutrição da Universidade de Ribeirão Preto (UNAERP), com atendimentos realizados por nutricionistas em formação e supervisionados por docentes qualificados da referida Universidade. Os pacientes chegavam a esse serviço por encaminhamento das Unidades de Saúde ligadas ao Sistema Único de Saúde (SUS) e foram convidados a participar do estudo (por convite direto da pesquisadora) quando compareciam a consultas regulares ou retornos na clínica. Os responsáveis pelas crianças optavam pela 
realização da pesquisa com a criança na própria UNAERP, em sala adequada disponibilizada para uso da pesquisadora, ou em sua residência, desde que houvesse um responsável no domicílio, em data combinada. A maioria dos casos do grupo clínico foi avaliada na própria instituição, mediante agendamento prévio após livre aceite da pesquisa.

A rotina dos atendimentos na clínica-escola de Nutrição da UNAERP implicava em atualização semanal dos casos, com agendamento previsto para casos novos (metade dos atendimentos) e para seguimentos regulares (retornos dos casos em acompanhamento). Não havia um banco de dados unificado com a listagem do conjunto de usuários do serviço, o que limitou a possibilidade de planejamento dos contatos da pesquisadora com eventuais voluntários ao estudo. Desse modo, a pesquisadora acompanhou o funcionamento do referido serviço durante nove meses, iniciando em dezembro de 2013 e durante parte do ano letivo de 2014, de fevereiro a setembro. Comparecia na clínica-escola durante o período dos atendimentos e então avaliava os prontuários disponíveis para averiguar a adequação de cada caso frente aos critérios de seleção de participantes. Quando atendiam aos critérios delineados e compareciam à consulta, eram, então, convidados a participar do estudo.

O Ambulatório de Nutrição do Núcleo de Gestão Ambulatorial - NGA no. 59 do Ambulatório Regional de Especialidades da Secretaria Municipal de Saúde de Ribeirão Preto (SP), por sua vez, foi o outro serviço contatado para busca de participantes do grupo clínico do estudo. Após as devidas tramitações técnicas e de caráter ético, o serviço disponibilizou a planilha dos atendimentos infantis realizados na clínica de Nutrição, de forma que a pesquisadora pode selecionar os casos que preenchiam os critérios de seleção na pesquisa. Do total de crianças em atendimento no período de consulta à base de dados (dezembro de 2013 e janeiro de 2014) foi possível identificar 
nove casos que haviam iniciado tratamento nutricional no último ano, sendo selecionados para a pesquisa. O contato com as famílias neste caso foi realizado pela pesquisadora via telefone, segundo dados disponibilizados pelo serviço de saúde, verificando a possibilidade de aceite no estudo. Aqueles casos cujos pais autorizaram o estudo foram agendados para aplicação dos instrumentos de avaliação psicológica no próprio serviço clínico, em dia de rotina ambulatorial, ou nas próprias residências das crianças, caso assim preferissem.

A partir desse enquadre foi possível avaliar 44 pacientes da clínica-escola de Nutrição da UNAERP. Deste total, 10 pacientes não compareceram ao serviço em seu agendamento e, por isso, não participaram do estudo. Dos 34 casos contatados, quatro pais e duas crianças não aceitaram a participação (seis casos) e um participante foi excluído devido ao critério cognitivo, não chegando a finalizar as atividades em função de sua limitação compreensiva sobre as instruções oferecidas pela pesquisadora para as atividades. Desta fonte, portanto, foram avaliadas 27 crianças.

Com relação ao NGA, dos nove contatos obtidos, uma mãe e uma criança não tiveram interesse em participar do estudo (dois casos) e seis não puderam ser acessados em função de imprecisão nos dados relativos ao contato telefônico fornecido. Assim, apenas uma criança proveniente do NGA pode ser avaliada e incluída no presente estudo.

Finalmente, contou-se também com dois casos acessados via contatos da pesquisadora com profissionais de Nutrição que colaboraram no estudo e que realizavam atendimentos em clínica particular em Ribeirão Preto (SP). Obteve-se acesso desta forma a dois casos que preenchiam os critérios de seleção do estudo e que estavam em acompanhamento nutricional. Ambas as crianças (e seus responsáveis) aceitaram o convite à participação do estudo, sendo assim completado o grupo clínico (n=30). 
O percurso para compor o Grupo 1 do presente estudo pode ser esquematicamente visualizado na Figura 2.

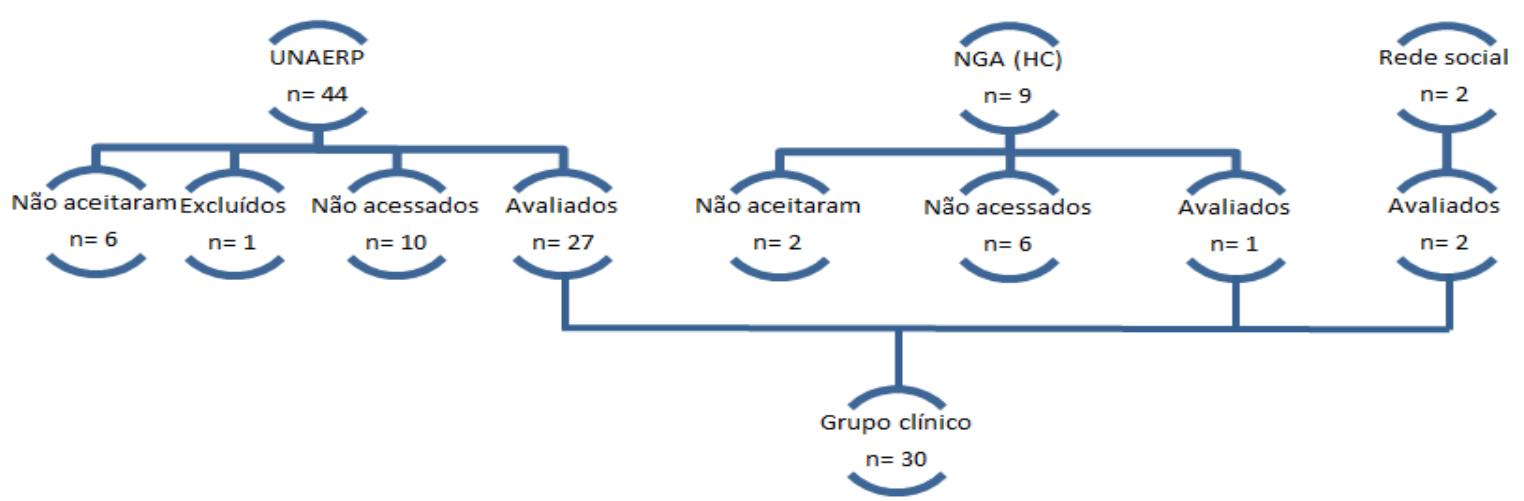

Figura 2: Percurso amostral do grupo clínico $(n=30)$.

Com relação ao grupo de comparação (G2), optou-se por realizar sua composição a partir de uma escola pública de cidade próxima a Ribeirão Preto, que se assemelhasse à realidade encontrada no grupo clínico, com habitações de periferia e bairros mais afastados, constituindo-se numa amostra por conveniência. Assim, uma escola de Ensino Fundamental Municipal de Cravinhos (SP) foi convidada a participar do trabalho, mediante assinatura de termo de concordância institucional com o estudo.

A partir dos casos obtidos no grupo clínico realizou-se um levantamento dos casos necessários para o Grupo 2 (grupo de comparação), balanceados em função do sexo, idade e ano escolar, mas crianças com peso considerado "normal" segundo o mesmo sistema utilizado para o primeiro grupo. Tal levantamento foi repassado para a Coordenação Pedagógica da escola que fazia, então, a seleção de alunos com o perfil desejado. Nos casos de concordância dos pais ou responsáveis para com participação da criança no estudo, essas foram, então, convidadas formalmente pela pesquisadora a participar da pesquisa. Dos 50 termos de consentimento livre e esclarecido (TCLE) enviados aos pais, 11 casos não aceitaram participar do estudo, restando 39 possíveis 
voluntários. Dos casos com aceitação dos responsáveis, cinco crianças não se encaixaram na faixa etária delineada para o estudo, não sendo convidadas, apesar da listagem prévia fornecida. Assim, 34 crianças foram avaliadas em âmbito escolar, tendo seu peso e altura mensurados para cálculo do IMC, sendo que cinco acabaram excluídas da pesquisa (três apresentaram sobrepeso, um estudante possuía baixo peso e outro caso foi eliminado por insuficiência de respostas no Método de Rorchach).

Buscou-se ainda a complementação de G2 por meio de contatos pessoais da pesquisadora com eventuais possíveis participantes, a partir de amplo convite a possíveis voluntários realizado entre os membros do grupo de pesquisa e seus conhecidos. Dessa forma, três crianças foram indicadas para participar do estudo, preenchendo os critérios delineados. Após avaliação desses casos, um voluntário foi excluído por apresentar sobrepeso e outro por limitação cognitiva. Assim, uma criança de escola pública foi incluída por esta via de contatos para o estudo, sendo possível completar o grupo de comparação da pesquisa.

O fluxograma da Figura 3 descreve o percurso amostral do grupo de comparação (G2).

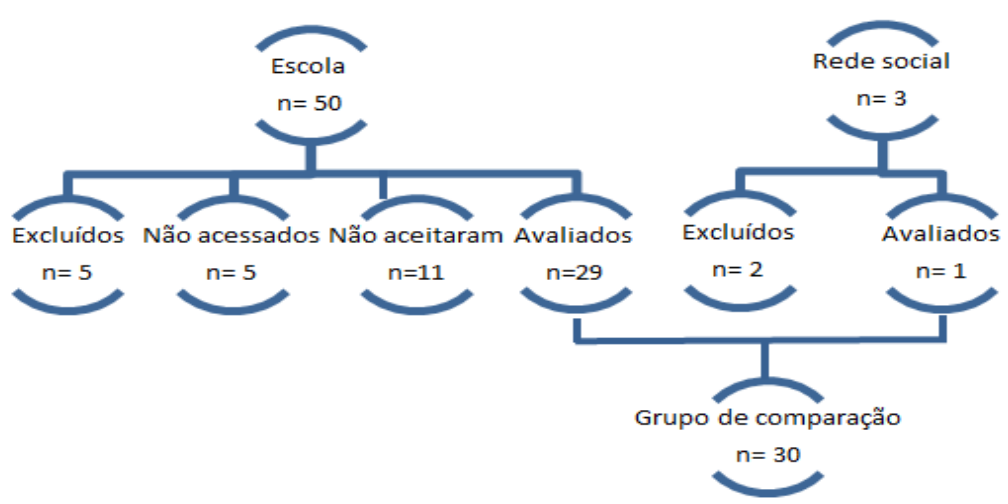

Figura 3: Percurso amostral do grupo de comparação $(n=30)$. 
A partir da aplicação dos critérios de seleção previstos para o presente trabalho, foi possível compor a amostra com 60 crianças, conforme inicialmente delineado. A Tabela 2 descreve a distribuição dos participantes em função do sexo e idade.

Tabela 2: Distribuição dos participantes do estudo em função do sexo e idade.

\begin{tabular}{cccccc}
\hline & \multicolumn{2}{c}{$\begin{array}{c}\text { Grupo Clínico } \\
(\mathrm{G} 1, \mathrm{n}=30)\end{array}$} & \multicolumn{2}{c}{$\begin{array}{c}\text { Grupo de Comparação } \\
(\mathrm{G} 2, \mathrm{n}=30)\end{array}$} & TOTAL \\
Idade (anos) & Masculino & Feminino & Masculino & Feminino & \\
\hline 7 & 3 & 3 & 3 & 4 & 13 \\
8 & 2 & 5 & 5 & 2 & 14 \\
9 & 2 & 4 & 3 & 7 & 16 \\
10 & 7 & 3 & 3 & 2 & 15 \\
11 & 1 & - & 1 & - & 2 \\
TOTAL & 15 & 15 & 15 & 15 & 60 \\
\hline
\end{tabular}

A amostra do presente estudo foi composta, dessa maneira, por 60 crianças entre sete a 11 anos, com idade média de 9,14 anos $( \pm 1,10)$ no total, sendo 9,32 anos $( \pm 1,12)$ para o Grupo Clínico e 8,97 anos $( \pm 1,07)$ para o grupo de comparação. Ambos os grupos tiveram participantes do sexo feminino e masculino em igual proporção. Foi realizada análise inferencial (teste $t$ de Student, $p \leq 0,5$ ) para verificar possível efeito da idade na amostra, não existindo sinal de diferença estatisticamente significativa entre $\mathrm{G} 1$ e $\mathrm{G} 2(t=1,22 ; p=0,28)$.

Com relação ao Índice de Massa Corporal (IMC), o Grupo Clínico apresentou média de $25,67 \mathrm{~kg} / \mathrm{m}^{2}( \pm 3,60)$ e o Grupo de Comparação teve média $15,43 \mathrm{~kg} / \mathrm{m}^{2}$ $( \pm 1,21)$. A análise inferencial (comparação de médias do IMC de G1 e de G2, utilizando-se o teste $t$ de Student, $p \leq 0,5)$ revelou diferença estatisticamente significativa entre os grupos $(t=14,61 ; p \leq 0,001 ; d$ de Cohen $=3,81$, tamanho do efeito $=$ 
0,88). Esse resultado acompanhou o esperado ao selecionar-se a amostra com base no diagnóstico médico de obesidade (G1) e na ausência desse quadro clínico (G2).

A seguir apresenta-se a caracterização da amostra em termos de nível intelectual (obtido pelo Teste das Matrizes Coloridas de Raven), utilizado para triagem cognitiva dos voluntários ao estudo. Esses dados compõem a Tabela 3.

Tabela 3: Distribuição (em frequência simples e em porcentagem) do desempenho intelectual das crianças em função do grupo do estudo - Grupo 1 (Clínico) e Grupo 2 (Comparação).

\begin{tabular}{|c|c|c|c|c|c|c|}
\hline \multirow[b]{2}{*}{ Nível intelectual } & \multicolumn{2}{|c|}{ Grupo 1} & \multicolumn{2}{|c|}{ Grupo 2} & \multicolumn{2}{|c|}{ Total } \\
\hline & $f$ & $\%$ & $f$ & $\%$ & $f$ & $\%$ \\
\hline $\begin{array}{l}\text { Intelectualmente Superior } \\
\quad(\text { percentil } \geq 95)\end{array}$ & 4 & 13,3 & 2 & 6,7 & 6 & 10,0 \\
\hline $\begin{array}{l}\text { Inteligência definidamente } \\
\text { superior à média } \\
(95>\text { percentil } \geq 90)\end{array}$ & 7 & 23,3 & 6 & 20,0 & 13 & 21,7 \\
\hline $\begin{array}{l}\text { Inteligência definidamente } \\
\text { superior à média } \\
(90>\text { percentil } \geq 75)\end{array}$ & 7 & 23,3 & 4 & 13,3 & 11 & 18,3 \\
\hline $\begin{array}{c}\text { Inteligência mediana }+ \\
(75>\text { percentil } \geq 50)\end{array}$ & 8 & 26,7 & 13 & 43,3 & 21 & 35,0 \\
\hline $\begin{array}{l}\text { Inteligência mediana - } \\
(50>\text { percentil } \geq 25)\end{array}$ & 4 & 13,3 & 5 & 16,7 & 9 & 15,0 \\
\hline
\end{tabular}

Observa-se incidência de escores em todas as classificações intelectuais, com especial concentração de resultados classificados na faixa "Média Superior". A média encontrada para o escore bruto do Grupo 1 foi de $24,9( \pm 4,91)$, enquanto que o Grupo 2 apresentou como média 22,83 pontos $( \pm 4,44)$. Já com relação aos percentis associados à comparação com a população de referência, encontrou-se para o Grupo Clínico uma média de $71,97( \pm 18,26)$, e para o Grupo de Comparação ao média foi de 66,27 $( \pm 15,88)$. A análise inferencial com auxílio do teste $t$ de Student evidenciou ausência de 
diferença estatisticamente significativa entre os grupos em função do desempenho intelectual $(t=1,71 ; p=0,09)$, ainda que o Grupo 1 tenha apresentado certa tendência a melhor desempenho.

Por fim, tem-se a distribuição da amostra em função do ano escolar cursado pela criança no momento de sua participação no estudo. Esses dados estão presentes na Tabela 4.

Tabela 4: Distribuição (em frequência simples e porcentagem) dos participantes do estudo em função do sexo e do ano escolar.

\begin{tabular}{ccccccccccc}
\hline Grupo & \multicolumn{3}{c}{ Grupo $1(\mathrm{n}=30)$} & \multicolumn{5}{c}{ Grupo $2(\mathrm{n}=30)$} & \multicolumn{2}{c}{ TOTAL } \\
Sexo & Masculino & Feminino & Masculino & Feminino & & \\
Ano escolar & $f$ & $\%$ & $f$ & $\%$ & $f$ & $\%$ & $f$ & $\%$ & $f$ & $\%$ \\
\hline Primeiro & 1 & 3,3 & 1 & 3,3 & - & - & - & - & 2 & 3,3 \\
Segundo & 2 & 6,7 & 2 & 6,7 & 4 & 13,3 & 4 & 13,3 & 12 & 20,0 \\
Terceiro & 1 & 3,3 & 5 & 16,7 & 4 & 13,3 & 4 & 13,3 & 14 & 23,3 \\
Quarto & 8 & 26,7 & 5 & 16,7 & 5 & 16,7 & 5 & 16,7 & 23 & 38,3 \\
Quinto & 2 & 6,7 & 2 & 6,7 & 2 & 6,7 & 2 & 6,7 & 8 & 13,3 \\
Sexto & 1 & 3,3 & - & - & - & - & - & - & 1 & 1,7 \\
\hline
\end{tabular}

Observou-se predomínio de crianças no quarto e no terceiro ano acadêmico nos dois grupos e, portanto, total da amostra, acompanhando a idade média dos participantes. Essa tendência já seria esperada, visto que um dos critérios de seleção dos participantes foi o adequado acompanhamento da rotina escolar (série adequada para sua faixa etária). 
A partir da presente caracterização amostral considera-se que os Grupos 1 e 2 podem ser comparáveis, conforme delineamento originalmente pensado, dadas suas características de homogeneidade em termos de idade, ano escolar e capacidade cognitiva. A única variável em que diferem, dentro das características examinadas, é o IMC, compondo, assim, a variável critério em estudo (obesidade versus eutrofia).

\subsection{Materiais}

Para o adequado desenvolvimento dessa pesquisa, de modo a atender aos objetivos delineados, foram necessários os materiais a seguir descritos.

3.2.1. Carta de apresentação da pesquisa (APÊNDICE A): documento para apresentar o projeto de pesquisa a dirigentes dos estabelecimentos de saúde e escolares, de modo a permitir sua avaliação da proposta e a possibilidade de colaboração com o estudo, consentindo com sua realização. Contém informações relacionadas aos objetivos do trabalho e processo de coleta de dados, bem como espaço destinado ao consentimento formal dos dirigentes à realização da pesquisa na instituição.

\subsubsection{Termo de Consentimento Livre Esclarecido (TCLE) (APÊNDICES B e C):} documento que contém a explicação dos objetivos do trabalho e direitos dos participantes. Destinado aos pais ou respectivos responsáveis das crianças voluntárias, formalizando consentimento formal ao estudo mediante assinatura no TCLE.

3.2.3. Termo de Assentimento (APÊNDICE D): documento redigido em formato e linguagem acessível às crianças convidadas ao estudo, por meio do qual puderam 
explicitar sua anuência na pesquisa, após terem sido suficientemente esclarecidas a respeito.

3.2.4. Material para cálculo do IMC: balança digital calibrada e fita métrica padronizada para a mensuração do índice de massa corporal de G2 (grupo de comparação). O grupo clínico (G1) teve suas medidas aferidas pelo próprio serviço de saúde. Para classificação dos valores obtidos em ambos os grupos foram utilizadas as curvas de crescimento da OMS (2007) (ANEXO 1).

3.2.5. Teste das Matrizes Progressivas Coloridas de Raven: técnica de múltipla escolha, com objetivo de avaliação do nível intelectual. Existem várias versões do instrumento, sendo que as Matrizes Progressivas Coloridas são voltadas à avaliação de crianças de seis a 11 anos. A técnica propõe matriz de figuras onde há um padrão lógico entre as representações figurativas presentes na página, solicitando-se à criança a escolha de apenas uma das alternativas para completar a matriz. Esta técnica foi estudada no contexto do Brasil por Angelini, Alves, Custódio, Duarte e Duarte (1999), sendo que este referencial técnico e normativo foi adotado no presente trabalho. O estudo de Nascimento, Gomes e Pasian (2016) indica que o Teste das Matrizes Progressivas Coloridas de Raven apresenta bons índices psicométricos para avaliar um fator geral e fatores específicos da inteligência.

3.2.6. Questionário de Capacidades e Dificuldades (SDQ) (Strengths and Difficulties Questonnaire, SDQ): instrumento objetivo de avaliação psicológica, que rastreia problemas de saúde mental infantil em cinco áreas: comportamento pró-social, hiperatividade, problemas emocionais, de conduta e de relacionamento. Esse 
instrumento pode ser aplicado a pais e professores, foi construído em 1997 por Goodman e validado no Brasil em 2000 por Fleitlich, Cortázar e Goodman (Saur \& Loureiro, 2012). Utilizou-se no presente estudo a versão dirigida aos pais, de modo a permitir a caracterização das crianças desse estudo termos de indicadores de saúde mental. Cabe destacar que os resultados desse instrumento não foram utilizados como recurso de triagem para composição da amostra, mas para sua caracterização em termos psíquicos, a partir da visão dos pais ou responsáveis. Como apontam Saur e Loureiro (2012) em sua revisão de literatura, O SDQ apresentou bons índices de validade e fidedignidade em diversos estudos brasileiros e internacionais, atestando sua viabilidade para avaliar sinais da saúde mental em crianças e adolescentes no Brasil.

3.2.7. Desenho da Figura Humana (DFH): método de avaliação psicológica que visa obter informações do funcionamento cognitivo e emocional do respondente a partir da interpretação de desenhos temáticos, a saber, o desenho de uma pessoa qualquer, seguido do desenho de pessoa do sexo oposto ao da primeira pessoa desenhada, bem como do inquérito feito pelo pesquisador com objetivo de adequadamente compreender as produções da criança. As reações e verbalizações do participante frente aos desenhos também foram devidamente registradas pelo pesquisador. Ofereceu-se para essa tarefa, ao participante, um lápis preto (no. 2), borracha macia e papel sulfite de tamanho A4 (entregue na posição vertical). Os desenhos resultantes desse procedimento foram avaliados a partir dos Indicadores Emocionais e Itens Evolutivos de Koppitz (1966), considerado recurso válido e adequado para exame dos aspectos afetivos e cognitivos da personalidade. O recente trabalho de Kobayashi (2015) avaliou a precisão dos Indicadores Emocionais no DFH com crianças de seis a nove anos, a partir do testereteste (intervalo entre aplicações de oito a 15 dias) e do acordo entre juízes, 
identificando resultados positivos e estatisticamente significativos. Já a fidedignidade dos Indicadores Maturacionais foi avaliada por Rosa (2006) com crianças de seis e nove anos, também pelo método teste-reteste, além da técnica das metades. No primeiro procedimento encontrou correlação total de 0,71 entre as duas aplicações e, no método das metades, a precisão para a amostra total foi de 0,86 . Assim, pode-se concluir que o DFH (Koppitz, 1966) é método válido para avaliar crianças brasileiras em termos de indicadores emocionais e de seu desenvolvimento cognitivo (índices maturacionais).

3.2.8. Método de Rorschach: método projetivo de avaliação psicológica que visa à avaliação de aspectos da dinâmica e estruturação da personalidade, podendo ser aplicado a diferentes idades, etnias e índices de escolaridade. O método é composto por dez pranchas contendo manchas imprecisas de tinta, sendo necessárias também folhas padronizadas para registro das respostas e para sua codificação. Recorreu-se ao sistema avaliativo da Escola Francesa (ou Escola de Paris - Chagnon, 2014) para aplicação, avaliação e interpretação dos resultados (Anzieu, 1986; Rausch de Traubenberg, 1998; Azoulay, Emmanuelli, Rausch de Traubenberg, Corroyer, Rozencwajg e Savina, 2007.). Além disso, um cronômetro foi utilizado para o registro de tempo das atividades interpretativas dos cartões do Rorschach. Para classificação dos resultados também foram utilizados os atlas e referenciais normativos produzidos por Fernandes (2010) e Raspantini (2010), adaptados à faixa etária em estudo e ao contexto sociocultural contemporâneo do interior do Estado de São Paulo.

Um glossário pormenorizado das principais variáveis da Escola Francesa encontra-se disponível em Jardim-Maran (2011) e em Cury-Jacquemin (2012).

Com relação às qualidades psicométricas do Método de Rorschach, o trabalho de revisão de literatura científica de Villemor-Amaral e Pasqualini-Casado (2006) descreve 
evidências de validade suficientemente embasada por sua estrutura teórica. Quanto a precisão do teste, tanto Fernandes (2010) como Raspantini (2010) encontraram valores superiores a $90 \%$ de concordância entre juízes independentes, respectivamente para crianças de seis a oito anos e crianças de nove a 11 anos, no tocante às localizações, determinantes, conteúdos e banalidades, atestando sua possibilidade de uso na atualidade, na faixa etária em estudo nesse trabalho.

3.2.9. Histórico médico: a pesquisadora realizou revisão de prontuários médicos e nutricionais dos casos do grupo clínico (G1), a fim de verificar sua classificação nutricional e identificar possíveis comorbidades, de modo a selecionar os voluntários do estudo, bem como caracterizá-los. As variáveis selecionadas foram relativas aos diagnósticos e tratamentos realizados existentes em seus respectivos prontuários, disponibilizados nos serviços de saúde colaboradores.

3.2.10. Recursos computacionais: com a finalidade de registro, armazenamento e análise de dados, foram utilizados os seguintes recursos computacionais: Microsoft Word 2010, Microsoft Office Excel 2010 e o Statistical Package for the Social Sciences (SPSS) para Windows (versão 22.0).

\subsection{Procedimentos}

\subsubsection{Aspectos éticos}

O presente trabalho foi examinado e aprovado pelo Comitê de Ética em Pesquisa com Seres Humanos da Faculdade de Filosofia, Ciências e Letras de Ribeirão Preto da Universidade de São Paulo, conforme Resolução 466/12 do Conselho Nacional de 
Saúde e Resolução 16/00 do Conselho Federal de Psicologia (ANEXO 2). Para a coleta de dados nas instituições de saúde foi necessária a aprovação do projeto de pesquisa também pela Secretaria Municipal de Saúde de Ribeirão Preto, conforme mostra o ANEXO 3.

Posteriormente à aprovação do estudo pelas instâncias competentes, deu-se início à coleta e à sistematização dos dados. Devido às particularidades do quadro clínico enfocado, optou-se pela composição da amostra clínica em ambientes onde já estivessem recebendo cuidado e tratamento profissional para suas necessidades (seguimento nutricional no caso das crianças com obesidade). Os princípios éticos de preservação dos participantes foram resguardados, de forma a estabelecer uma aliança colaborativa entre pesquisadora, instituições colaboradoras e voluntários, uma vez que o objetivo do presente estudo visa a contribuir com subsídios para atividades interventivas no campo da saúde.

A relação entre pesquisador e participantes foi mediada, formalmente, pelo Termo de Consentimento Livre e Esclarecido (dirigido aos responsáveis pelas crianças) e do Termo de Assentimento (voltado aos voluntários). Ambos priorizaram esclarecimentos sobre as implicações da participação na pesquisa (riscos e benefícios), bem como garantia de sigilo da identidade e de liberdade na participação como voluntário, além da possibilidade de desistência da pesquisa em qualquer uma de suas etapas. Da mesma forma, os consentimentos das instituições de saúde e escolares foram devidamente formalizados. Apenas após esses cuidados é que a coleta de dados pôde ser realizada.

Adicionalmente, nos momentos em que foram identificadas necessidades psicológicas específicas durante a coleta de dados, tanto na amostra clínica quanto no grupo controle, cuidados foram tomados em relação à devolutiva aos responsáveis das 
crianças. Quando adequado, foram feitas indicações de serviços de saúde em seus respectivos órgãos de referência de atendimento psicológico na cidade em estudo para o devido cuidado à necessidade identificada.

Em ambos os grupos, a pesquisadora mostrou-se disponível para retirada de dúvidas logo após a aplicação dos instrumentos. No Grupo 1 houve a necessidade de devolutiva a três pais que se mostraram mais preocupados com o filho e, em dois casos, realizou-se encaminhamento para atendimento psicológico no próprio serviço de saúde onde já tratavam a obesidade. Já o Grupo 2 não apresentou demanda direta por entrevistas devolutivas, sendo realizada, então, uma atividade de orientação geral (sobre desenvolvimento, aspectos nutricionais e a obesidade) dirigida aos pais, efetivada durante reunião escolar previamente agendada pela escola, para discussão das temáticas do estudo.

\subsubsection{Coleta de dados}

Após a aprovação do presente projeto pelo Comitê de Ética em Pesquisa com Seres Humanos, estabeleceu-se uma parceria de estudo com dois serviços públicos de saúde da cidade de Ribeirão Preto que realizavam atendimentos clínicos para a obesidade infantil. Após contatos iniciais para apresentação do projeto e de seus objetivos, obteve-se a devida concordância e autorização ao trabalho destas instituições colaboradoras, já referidas anteriormente. Foi constituída, portanto, uma amostra de conveniência, para tornar viável a realização do presente trabalho.

A pesquisadora acessou pacientes diagnosticados como obesos a partir da consulta ao prontuário médico dos usuários dos serviços clínicos pesquisados (Clínicaescola de Nutrição da Universidade de Ribeirão Preto e Ambulatório de Nutrição do Núcleo de Gestão Ambulatorial - NGA no. 59 do Ambulatório Regional de 
Especialidades da Secretaria Municipal de Saúde de Ribeirão Preto). Após essa etapa de pré-seleção de casos, apresentou aos pais ou responsáveis do Termo de Consentimento Livre e Esclarecido ao estudo, a seguir convidando as crianças a participarem da pesquisa (firmando o Termo de Assentimento).

As aplicações dos instrumentos de avaliação psicológica foram realizadas individualmente pela pesquisadora, em sala especial cedida pelos centros de saúde ou pela escola colaboradora. Quando oportuno aos participantes, a coleta de dados foi realizada na residência dos voluntários, desde que respeitadas condições mínimas de sigilo e preservação do conteúdo produzido no processo. Nestas situações buscou-se adaptar o ambiente residencial para maior tranquilidade e padronização das aplicações dos instrumentos da pesquisa.

O responsável que, esclarecido de suas dúvidas, concordasse com a participação de seu (sua) filho(a) no estudo, assinava o Termo de Consentimento Livre e Esclarecido. A seguir era convidado a responder ao Questionário de Capacidades e Dificuldades, conforme suas normas específicas de aplicação, individualmente e em forma de autorrelato (em espaço físico diferente de onde era avaliada a criança).

No caso do Grupo 2, os termos e o questionário foram enviados aos alunos selecionados pela coordenação pedagógica da escola colaboradora, com o contato da pesquisadora para retirada de possíveis dúvidas. Foram inclusas neste grupo apenas as crianças que retornaram com toda a documentação devidamente preenchida.

Antes de iniciar a aplicação dos instrumentos de avaliação psicológica, a pesquisadora voltou a apresentar à criança os propósitos da pesquisa, com espaço para a expressão de dúvidas e possíveis inseguranças. Após o estabelecimento de apropriado rapport, os instrumentos de avaliação psicológica foram aplicados conforme específicas diretrizes técnicas de seus manuais, na seguinte ordem: Teste das Matrizes Progressivas 
Coloridas de Raven, Desenho da Figura Humana e Método de Rorschach, totalizando aproximadamente 60 minutos de atividades com cada criança, embora com tempo livre para realização das atividades. Ao término das atividades avaliativas, a pesquisadora reservava ainda um espaço para que a criança pudesse expressar sua experiência com as aplicações, eventuais dúvidas ou comentários, e realizava um fechamento do encontro (síntese das atividades, valorizando a colaboração da criança e agradecendo sua participação no estudo). Em seguida, a pesquisadora acompanhava a criança novamente à companhia de seu responsável. Enquanto a criança era avaliada pela pesquisadora, seu responsável respondia ao SDQ.

Após o término da coleta de dados referente aos 30 participantes do Grupo 1, selecionaram-se escolas de ensino fundamental da rede pública de Ribeirão Preto e região, a fim de atenderem às especificidades da amostra obtida no primeiro grupo. Uma escola do município de Cravinhos (SP) que atendia aos critérios aceitou participar do estudo como instituição colaboradora, estabelecendo-se acordo de realização de devolutiva dos dados para pais e professores interessados. Estas devolutivas foram realizadas após o término da coleta dos dados, em data agendada pela escola, com a participação de reduzido número de pais (cerca de oito casos). Esse grupo eutrófico (Grupo 2) foi submetido aos mesmos procedimentos éticos e técnicos, compondo também amostra de conveniência, sendo balanceada com as características dos participantes do Grupo 1 (clínico) em função de sexo, ano e origem escolar. As aplicações se deram em sala especialmente cedida pela escola, em horário letivo que não atrapalhasse o desenvolvimento das atividades acadêmicas das crianças, conforme o julgamento de seus professores.

Após a aplicação dos instrumentos de avaliação psicológica, as crianças do Grupo 2 tiveram seu peso e altura mensurados com instrumentos calibrados, para 
posterior cálculo do IMC. Esses dados foram essenciais para a adequada composição desse grupo de comparação, visto que muitos registros escolares não continham informações atualizadas a respeito dessas variáveis do desenvolvimento infantil.

\subsubsection{Análise dos Resultados}

Os dados foram sistematizados de forma a atender aos objetivos propostos pelo presente estudo. Inicialmente foram realizadas as codificações dos instrumentos de avaliação psicológica utilizados, respeitando-se suas respectivas diretrizes técnicocientíficas e referenciais normativos já apresentados. No caso dos métodos projetivos, cabe destacar que o Desenho da Figura Humana foi avaliado pelos Indicadores Emocionais e Itens Evolutivos de Koppitz (1966). Os protocolos de Rorschach, por sua vez, foram codificados por avaliadores distintos a partir das referências de Anzieu (1986), Raush de Traubenberg (1998), Fernandes (2010) e Raspantini (2010). Devido à questão do sigilo profissional, os protocolos foram identificados apenas por um número e dados referentes a sexo e idade dos participantes, garantindo análises às cegas. Tal procedimento permite a realização de comparações entre examinadores independentes, a fim de avaliar o índice de concordância entre eles, verificando-se índices de precisão nos processos avaliativos dos casos.

Cada um dos 60 protocolos do Psicodiagnóstico de Rorschach foi codificado por dois examinadores independentes para posterior verificação de sua precisão. Esses avaliadores eram psicólogos ( $\mathrm{n}=5$, incluindo a pesquisadora) e um aluno de graduação (em final de curso), todos com experiência prévia em processos de avaliação psicológica e membros do Centro de Pesquisas em Psicodiagnóstico (CPP) da Faculdade de Filosofia, Ciências e Letras de Ribeirão Preto da Universidade de São Paulo. Todos receberam treinamento prévio à própria análise dos casos, envolvendo 
revisão teórica de conceitos da Escola Francesa do Rorschach e treino prático da codificação em casos-piloto, visando resolução de possíveis dúvidas nos procedimentos técnicos. Utilizou-se como material de referência para a classificação das respostas os atlas produzidos por Fernandes (2010), utilizado para as crianças na faixa de seis a oito anos de idade, além do estudo de Raspantini (2010) para aquelas que contassem com nove a 11 anos.

Considerou-se necessário avaliar o nível de concordância entre juízes antes de distribuir os casos do estudo entre os codificadores. Para tanto, após realização das codificações de dois casos-piloto pelos seis juízes treinados, calculou-se o nível de concordância entre eles, seguindo-se as orientações de Weiner (1991). Os índices de concordância (em porcentagem) atingiram padrões adequados aos esperados nas quatro principais categorias de codificação do Método de Rorschach, segundo a Escola Francesa. Foram encontrados os seguintes valores de acordo: Índice Geral $=90 \%$; Localização $=87,8 \% ;$ Determinantes $=79,7 \%$; Conteúdos $=95,1 \% ;$ Banalidades $=$ 100,0\%. Tais evidências possibilitaram o avançar nos procedimentos de codificação dos casos da pesquisa, ao concluir que o treinamento efetuado nos examinadores independentes alcançou seu objetivo, favorecendo a precisão do trabalho.

Após este preparo inicial, a pesquisadora distribuiu aleatoriamente 10 casos para cada avaliador independente, mantendo às cegas o grupo de origem, de forma a evitar vieses nas análises. Assim, cada caso foi codificado pela própria pesquisadora e mais um examinador independente. Como cuidado adicional, nos casos de discordância entre os juízes independentes, a orientadora do presente estudo atuou como terceiro juiz, chegando-se, dessa forma, a uma codificação final de cada resposta das crianças avaliadas. 
A avaliação da concordância entre examinadores independentes para os dados do atual estudo foi, então, avaliada a partir do índice kappa, considerando-se um conjunto de 15 casos aleatoriamente selecionados da amostra (25\% do total). Foram obtidos os seguintes valores de kappa: Índice Geral =0,87; Localização $=0,97 \%$; Determinantes $=0,80 ;$ Conteúdos $=0,92 ;$ Banalidades $=0,81$. Segundo a classificação de Landis e Koch (1977), os valores de 0,80 a 1,0 são considerados como excelente concordância entre avaliadores, apontando adequada precisão nas classificações efetuadas.

O Desenho da Figura Humana, codificado a partir do sistema Koppitz (1966), avalia os componentes do desenho segundo os seguintes indicadores:

a) Indicadores Emocionais (total de 30 itens avaliativos): integração pobre entre partes da figura; sombreamento do rosto; sombreamento do corpo e/ou membros; sombreamento de mãos e/ou pescoço; assimetria grosseira dos membros; figura inclinada; figura pequena; figura grande; transparências; cabeça pequena; olhos cruzados ou opostos; dentes; braços curtos; braços compridos; braços agarrados ao corpo; mãos grandes; mãos cortadas; pernas apertadas uma contra a outra; genitais; figura monstruosa ou grotesca; três ou mais desenhos espontâneos; nuvens; omissão de olhos; omissão do nariz; omissão da boca; omissão do tronco; omissão dos braços; omissão das pernas; omissão dos pés, omissão do pescoço.

b) Itens Evolutivos ou Maturacionais (total de 30 itens avaliativos): presença de cabeça; olhos; pupilas; sobrancelhas ou pestanas; nariz; fossas nasais; boca; dois lábios; orelhas; cabelo; pescoço; tronco; braços; braços em das dimensões; braços apontando para baixo; braços corretamente unidos ao corpo; cotovelo; mãos; dedos; número correto de dedos; pernas; pernas em duas dimensões; joelhos; pés; pés bidimensionais; perfil; 
uma/nenhuma peça de roupa; duas ou três peças de roupa; quatro ou mais itens de roupa; boas proporções.

Para a análise dos itens evolutivos dos DFH seguiu-se a orientação de Hutz e Antoniazzi (1995). Desse modo, atribuiu-se um ponto adicional para cada item excepcional (presente em menos de $16 \%$ da população de referência) e subtraiu-se um ponto para cada item esperado (item com ocorrência superior a $85 \%$ na população) que não estivesse presente naquela produção.

O cuidado metodológico para assegurar a precisão das codificações no DFH seguiu estratégias similares ao processo de análise do Método de Rorschach, recorrendo-se a avaliações independentes e às cegas para cada desenho. Os mesmos psicólogos colaboradores na avaliação do Rorschach, passaram também por treinamento no processo analítico do DFH segundo referencial de Koppitz (1966). Da mesma forma, o índice de acordo entre as codificações realizadas pelos avaliadores para cada desenho de dois casos-piloto foi examinado a partir de indicadores de porcentagem de acordos. Nesta etapa, os examinadores obtiveram os seguintes resultados: Indicadores Emocionais $=98,3 \%$; Itens Evolutivos $=97,4 \%$, sugerindo adequado nível de precisão em suas análises.

A partir desse treinamento, os DFH das crianças participantes foram, então, codificados pelos examinadores independentes. Em casos onde houve discordância inicial entre avaliadores, a orientadora deste trabalho atuou como terceira juíza para definição da classificação final dos itens avaliativos. Da mesma forma que no Rorschach, 15 casos aleatórios foram selecionados (30 DFH) para cálculo do índice kappa de concordância, identificando valor de 0,87 para Indicadores Emocionais e 0,89 para Itens Evolutivos, ambos sinalizadores de excelente precisão nas análises. 
Considerou-se importante comparar as duas figuras humanas produzidas por cada criança, visando a verificar eventual diferenciação. Foram realizados testes de McNemar $(p \leq 0,05)$, devido ao caráter pareado das duas produções, para cada um dos 60 Indicadores Emocionais e Itens Evolutivos. Os resultados mostraram igualdade entre todos os Indicadores Emocionais e diferença em apenas dois Itens Evolutivos, sendo estes a presença de orelhas e presença de pescoço, ambos mais apresentados na primeira figura desenhada. Em função desses achados de similaridade entre primeira e segunda figuras desenhadas, foram utilizadas para as análises desse estudo, a partir de então, apenas o primeiro DFH. Ficou, então, empiricamente demonstrada a possibilidade de solicitação de apenas uma figura humana nas crianças examinadas nesse estudo, o que merece reflexão futura em termos da utilização desse instrumento em contextos similares ao presentemente examinado, reduzindo-se o esforço e o tempo dispendido nesse instrumento avaliativo.

Findadas as codificações dos instrumentos de avaliação psicológica, foi criado um banco de dados computacional em planilha do Microsoft Excel 2010, integrando os resultados dos instrumentos de avaliação psicológica e dados sócio demográficos. Esses resultados foram transportados para planilhas no programa estatístico Statistical Package for the Social Sciences (SPSS, versão 22.0) para realização de análises descritivas e inferenciais.

Inicialmente foram realizadas análises descritivas dos resultados em cada método de avaliação psicológica SDQ (Strengths and Difficulties Questionnaire), Desenho da Figura Humana e Método de Rorschach (Escola Francesa). Para determinar as ferramentas para as análises inferenciais, foram realizados testes KolmogorovSmirnov para determinar o comportamento das variáveis utilizadas. Os resultados 
evidenciaram distribuição normal, indicando a possibilidade de uso de análises paramétricas, utilizando nível de significância de 5\% $(p \leq 0,05)$.

Primeiramente realizou-se comparação de dados médios dos grupos (G1 e G2) em função das principais variáveis dos instrumentos (Teste $t$ de Student). A seguir, foram selecionadas algumas variáveis dos métodos projetivos (indicadores selecionados a partir de seu significado clínico) e testadas sua incidência em G1 e em G2 (teste chiquadrado), procurando-se identificar peculiaridades no funcionamento cognitivo e afetivo das crianças avaliadas, conforme objetivos iniciais delineados para o estudo. Analisou-se em seguida o possível efeito do sexo e da idade dos participantes nos resultados, tanto entre grupos como no total da amostra (Teste $t$ de Student e teste chiquadrado). Foi também efetivada análise de correlação entre achados (correlação de Pearson), bem como comparação dos dados com referenciais normativos dos instrumentos usados, de modo a favorecer possibilidades interpretativas das variáveis em foco. 
4. RESULTADOS 


\subsection{Resultados descritivos e comparação de valores médios}

\subsubsection{Questionário de Capacidades e Habilidades (SDQ)}

O SDQ oferece informações relativas ao nível de saúde mental da criança, sendo aqui utilizada a versão respondida por pais ou responsáveis. A partir do total de pontos obtidos no questionário, o escore bruto segue uma classificação definida como: Normal (0-13 pontos); Limítrofe (14-16 pontos); Anormal (17-40 pontos) conforme proposto originalmente por Goodman (1997). A versão em português utilizada foi recuperada a partir do site http://www.sdqinfo.com/ que disponibiliza gratuitamente o questionário em mais de 40 idiomas. Este mesmo endereço oferece as instruções específicas para codificação das respostas, adotadas no presente trabalho. A Tabela 5 ilustra os resultados obtidos na amostra geral e por grupo de estudantes avaliados.

Tabela 5: Distribuição (em frequência simples e porcentagem) dos participantes em função da classificação no $S D Q$ (versão pais).

\begin{tabular}{|c|c|c|c|c|c|c|}
\hline \multirow{2}{*}{$\begin{array}{l}\text { Nível de Saúde } \\
\text { Mental infantil }\end{array}$} & \multicolumn{2}{|c|}{ Geral } & \multicolumn{2}{|c|}{$\begin{array}{l}\text { Grupo } 1 \\
(n=30)\end{array}$} & \multicolumn{2}{|c|}{$\begin{array}{l}\text { Grupo } 2 \\
(n=30)\end{array}$} \\
\hline & $f$ & $\%$ & $f$ & $\%$ & $f$ & $\%$ \\
\hline Normal & 28 & 46,7 & 15 & 50,0 & 13 & 43,3 \\
\hline Limítrofe & 13 & 21,7 & 6 & 20,0 & 7 & 23,3 \\
\hline Anormal & 19 & 31,7 & 9 & 30,0 & 10 & 33,3 \\
\hline
\end{tabular}

Com relação ao escore bruto obtido no SDQ, G1 apresentou média de 12,47 pontos $( \pm 5,94)$ e mediana 13,00 ; e G2 exibiu média 14,00 pontos $( \pm 6,77)$ e mediana 14,00. A análise comparativa entre os resultados médios desses grupos (teste $t$ de Student) não apontou diferença estatisticamente significativa $(t=-0,93 ; p=0,35)$. Pode-se 
apontar, portanto, que crianças com obesidade e crianças eutróficas sinalizaram nível similar de saúde mental, segundo seus pais ou responsáveis. Em ambos os grupos predominam estudantes classificados na faixa normal e limítrofe (envolvendo cerca de $70 \%$ dos casos), restando cerca de $30 \%$ de crianças consideradas como possuidoras de dificuldades no campo da saúde mental.

\subsubsection{Desenho da Figura Humana (DFH)}

O DFH foi analisado em função do total de Indicadores Emocionais e Índices Evolutivos (Koppitz, 1966) apresentados pelos participantes. Ambos os índices variam de zero a 30 pontos, porém a presença de Indicadores Emocionais associa-se a dificuldades no desenvolvimento sócio afetivo, enquanto a pontuação nos Itens Evolutivos (ou maturacionais) representa indicador de amadurecimento cognitivo e psicomotor. Cabe relembrar que, para as análises a seguir, foram utilizados os dados referentes ao primeiro $\mathrm{DFH}$, visto que a produção das crianças dos dois grupos foi similar no segundo DFH.

Os resultados médios e a comparação estatística dos achados de G1 e G2 podem ser visualizados na Tabela 6. Os escores foram avaliados tanto em pontos brutos, quanto segundo os percentis propostos por Hutz e Antoniazzi (1995). 
Tabela 6: Resultados médios (pontos brutos e percentis) do DFH e comparação estatística em função dos grupos de crianças.

\begin{tabular}{llcccc}
\hline \multicolumn{2}{c}{ Indicadores DFH } & $\begin{array}{c}\text { Grupo 1 } \\
(\mathrm{n}=30)\end{array}$ & $\begin{array}{c}\text { Grupo 2 } \\
(\mathrm{n}=30)\end{array}$ & $t$ & $p$ \\
\hline Emocionais & Pontos brutos & 2,53 & 2,00 & 1,33 & 0,19 \\
& Percentil & 47,50 & 55,36 & $-1,31$ & 0,20 \\
Evolutivos & Pontos brutos & 19,57 & 19,30 & $-0,32$ & 0,18 \\
& Percentil & 66,63 & 63,90 & $-0,47$ & 0,29 \\
\hline
\end{tabular}

Os resultados não apresentam diferenças estatisticamente significativas entre G1 e G2, tanto em função de escores brutos quanto em função do percentil dos indicadores emocionais e evolutivos do DFH das crianças. Dessa maneira, ambos os grupos sinalizaram representação gráfica da figura humana compatível com o esperado para sua faixa etária. Essa evidência se confirma ao tomar os resultados médios encontrados nos percentis da amostra total $(n=60)$, a saber: a) para Indicadores Emocionais: 51,43 $( \pm 23,45)$ e b) para Itens Evolutivos: $51,43( \pm 23,24)$.

Outra forma de análise dos DFH focaliza a contagem das crianças (de cada grupo) em função do número de indicadores emocionais presentes em seus desenhos, tendo em vista que o referencial de Koppitz (1996) aponta significado clínico especial para quem apresenta dois os mais sinais presentes em sua produção (dificuldades emocionais). O levantamento desses indicadores pode ser visualizado na Tabela 7 , bem como a comparação estatística entre G1 e G2. 
Tabela 7: Distribuição dos casos e sua comparação estatística em função do número de indicadores emocionais presentes no DFH dos dois grupos de crianças.

\begin{tabular}{ccccc}
\hline $\begin{array}{c}\text { Indicadores emocionais } \\
\text { DFH }\end{array}$ & $\begin{array}{c}\text { Grupo 1 } \\
(\mathrm{n}=30)\end{array}$ & $\begin{array}{c}\text { Grupo 2 } \\
(\mathrm{n}=30)\end{array}$ & $p$ \\
\hline Zero ou um & 12 & 12 & & \\
Dois & 7 & 7 & 0 & 1,0 \\
Três ou mais & 11 & 11 & & \\
\hline
\end{tabular}

Os resultados sinalizaram ausência de diferenças estatisticamente significativas na distribuição de casos de G1 e G2 em função do número de indicadores emocionais presentes em seus desenhos. Nota-se, na verdade, que a distribuição das crianças, tendo em conta seu número de indicadores emocionais, foi idêntica entre os dois grupos. Pode-se notar que houve maior incidência de crianças com zero a dois indicadores emocionais em ambos os grupos, reforçando similaridade de produção gráfica, bem como adequação às expectativas normativas para essa faixa etária.

\subsubsection{Método de Rorschach}

Com relação às análises do Método de Rorschach, codificado a partir dos atlas de Fernandes (2010) e Raspantini (2010), optou-se por apresentá-las agrupadas de acordo com as principais categorias de análise: Produtividade, Localizações, Determinantes e Conteúdos, juntamente com as Banalidades e Fórmulas Afetivas. Assim, os principais resultados relativos aos indicadores de produtividade e ritmo de trabalho no Rorschach encontram-se na Tabela 8. 
Tabela 8: Caracterização e comparação estatística de resultados médios na produtividade e ritmo no Rorschach em função dos grupos de crianças.

\begin{tabular}{|c|c|c|c|c|c|c|c|c|c|c|c|c|c|c|c|c|}
\hline \multirow{2}{*}{$\begin{array}{c}\text { Variável } \\
\text { Rorschach* }\end{array}$} & \multicolumn{7}{|c|}{ Grupo $1(n=30)$} & \multicolumn{7}{|c|}{ Grupo $2(\mathrm{n}=30)$} & \multirow[t]{2}{*}{$t$} & \multirow[t]{2}{*}{$p$} \\
\hline & M & DP & P25 & Med & P75 & Min & Máx & M & DP & P25 & Med & P75 & Min & Máx & & \\
\hline $\mathrm{R}$ & 17,8 & 6,7 & 11,7 & 16 & 24,0 & 9 & 30 & 17,0 & 7,5 & 11,0 & 14,5 & 19,2 & 9 & 35 & 0,50 & 0,63 \\
\hline RA & 1,2 & 2,1 & 0 & 0,5 & 1,2 & 0 & 9 & 1,2 & 1,6 & 0 & 1,0 & 2,0 & 0 & 7 & 0 & 1,00 \\
\hline Recusa & 0,2 & 0,5 & 0 & 0 & 0 & 0 & 2 & 0,2 & 0,6 & 0 & 0 & 0 & 0 & 3 & $-0,20$ & 0,82 \\
\hline Den. & 0,2 & 0,5 & 0 & 0 & 0 & 0 & 2 & 0,3 & 0,6 & 0 & 0 & 0 & 0 & 2 & $-0,40$ & 0,66 \\
\hline TLm** & 16,3 & 10,2 & 9,8 & 12,5 & 20,0 & 7 & 52 & 13,0 & 10,6 & 6,7 & 10,0 & 14,2 & 5 & 50 & 1,30 & 0,21 \\
\hline $\mathrm{TRm}^{* *}$ & 31,1 & 11,9 & 22,7 & 28,0 & 37,2 & 12 & 66 & 24,1 & 13,4 & 16,7 & 19,5 & 27,5 & 9 & 62 & 2,10 & 0,04 \\
\hline
\end{tabular}

A única diferença estatisticamente significativa entre G1 e G2 nesses indicadores do Rorschach ocorreu com relação ao tempo de reação médio (TRm), sendo mais breve em G2 ( $d$ de Cohen $=0,27)$. Desse modo, trata-se de diferença entre os grupos com efeito considerado médio (Becker, http://www.uccs.edu/ lbecker/), retratando variável importante para análise da produção infantil.

Assim, é possível elaborar um panorama geral dos indicadores de produção no Método de Rorschach do conjunto de crianças avaliadas $(n=60)$. Elas apresentaram os seguintes resultados: $\mathrm{R}=17,42( \pm 7,1)$, mediana $=15,5 ; \mathrm{RA}=1,23( \pm 1,9)$ mediana $=$ 1,$0 ;$ Recusas $=0,22( \pm 0,55)$, mediana $=0$; Denegações $0,27( \pm 0,58)$, mediana $=0 ;$ TLm $=14,61( \pm 10,48)$, mediana $=11,5 ;$ e TRm $=27,59( \pm 13,08)$, mediana $=24,5$.

Na sequência das análises das variáveis da Escola Francesa do Rorschach aparecem as proporções de resposta relativas a cada um dos modos de apreensão dos estímulos (localização das interpretações). Esses resultados compõem a Tabela 9, destacando que não ocorreram respostas na categoria Do (detalhe inibitório). 
Tabela 9: Caracterização e comparação estatística de resultados médios (em porcentagem) nos modos de apreensão no Rorschach em função dos grupos de crianças.

\begin{tabular}{cccccccccccccccccc}
\hline Variável & \multicolumn{1}{c}{ Grupo $1(\mathrm{n}=30)$} & & \multicolumn{1}{c}{ Grupo 2 $(\mathrm{n}=30)$} & & & $p$ \\
Rorschach & M & DP & P25 & Med & P75 & Min & Máx & M & DP & P25 & Med & P75 & Min & Máx & \\
\hline G\% & 38,1 & 20,0 & 27,2 & 36,5 & 50,0 & 0 & 89 & 39,6 & 27,1 & 18,7 & 30,0 & 68,5 & 0 & 90 & 0,20 & 0,80 \\
D\% & 40,9 & 16,3 & 30,7 & 40,5 & 50,0 & 11 & 86 & 40,8 & 21,8 & 27,0 & 45,0 & 57,0 & 0 & 86 & 0 & 1,00 \\
Dd\% & 20,8 & 11,0 & 13,7 & 21,0 & 30,0 & 0 & 43 & 19,6 & 13,4 & 8,75 & 18,5 & 31,5 & 0 & 46 & 0,40 & 0,70 \\
Dbl\% & 0,1 & 0,7 & 0 & 0 & 0 & 0 & 4 & - & - & - & - & - & 0 & - & 1,00 & 0,30 \\
\hline
\end{tabular}

M = média; DP = desvio-padrão; Med = mediana; Min = mínimo; Máx = máximo.

Os dois grupos de crianças não sinalizaram diferenças estatisticamente significativas na distribuição de seus modos de apreensão dos estímulos do Rorschach, com proporções bastante semelhantes entre as áreas interpretadas. Para a amostra total foram obtidos os seguintes resultados em termos de localização das respostas: G\% = $38,8( \pm 23,7)$, mediana $=33,0 ; \mathrm{D} \%=40,9( \pm 19,1)$, mediana $=42,0 ; \mathrm{Dd} \%=20,2( \pm 23,2)$, mediana $=19,5 ; \mathrm{Dbl} \%=0,07( \pm 0,5)$, mediana $=0 ; \mathrm{Do}=$ não foram observados

Passou-se, então, a examinar a distribuição das respostas ao Rorschach dos dois grupos de crianças em função de seus determinantes, conforme Escola Francesa. Esses dados estão apresentados na Tabela 10. 
Tabela 10: Caracterização e comparação estatística de resultados médios nos determinantes das respostas no Rorschach em função dos grupos de crianças.

\begin{tabular}{|c|c|c|c|c|c|c|c|c|c|c|c|c|c|c|c|c|}
\hline \multirow{2}{*}{$\begin{array}{l}\text { Variável } \\
\text { Rorschach }\end{array}$} & \multicolumn{7}{|c|}{ Grupo $1(\mathrm{n}=30)$} & \multicolumn{7}{|c|}{ Grupo $2(n=30)$} & \multirow[t]{2}{*}{$t$} & \multirow[t]{2}{*}{$p$} \\
\hline & $\mathrm{M}$ & DP & P25 & Med & P75 & Min & Máx & $\mathrm{M}$ & DP & P25 & Med & P75 & Min & Máx & & \\
\hline $\mathrm{F} \%$ & 22,6 & 15,9 & 8,7 & 19,5 & 36,5 & 0 & 56 & 26,0 & 20,5 & 10,0 & 21,5 & 39,0 & 0 & 78 & $-0,70$ & 0,50 \\
\hline $\mathrm{F}+\%$ & 73,9 & 25,7 & 60,0 & 75,0 & 100,0 & 0 & 100 & 74,0 & 27,7 & 50,0 & 75,0 & 100,0 & 0 & 100 & $-0,00$ & 0,99 \\
\hline $\mathrm{F}+\mathrm{ext} \%$ & 71,0 & 12,1 & 60,0 & 70,0 & 79,0 & 50 & 93 & 71,9 & 16,9 & 63,7 & 72,5 & 84,2 & 31 & 100 & $-0,20$ & 0,80 \\
\hline $\mathrm{K}$ & 2,4 & 2,2 & 1,0 & 1,5 & 3,0 & 0 & 8 & 1,4 & 1,6 & 0 & 1,0 & 2,0 & 0 & 6 & 1,80 & 0,07 \\
\hline Soma k & 5,9 & 3,7 & 3,7 & 5,0 & 7,5 & 0 & 18 & 5,9 & 4,7 & 3,0 & 5,0 & 8,0 & 0 & 17 & $-0,00$ & 0,90 \\
\hline FC & 2,3 & 2,0 & 1,0 & 2,0 & 3,0 & 0 & 8 & 2,2 & 2,3 & 1,0 & 1,0 & 4,0 & 0 & 10 & 0,12 & 0,90 \\
\hline $\mathrm{CF}$ & 1,2 & 1,4 & 0 & 1,0 & 2,0 & 0 & 6 & 1,1 & 1,5 & 0 & 1,0 & 1,0 & 0 & 6 & 0,45 & 0,70 \\
\hline $\mathrm{C}$ & 0,2 & 0,5 & 0 & 0 & 0 & 0 & 2 & 0,1 & 0,3 & 0 & 0 & 0 & 0 & 1 & 1,00 & 0,30 \\
\hline Soma Cp & 2,7 & 1,9 & 1,7 & 2,0 & 4,0 & 0 & 8 & 2,3 & 2,3 & 0,7 & 2,0 & 2,5 & 0 & 10 & 0,70 & 0,50 \\
\hline FE & 1,1 & 1,2 & 0 & 1,0 & 2,0 & 0 & 4 & 1,5 & 1,5 & 0 & 1,0 & 2,0 & 0 & 7 & $-1,00$ & 0,30 \\
\hline $\mathrm{EF}$ & 0,4 & 0,5 & 0 & 0 & 1,0 & 0 & 1 & 0,6 & 0,8 & 0 & 0 & 1,0 & 0 & 3 & $-1,10$ & 0,30 \\
\hline E & - & - & - & - & - & 0 & - & - & - & - & - & - & 0 & - & - & - \\
\hline Soma Ep & 0,9 & 0,9 & 0 & 0 & 2,0 & 0 & 3 & 1,3 & 1,3 & 0 & 1,5 & 2,0 & 0 & 4 & $-1,50$ & 0,10 \\
\hline FClob & - & - & - & - & - & 0 & - & 0 & 0,2 & 0 & 0 & 0 & 0 & 1 & $-1,00$ & 0,30 \\
\hline ClobF & - & - & - & - & - & 0 & - & 0 & 2,5 & 0 & 0 & 0 & 0 & 1 & $-1,40$ & 0,20 \\
\hline Clob & - & - & - & - & - & 0 & - & - & - & - & - & - & 0 & - & - & - \\
\hline
\end{tabular}

M = média; DP = desvio-padrão; Med = mediana; Min = mínimo; Máx = máximo.

Como se pode notar, mais uma vez a produção de G1 e G2 não apresentou diferenças estatisticamente significativas no tocante aos determinantes das respostas das crianças diante do Rorschach. Assim, pode-se buscar uma visão panorâmica dos 
resultados relativos aos determinantes das respostas das crianças ao Rorschach. Os principais achados foram: $\mathrm{F} \%=24,2( \pm 18,3)$, mediana $=20,5 ; \mathrm{F}+\%=74,0( \pm 26,5)$, mediana $=75,0 ; \mathrm{F}+\operatorname{ext} \%=71,4( \pm 14,6)$, mediana $=72,1 ; \mathrm{K}=1,9( \pm 2,0)$, mediana $=1,0$; Soma de pequenas cinestesias $(\mathrm{k})=5,9( \pm 4,3)$, mediana $=5,0 ; \mathrm{FC}=2,2( \pm 2,2)$, mediana $=1,0, \mathrm{CF}=1,2( \pm 1,4)$, mediana $=1,0 ; \mathrm{C}=0,1( \pm 0,4)$, mediana $=0$; Soma de Cor ponderada $(\mathrm{Cp})=2,5( \pm 2,1)$, mediana $=2,0 ; \mathrm{FE}=1,3( \pm 1,4)$, mediana $=1,0 ; \mathrm{EF}=0,5$ $( \pm 0,7)$, mediana $=0$; Soma de sombreado ponderada $($ Ep $)=1,1( \pm 1,2)$, mediana $=1,0$; praticamente com ausências de FClob, ClobF e Clob. Desse modo, pode-se destacar que as crianças avaliadas recorreram aos aspectos formais dos cartões do Rorschach em praticamente $25 \%$ de suas respostas $(\mathrm{F} \%)$, na maioria das vezes com preservação da lógica $(\mathrm{F}+\%)$. Sinalizaram, portanto, que outros elementos das manchas (sobretudo cores) as mobilizaram para produzir respostas, bem como projeções vinculadas aos movimentos, ambos considerados determinantes representativos da afetividade nesse método projetivo de avaliação psicológica.

Ainda com foco no Método de Rorschach, sistematizou-se, na Tabela 11, as informações referentes aos conteúdos, respostas do tipo banalidade e as proporções da terceira fórmula afetiva (reatividade à cor) e da fórmula da angústia. Esses resultados foram comparados em termos de suas médias, examinando-se possíveis especificidades no padrão de reação das crianças com obesidade ou eutróficas. 
Tabela 11 Caracterização e comparação estatística de resultados médios nos conteúdos, banalidades, reatividade cromática e fórmula de angústia do Rorschach, em função dos grupos de crianças.

\begin{tabular}{|c|c|c|c|c|c|c|c|c|c|c|c|c|c|c|c|c|}
\hline \multirow{2}{*}{$\begin{array}{l}\text { Variável } \\
\text { Rorschach }\end{array}$} & \multicolumn{7}{|c|}{ Grupo $1(n=30)$} & \multicolumn{7}{|c|}{ Grupo $2(\mathrm{n}=30)$} & \multirow[t]{2}{*}{$t$} & \multirow[t]{2}{*}{$p$} \\
\hline & M & DP & $\mathrm{P} 25$ & Med & P75 & Min & Máx & M & DP & $\mathrm{P} 25$ & Med & P75 & Min & Máx & & \\
\hline $\mathrm{A}$ & 10,4 & 3,8 & 4,0 & 7,0 & 10,2 & 1 & 16 & 11,5 & 3,9 & 5,0 & 7,0 & 10,0 & 4 & 21 & $-0,75$ & 0,46 \\
\hline $\mathrm{A} \%$ & 58,9 & 17,4 & 47,5 & 59,0 & 69,2 & 9 & 92 & 66,9 & 15,6 & 57,5 & 69,0 & 75,5 & 29 & 100 & $-1,89$ & 0,06 \\
\hline $\mathrm{H}$ & 3,7 & 2,2 & 0,7 & 2,0 & 4,0 & 0 & 8 & 2,8 & 1,8 & 0 & 1,0 & 2,0 & 0 & 8 & 1,55 & 0,13 \\
\hline $\mathrm{H} \%$ & 21,6 & 14,3 & 11,7 & 19,5 & 30,0 & 0 & 73 & 18,2 & 14,3 & 8,0 & 12,5 & 29,2 & 0 & 54 & 0,92 & 0,36 \\
\hline Anat & 0,4 & 0,5 & 0 & 0 & 1,0 & 0 & 2 & 0,4 & 1,0 & 0 & 0 & 0,2 & 0 & 5 & $-0,16$ & 0,87 \\
\hline $\mathrm{Sg}$ & 0 & 0,2 & 0 & 0 & 0 & 0 & 1 & 0 & 0 & 0 & 0 & 0 & 0 & 0 & - & - \\
\hline Sex & - & - & - & - & - & 0 & - & - & - & - & - & - & 0 & - & - & - \\
\hline Obj & 1,5 & 1,7 & 0 & 1,0 & 2,0 & 0 & 7 & 1,2 & 1,4 & 0 & 1,0 & 2,0 & 0 & 4 & 0,73 & 0,47 \\
\hline Art & 0,2 & 0,5 & 0 & 0 & 0 & 0 & 2 & 0,1 & 0,3 & 0 & 0 & 0 & 0 & 1 & 0,32 & 0,75 \\
\hline Arq & 0,1 & 0,3 & 0 & 0 & 0 & 0 & 1 & 0,1 & 2,5 & 0 & 0 & 0 & 0 & 1 & 0,46 & 0,65 \\
\hline Símb & 0,3 & 0,5 & 0 & 0 & 1,0 & 0 & 1 & 0,1 & 2,5 & 0 & 0 & 0 & 0 & 1 & 2,12 & 0,04 \\
\hline Abst & - & - & - & - & - & 0 & - & - & - & - & - & - & 0 & - & - & - \\
\hline Bot & 0,5 & 0,8 & 0 & 0 & 1,0 & 0 & 3 & 0,5 & 0,9 & 0 & 0 & 1,0 & 0 & 4 & 0,15 & 0,88 \\
\hline Geo & 0,3 & 0,8 & 0 & 0 & 0 & 0 & 3 & 0,1 & 0,4 & 0 & 0 & 0 & 0 & 2 & 1,18 & 0,24 \\
\hline Nat & 0,1 & 0,2 & 0 & 0 & 0 & 0 & 1 & 0,1 & 0,4 & 0 & 0 & 0 & 0 & 2 & $-0,73$ & 0,47 \\
\hline Pais & 0,1 & 0,2 & 0 & 0 & 0 & 0 & 1 & 0 & 0,2 & 0 & 0 & 0 & 0 & 1 & 0,58 & 0,56 \\
\hline Elem & 0,2 & 0,6 & 0 & 0 & 0 & 0 & 2 & 0 & 0,2 & 0 & 0 & 0 & 0 & 1 & 1,68 & 0,10 \\
\hline Elem (Fog) & 0,2 & 0,5 & 0 & 0 & 0 & 0 & 2 & 0 & 0,2 & 0 & 0 & 0 & 0 & 1 & 1,47 & 0,15 \\
\hline Frag & 0,1 & 0,3 & 0 & 0 & 0 & 0 & 1 & 0,1 & 0,3 & 0 & 0 & 0 & 0 & 1 & 0,40 & 0,69 \\
\hline Ban & 2,6 & 1,6 & 2,0 & 2,0 & 3,0 & 0 & 9 & 2,5 & 1,3 & 1,0 & 3,0 & 3,25 & 0 & 5 & 0,26 & 0,79 \\
\hline $\operatorname{Ban} \%$ & 15,6 & 10,1 & 8,0 & 13,0 & 19,0 & 0 & 50 & 16,1 & 9,9 & 8,7 & 15,0 & 23,0 & 0 & 44 & $-0,19$ & 0,85 \\
\hline $3^{\mathrm{a} F o r m . ~}$ & 36,8 & 10,3 & 29,0 & 36,0 & 43,2 & 20 & 56 & 31,8 & 7,4 & 25,0 & 31,0 & 38,2 & 20 & 45 & 2,16 & 0,04 \\
\hline $\begin{array}{l}\text { Form. } \\
\text { Angústia }\end{array}$ & 5,7 & 6,6 & 0 & 4,5 & 8,2 & 0 & 30 & 4,3 & 5,2 & 0 & 3,0 & 8,0 & 0 & 21 & 0,95 & 0,35 \\
\hline
\end{tabular}

M = média; DP = desvio-padrão; Med = mediana; Min = mínimo; Máx = máximo.

A análise inferencial desses resultados apontou que G1 e G2 apresentaram diferenças estatisticamente significativas no tocante a duas variáveis: conteúdo símbolo 
$(d$ de Cohen $=0,05)$ e a terceira fórmula afetiva $(d$ de Cohen $=0,27)$. No caso do conteúdo símbolo, sua frequência nos grupos é muito pequena, apesar de grande variabilidade entre indivíduos, o que minimiza a relevância desse achado, sobretudo diante do reduzido tamanho do efeito dessa diferença. Com relação à fórmula da reatividade a cor (terceira fórmula afetiva), os valores maiores ocorreram em G1, sugerindo maior mobilização emocional nas crianças com obesidade. Contudo, essa única variável também relativiza e enfraquece qualquer diferenciação entre G1 e G2, podendo-se examinar os resultados das crianças em termos globais.

Procurou-se, então, caracterizar os indicadores (em porcentagem) das principais variáveis do conteúdo do Rorschach para o grupo total de crianças $(n=60)$. Os conteúdos referem-se a principais interesses dos respondentes. Foi possível identificar os seguintes resultados: $\mathrm{A} \%=62,9( \pm 16,9)$, mediana $=64,0 ; \mathrm{H} \%=19,9( \pm 14,3)$, mediana $=17,5 . \mathrm{O}$ índice médio de respostas banais atingiu o valor de $\mathrm{Ban} \%=15,9$ $( \pm 10,0)$, mediana $=13,5$. Por sua vez, a terceira fórmula afetiva atingiu média geral de $34,4 \%( \pm 9,3)$, mediana $=32,0$, enquanto a Fórmula da Angústia teve média geral de $5,0 \%( \pm 6,0)$, mediana $=4,0$. Nota-se grande variabilidade nesses dados médios, como pode ser visto pelo elevado valor assumido no desvio-padrão dessas variáveis, o que coloca ressalvas no processo interpretativo desse tipo de resultado (média). Apesar desse limite técnico, pode-se comentar que esses achados tendem a acompanhar expectativas normativas da faixa etária em estudo, sugerindo adequada adaptação sócio afetiva no desenvolvimento dessas crianças, independentemente de seu quadro de saúde (grupo clínico ou de comparação).

Na tentativa de examinar os dados sobre outra perspectiva (para além da média por grupo), fez-se análise comparativa da distribuição das crianças de G1 e de G2 (teste 
qui-quadrado, $p \leq 0,05)$ a partir de algumas variáveis do Rorschach, consideradas relevantes para interpretação clínica. Esses dados estão sistematizados na Tabela 12.

Tabela 12: Distribuição e comparação estatística das crianças de G1 e G2 de acordo com variáveis selecionadas do Método de Rorschach.

\begin{tabular}{|c|c|c|c|c|c|}
\hline Variáveis Rorschach & Classificações* & $\begin{array}{c}\text { Grupo } 1 \\
(\mathrm{n}=30)\end{array}$ & $\begin{array}{c}\text { Grupo } 2 \\
(\mathrm{n}=30)\end{array}$ & $\chi^{2}$ & $p$ \\
\hline \multirow{3}{*}{$\mathrm{F} \%$} & Acima média & 30 & 28 & \multirow{3}{*}{2,069} & \multirow{3}{*}{0,150} \\
\hline & Média & - & - & & \\
\hline & Abaixo média & - & 2 & & \\
\hline \multirow{3}{*}{$\mathrm{F}+\%$} & Acima média & 14 & 13 & \multirow{3}{*}{0,085} & \multirow{3}{*}{0,959} \\
\hline & Média & 6 & 6 & & \\
\hline & Abaixo média & 10 & 11 & & \\
\hline \multirow{3}{*}{$\mathrm{F}+\operatorname{ext} \%$} & Acima média & 18 & 15 & \multirow{3}{*}{0,873} & \multirow{3}{*}{0,646} \\
\hline & Média & 6 & 6 & & \\
\hline & Abaixo média & 6 & 9 & & \\
\hline \multirow{3}{*}{ TRI } & Extratensivo & 18 & 13 & \multirow{3}{*}{2,016} & \multirow{3}{*}{0,365} \\
\hline & Introversivo & 7 & 8 & & \\
\hline & Ambigual/coartativo & 5 & 9 & & \\
\hline \multirow{3}{*}{$2^{\mathrm{a}}$. Fórmula afetiva } & Extratensivo & 2 & 3 & \multirow{3}{*}{3,377} & \multirow{3}{*}{0,185} \\
\hline & Introversivo & 27 & 22 & & \\
\hline & Ambigual/coartativo & 1 & 5 & & \\
\hline \multirow{3}{*}{$3^{a}$. Fórmula afetiva } & Extratensivo & 10 & 3 & \multirow{3}{*}{5,108} & \multirow{3}{*}{0,078} \\
\hline & Introversivo & 9 & 10 & & \\
\hline & Ambigual/coartativo & 11 & 17 & & \\
\hline \multirow{2}{*}{$\mathrm{FC}: \mathrm{CF}+\mathrm{C}$} & $\mathrm{FC}>\mathrm{CF}+\mathrm{C}$ & 18 & 15 & \multirow{2}{*}{0,606} & \multirow{2}{*}{0,436} \\
\hline & $\mathrm{FC} \leq \mathrm{CF}+\mathrm{C}$ & 12 & 15 & & \\
\hline \multirow{2}{*}{$\mathrm{FE}: \mathrm{EF}+\mathrm{E}$} & $\mathrm{FE}>\mathrm{EF}+\mathrm{E}$ & 17 & 15 & \multirow[b]{2}{*}{0,268} & \multirow{2}{*}{0,605} \\
\hline & $\mathrm{FE} \leq \mathrm{EF}+\mathrm{E}$ & 13 & 15 & & \\
\hline \multirow{2}{*}{$\mathrm{K}:(\mathrm{kan}+\mathrm{kob}+\mathrm{kp})$} & $\mathrm{K}>\mathrm{kan}+\mathrm{kob}+\mathrm{kp}$ & 5 & 2 & \multirow{2}{*}{1,456} & \multirow{2}{*}{0,228} \\
\hline & $\mathrm{K} \leq \mathrm{kan}+\mathrm{kob}+\mathrm{kp}$ & 25 & 28 & & \\
\hline \multirow{2}{*}{$\sum \mathrm{Cp}: \sum \mathrm{Ep}$} & $\sum \mathrm{Cp}>\sum \mathrm{Ep}$ & 25 & 20 & \multirow{2}{*}{2,222} & \multirow{2}{*}{0,136} \\
\hline & $\sum \mathrm{Cp} \leq \sum \mathrm{Ep}$ & 5 & 10 & & \\
\hline Fórmula angústia & $\begin{array}{l}>12 \% \\
\leq 12 \%\end{array}$ & $\begin{array}{c}28 \\
2\end{array}$ & $\begin{array}{c}29 \\
1\end{array}$ & 0,351 & 0,554 \\
\hline
\end{tabular}




$\begin{array}{cccccc}\sum \mathrm{H}: \sum \mathrm{Hd} & \sum \sum \mathrm{Hd} & 26 & 22 & & \\ & \sum \mathrm{H} \leq \sum \mathrm{Hd} & 4 & 8 & 1,667 & 0,197\end{array}$

* Para essas classificações foram usados como referência os parâmetros normativos disponíveis (na média, abaixo ou acima da média), conforme o tipo de variável analisada.

Esta abordagem complementar para análise dos dados não apontou diferenças estatisticamente significativas entre G1 e G2 na distribuição das crianças em função dos agrupamentos clínicos das variáveis do Rorschach. Entretanto, pode-se observar tendência à diferença entre os grupos no tocante à distribuição dos tipos afetivos na terceira fórmula afetiva. Nota-se que o tipo extratensivo foi mais frequente nas crianças com obesidade do que nas crianças eutróficas, enquanto o tipo ambigual de reatividade cromática ocorreu em mais casos do grupo de comparação.

\subsection{Resultados relativos a variáveis com significado clínico}

Diante dos indicativos de similaridade no padrão de respostas das crianças com obesidade (G1) e sem obesidade (G2), a partir da comparação de resultados médios nas principais variáveis do SDQ, do DFH e do Rorschach, considerou-se sensato selecionar alguns indicadores clínicos dos métodos projetivos para tentar examinar a distribuição de frequência dos casos em relação aos parâmetros normativos nos dois grupos. Disso poderiam resultar evidências empíricas com significado clínico, auxiliares para compreender e caracterizar psicologicamente as crianças avaliadas. Para tanto, considerou-se os seguintes indicadores no Rorschach, conforme Rausch de Traubenberg (1998) e Loureiro e Romaro (1985):

a) relativos a organização lógica: variáveis F\%, F+\% e F+ext\% (controle de impulsos a partir da razão). 
b) relativos a funcionamento afetivo: Tipo de Ressonância Íntima ( $\left.\sum \mathrm{K}: \sum \mathrm{Cp}\right)$; Tendências Latentes ( $\sum \mathrm{k}: \sum \mathrm{Ep}$ ); Terceira Fórmula Afetiva (proporção de respostas dadas nas pranchas VIII, IX e X em relação ao total de respostas); proporção de grande e pequenas cinestesias $(K:$ kan $+k p+k o b)$; proporção da determinação formal em relação à cor $(\mathrm{FC}: \mathrm{CF}+\mathrm{C})$; proporção da determinação formal em relação ao sombreado $(\mathrm{FE}: \mathrm{EF}+\mathrm{E})$; proporção da somatória da cor ponderada à somatória do sombreamento ponderado ( $\left.\sum \mathrm{Cp}: \sum \mathrm{Ep}\right)$, e a Fórmula da Angústia.

c) relativos a relacionamentos interpessoais: proporção de respostas de conteúdo humano inteiro em relação a conteúdo parcial humano, ou seja: [soma de $\mathrm{H}$ e $(\mathrm{H})$ ] : [soma de Hd e (Hd)].

Para classificar os dados dos participantes no Rorschach foram utilizados os dados normativos de Raspantini (2010) e Fernandes (2010), categorizando-os como "na média" se estivessem entre os percentis 40 e 60 de sua faixa etária normativa. Os resultados acima e abaixo destes parâmetros foram classificados com "acima da média" e "abaixo da média", respectivamente. Os dados normativos dos citados estudos constam do ANEXO 4, ao final desse trabalho, para facilidade de análise comparativa, caso necessário.

Com relação ao DFH, os dados foram sistematizados em função do número de indicadores emocionais (IE) presentes. Os casos ficaram distribuídos em termos de três classes: DFH com zero ou um IE; DFH com dois IE; DFH com três ou mais IE. Cabe lembrar que, para Koppitz (1966), o maior número de IEs presente no DFH representaria evidência de dificuldade afetiva na criança, sobretudo a partir da identificação de três sinais no desenho.

Procurou-se sistematizar esses achados relativos ao Rorschach e ao DFH de forma cruzada, respeitando-se a distribuição das crianças em G1 e em G2, comparando- 
se a distribuição dos casos (pelo Teste qui-quadrado, $p \leq 0,05$ ) nessas variáveis selecionadas dos métodos projetivos. Esses resultados compõem as Tabelas 13 a 15, cada qual respectivamente focalizando funcionamento lógico, dinâmica afetiva e relacionamentos interpessoais.

Tabela 13: Distribuição e comparação estatística das crianças de G1 e G2 de acordo com funcionamento lógico pelo Método de Rorschach, em função do número de indicadores emocionais no DFH.

\begin{tabular}{|c|c|c|c|c|c|c|c|c|c|}
\hline VARIÁ & $\mathrm{EL}$ & & Con & araçã & Rors & ach & & & \\
\hline Funcionamento & $\begin{array}{l}\text { Indicadores } \\
\text { emocionais }\end{array}$ & & & & & & & $x^{2}$ & $p$ \\
\hline & DFH & G1 & $\mathrm{G} 2$ & G1 & $\mathrm{G} 2$ & G1 & $\mathrm{G} 2$ & & \\
\hline & $0-1$ & 11 & 11 & - & - & - & 1 & 0,958 & 0,328 \\
\hline F\% & 2 & 8 & 6 & - & - & - & 1 & 1,224 & 0,268 \\
\hline & 3 ou mais & 11 & 11 & - & - & - & - & - & - \\
\hline & $0-1$ & 5 & 5 & 3 & 3 & 3 & 4 & 0,100 & 0,951 \\
\hline $\mathrm{F}+\%$ & 2 & 4 & 5 & 1 & 1 & 3 & 1 & 1,049 & 0,592 \\
\hline & 3 ou mais & 5 & 3 & 2 & 2 & 4 & 6 & 0,900 & 0,638 \\
\hline & $0-1$ & 5 & 7 & 2 & 2 & 4 & 3 & 0,434 & 0,805 \\
\hline $\mathrm{F}+\mathrm{ext} \%$ & 2 & 5 & 4 & 3 & 1 & - & 2 & 3,058 & 0,217 \\
\hline & 3 ou mais & 8 & 4 & 1 & 3 & 2 & 4 & 3,000 & 0,223 \\
\hline
\end{tabular}


Como é possível observar, os dois grupos não se diferenciaram significativamente no tocante ao funcionamento lógico em nenhuma das variáveis selecionadas do Rorschach, quando cruzadas com o número de IEs apresentados no DFH, segundo suas classificações clínicas. Tais resultados são indicativos de similaridade entre os grupos quanto à utilização de recursos cognitivos para a contenção afetiva e adaptação lógico formal.

Em continuidade às análises, é apresentada a Tabela 14. Ela traz dados referentes ao funcionamento afetivo dos participantes no Rorschach, em cruzamento com os IEs do DFH. 
Tabela 14: Distribuição e comparação estatística das crianças de G1 e G2 de acordo com funcionamento afetivo pelo Método de Rorschach, em função do número de indicadores emocionais no DFH.

\begin{tabular}{|c|c|c|c|c|c|c|c|c|c|}
\hline \multirow{3}{*}{$\begin{array}{c}\text { Funcionamento } \\
\text { afetivo }\end{array}$} & \multirow{3}{*}{$\begin{array}{c}\text { Indicadores } \\
\text { emocionais } \\
\text { DFH }\end{array}$} & \multicolumn{6}{|c|}{ Comparação Rorschach } & \multirow{3}{*}{$\chi^{2}$} & \multirow{3}{*}{$p$} \\
\hline & & \multicolumn{2}{|c|}{ Extratensivo } & \multicolumn{2}{|c|}{ Introversivo } & \multicolumn{2}{|c|}{$\begin{array}{l}\text { Ambigual / } \\
\text { Coartado }\end{array}$} & & \\
\hline & & G1 & G2 & G1 & G2 & G1 & G2 & & \\
\hline \multirow{3}{*}{ TRI } & $0-1$ & 7 & 6 & 3 & 3 & 2 & 3 & 0,277 & 0,871 \\
\hline & 2 & 5 & 3 & 1 & 1 & 1 & 2 & 0,761 & 0,684 \\
\hline & 3 ou mais & 6 & 4 & 3 & 4 & 2 & 4 & 1,168 & 0,558 \\
\hline \multirow{3}{*}{$2^{\mathrm{a}}$. Fórmula afetiva } & $0-1$ & 1 & 2 & 10 & 8 & - & 3 & 3,413 & 0,182 \\
\hline & 2 & 0 & 1 & 8 & 5 & - & - & 1,436 & 0,231 \\
\hline & 3 ou mais & 1 & 0 & 9 & 9 & 1 & 2 & 1,333 & 0,513 \\
\hline \multirow{3}{*}{$3^{\mathrm{a}}$. Fórmula afetiva } & $0-1$ & 3 & - & 4 & 2 & 5 & 10 & 5,333 & 0,069 \\
\hline & 2 & 4 & - & 2 & 1 & 1 & 5 & 6,964 & 0,031 \\
\hline & 3 ou mais & 3 & 3 & 3 & 7 & 5 & 2 & 2,848 & 0,241 \\
\hline \multirow{4}{*}{$\mathrm{FC}: \mathrm{CF}+\mathrm{C}$} & & \multicolumn{3}{|c|}{$\mathrm{FC}>\mathrm{CF}+\mathrm{C}$} & \multicolumn{3}{|c|}{$\mathrm{FC} \leq \mathrm{CF}+\mathrm{C}$} & & \\
\hline & $0-1$ & 8 & & 4 & 4 & & 8 & 2,667 & 0,102 \\
\hline & 2 & 4 & & 4 & 3 & & 2 & 0,124 & 0,725 \\
\hline & 3 ou mais & 6 & & 7 & 5 & & 5 & 0,034 & 0,855 \\
\hline \multirow{4}{*}{$\mathrm{FE}: \mathrm{EF}+\mathrm{E}$} & & \multicolumn{3}{|c|}{$\mathrm{FE}>\mathrm{EF}+\mathrm{E}$} & \multicolumn{3}{|c|}{$\mathrm{FE} \leq \mathrm{EF}+\mathrm{E}$} & & \\
\hline & $0-1$ & 6 & & 7 & 6 & & 5 & 0,168 & 0,682 \\
\hline & 2 & 6 & & 2 & 1 & & 4 & 3,745 & $\mathbf{0 , 0 5 3}$ \\
\hline & 3 ou mais & 5 & & 6 & 6 & & 6 & 0,048 & 0,827 \\
\hline \multirow{4}{*}{$\mathrm{K}: \mathrm{kan}+\mathrm{kob}+\mathrm{kp}$} & & \multicolumn{3}{|c|}{$\mathrm{K}>\mathrm{kan}+\mathrm{kob}+\mathrm{kp}$} & \multicolumn{3}{|c|}{$\mathrm{K} \leq \mathrm{kan}+\mathrm{kob}+\mathrm{kp}$} & & \\
\hline & $0-1$ & 3 & & 2 & 9 & & 10 & 0,253 & 0,615 \\
\hline & 2 & 7 & & 6 & - & & - & - & - \\
\hline & 3 ou mais & 2 & & - & 9 & & 12 & 2,390 & 0,122 \\
\hline \multirow{4}{*}{$\sum \mathrm{Cp}: \sum \mathrm{Ep}$} & & \multicolumn{3}{|c|}{$\sum \mathrm{Cp}>\sum \mathrm{Ep}$} & \multicolumn{3}{|c|}{$\sum \mathrm{Cp} \leq \sum \mathrm{Ep}$} & & \\
\hline & $0-1$ & 9 & & 8 & 3 & & 4 & 0,202 & 0,653 \\
\hline & 2 & 7 & & 4 & - & & 2 & 2,758 & 0,097 \\
\hline & 3 ou mais & 9 & & 8 & 2 & & 4 & 0,683 & 0,408 \\
\hline \multirow{4}{*}{ Fórmula angústia } & & \multicolumn{3}{|c|}{$>12 \%$} & \multicolumn{3}{|c|}{$\leq 12 \%$} & & \\
\hline & $0-1$ & 11 & & 11 & 1 & & 1 & $<0,001$ & 1,000 \\
\hline & 2 & 6 & & 6 & 1 & & 0 & 0,929 & 0,335 \\
\hline & 3 ou mais & 11 & & 12 & - & & - & - & - \\
\hline
\end{tabular}


É possível constatar ausência de diferenças estatisticamente significativas na maior parte das variáveis comparadas entre os grupos, com exceção dos resultados obtidos na terceira Fórmula Afetiva, bem como na proporção entre (FE : EF + E). A primeira diferença é sugestiva de que, em situação limítrofe segundo o DFH (dois IEs), mais crianças com obesidade apresentariam reatividade emocional do tipo extratensivo, enquanto que seus pares eutróficos evidenciariam, com maior frequência, perfil ambigual ou coartado. Esse resultado permite a inferência de que crianças com obesidade e com mais IEs em seus DFH tenderiam a reagir de forma extratensiva aos estímulos da realidade, ou seja, expressando mais diretamente no ambiente suas vivencias emocionais, comparativamente ao grupo sem obesidade, composto por mais crianças com reatividade do tipo ambigual ou coartado.

Já a segunda diferença estatisticamente significativa aqui identificada apontou que houve mais crianças de Grupo 1 com dois IEs e adequado controle lógico das vivência de angústia $(\mathrm{FE}>\mathrm{EF}+\mathrm{E})$, comparativamente a seus pares eutróficos. No entanto, essa especificidade de produção não se manteve a partir dos três ou mais IEs, fragilizando alguma possibilidade interpretativa consistente sobre os recursos de contenção da ansiedade entre essas crianças avaliadas.

Interessante notar que as crianças de ambos os grupos que apresentaram resultado da Fórmula da Angústia inferior a 12\% (ou seja, não indicando vivência de angústia) produziram DFH praticamente sem IEs. Em complemento, a maioria dos casos com resultado superior a 12\% na Fórmula de Angústia do Rorschach produziram desenhos com dois ou mais sinais emocionais. Esse resultado, embora específico, constitui relevante evidência de validade clínica dos métodos projetivos de avaliação psicológica utilizados nesse trabalho (DFH e Rorschach). 
Por fim, foram sistematizadas as análises referentes às variáveis relativas aos relacionamentos interpessoais. Esses resultados compõem a Tabela 15.

Tabela 15: Distribuição e comparação estatística das crianças de G1 e G2 de acordo com os relacionamentos interpessoais pelo Método de Rorschach, em função do número de indicadores emocionais no DFH.

\begin{tabular}{|c|c|c|c|c|c|c|c|}
\hline \multicolumn{2}{|c|}{ VARIÁVEL } & \multicolumn{4}{|c|}{ Comparação Rorschach } & \multirow[b]{3}{*}{$\chi^{2}$} & \multirow[b]{3}{*}{$p$} \\
\hline \multirow{2}{*}{$\begin{array}{c}\text { Relacionamento } \\
\text { Interpessoal }\end{array}$} & \multirow{2}{*}{$\begin{array}{c}\text { Indicadores } \\
\text { emocionais } \\
\text { DFH }\end{array}$} & \multicolumn{2}{|c|}{$\mathrm{H}>\mathrm{Hd}$} & \multicolumn{2}{|c|}{$\mathrm{H} \leq \mathrm{Hd}$} & & \\
\hline & & G1 & $\mathrm{G} 2$ & G1 & $\mathrm{G} 2$ & & \\
\hline \multirow{3}{*}{ Soma H : Soma Hd } & $0-1$ & 10 & 8 & 2 & 4 & 0,889 & 0,346 \\
\hline & 2 & 7 & 4 & 0 & 2 & 2,758 & 0,097 \\
\hline & 3 ou mais & 9 & 10 & 2 & 2 & 0,009 & 0,924 \\
\hline
\end{tabular}

A análise da distribuição das crianças de G1 e G2 nos indicadores de integridade e interesse pelos contatos humanos (soma de conteúdos humanos inteiros em relação a soma dos conteúdos parciais humanos) não evidenciou diferença estatisticamente significativa entre os grupos. Houve tendência geral de preservação da integridade dos conteúdos humanos ao interpretar o Rorschach em crianças com e sem obesidade, mesmo com diferenciados números de indicadores emocionais em seus desenhos.

\subsection{Resultados relativos a análises correlacionais}

Como opção exploratória dos dados optou-se por abordar os participantes não segundo os dois grupos pré-estabelecidos (com obesidade e eutrófico), mas sim em função de seu Índice de Massa Corporal (IMC), mensurado em uma disposição contínua. Nesta perspectiva, foram correlacionados (correlação de Pearson, $p \leq 0,05$ ) os 
valores de IMC dos participantes com as seguintes variáveis dos instrumentos utilizados: a) número de Indicadores Emocionais e Itens Evolutivos presentes em seus DFH; b) respectivos percentis nas seguintes variáveis do Rorschach: R, RA, Rec, Den, Tempos médio de resposta e de latência, G\%, D\%, Dd\%, Db1\%, Do\%, F\%, F+\%, $\mathrm{F}+\mathrm{ext} \%$, soma dos movimentos humanos e das pequenas cinestesias, cor e estompagem ponderados, A\%, H\%, Ban\%, Terceira Fórmula Afetiva e Fórmula da Angústia; c) escore geral e nas subescalas sintomas emocionais, problemas de conduta, hiperatividade, problemas de relacionamento com colegas e comportamento pró-social.

Por se tratar de inúmeras tentativas exploratórias, optou-se por aqui apresentar o único resultado que se mostrou positiva e significativamente correlacionado com o IMC das crianças. Essa variável foi o tempo médio de respostas (TRm) no Método de Rorschach, cuja correlação foi significativa e positiva com o IMC $(r=0,29 ; p=0,02)$. Por se tratar de resultado isolado, frente ao conjunto de variáveis examinadas, pode-se inferir que o padrão de respostas das crianças nos instrumentos de avaliação psicológica pouco se associou a seu índice de massa corporal, sinalizando similaridades entre os recursos dos dois grupos.

\subsection{Resultados em função do sexo e da idade}

Para analisar a existência de possíveis diferenças nos resultados das crianças (independentemente de seu tamanho corporal) em função do sexo, optou-se por realizar uma sequência de investigações. Foi realizado um teste de comparação de médias $(t$ de Student) entre meninos e meninas para as principais variáveis de cada instrumento de avaliação psicológica utilizado nesse trabalho (SDQ, DFH e Método de Rorschach). Esses achados foram sistematizados na Tabela 16. 
Tabela 16: Resultados descritivos nos instrumentos na amostra total $(n=60)$ e sua comparação estatística segundo o sexo.

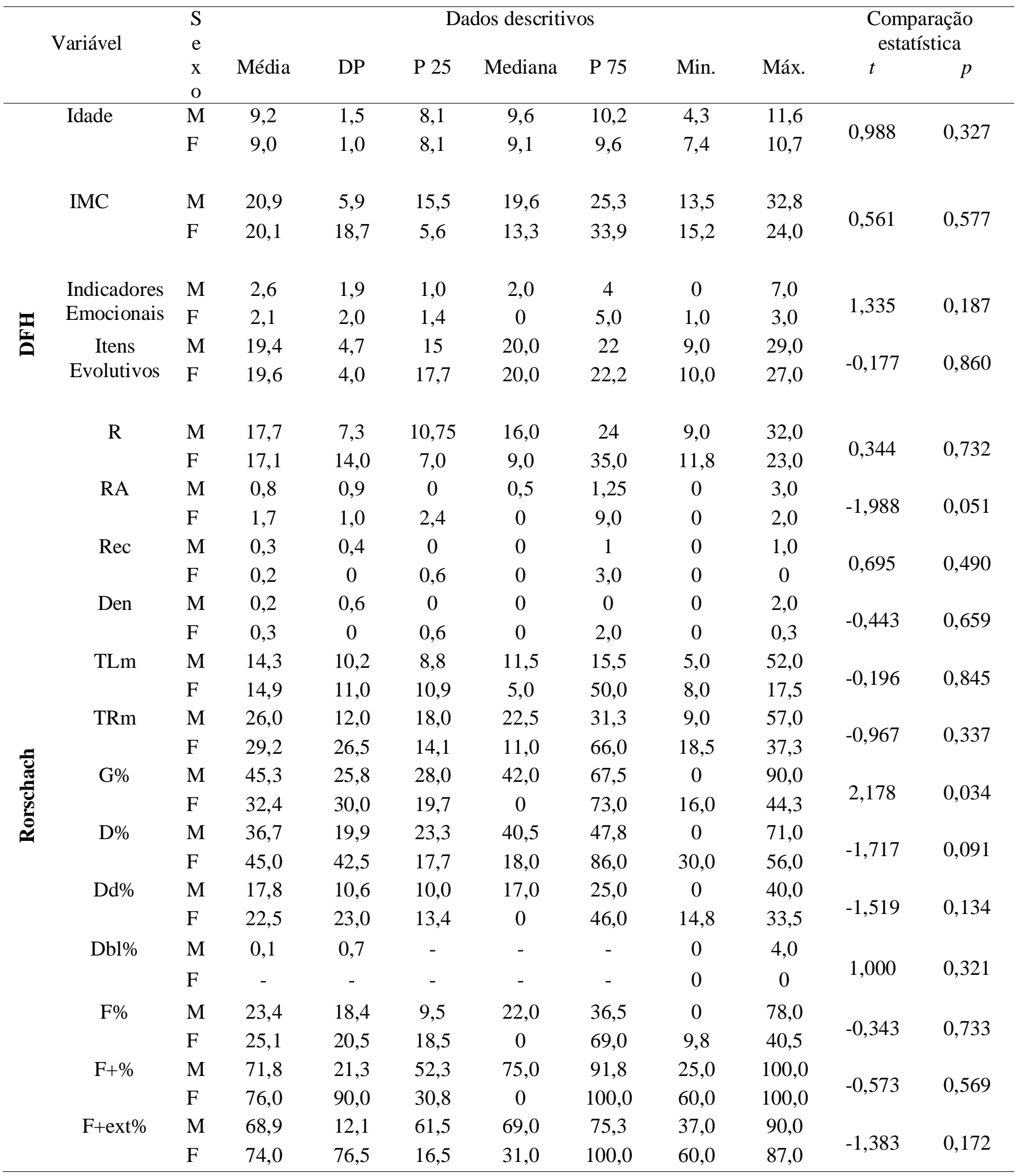




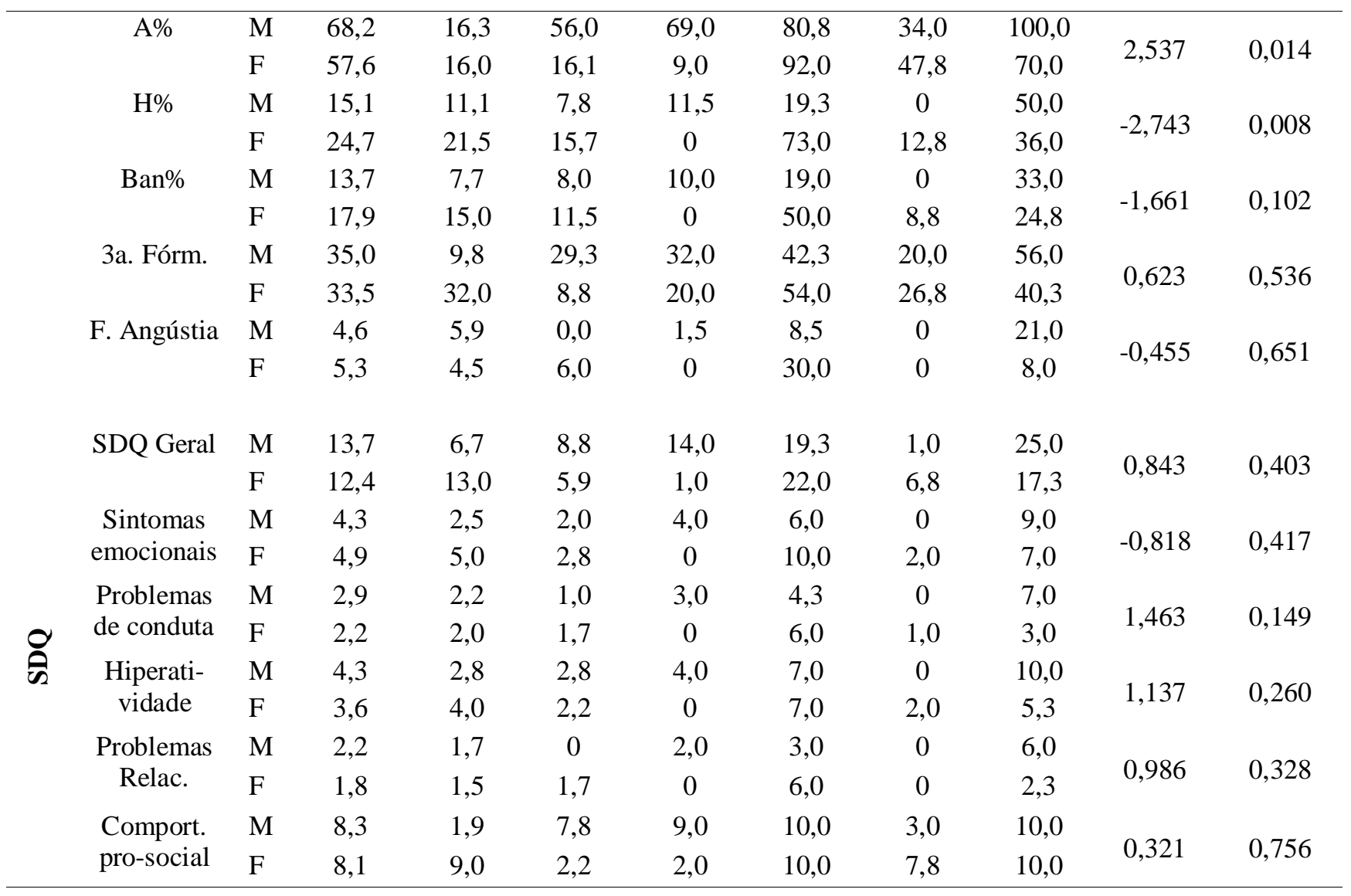

Esta primeira análise resultou em diferenças estatisticamente significativas, segundo o sexo, para quatro variáveis do Rorschach, a saber: Respostas Adicionais (d de Cohen $=-0,95) ; \mathrm{G} \%(d$ de Cohen $=0,40) ; \mathrm{A} \%(d$ de Cohen $=0,66)$ e $\mathrm{H} \%(d$ de Cohen $=-0,56)$. Pode-se inferir, portanto, que o sexo das crianças influenciou, com moderado efeito, seu padrão de respostas a esse método projetivo de avaliação psicológica, embora em poucos indicadores técnicos. Nos demais instrumentos e medidas essa variável demográfica pareceu não interferir de modo relevante. Apesar de restritos, as evidências sinalizaram mais RA e maior média de $\mathrm{H} \%$ nas meninas, enquanto os meninos mostraram maior média em G\% e A\%. Pode-se pensar que o grupo feminino indicou maior interesse pelos contatos humanos, enquanto as crianças do sexo masculino sinalizaram abordagem mais superficial e socialmente compartilhada dos estímulos. São pistas sobre características de personalidade associadas ao sexo no 
grupo total de crianças examinadas nesse trabalho, independentemente de sua condição clínica (com ou sem obesidade).

Após esta análise mais geral, as crianças foram subdivididas em dois grandes grupos, em função do sexo, totalizando 15 casos com obesidade e 15 casos eutróficos em cada novo agrupamento. Seus resultados médios nos diferentes indicadores técnicos foram comparados (teste $t$ de Student), além da correlação de cada variável dos instrumentos de avaliação com o IMC das crianças. Esses resultados estão sistematizados na Tabela 17 (para o grupo masculino) e Tabela 18 (para o grupo feminino).

Tabela 17: Resultados descritivos, comparação estatística das principais variáveis de cada instrumento avaliativo, e correlações com IMC no grupo masculino (15 com obesidade e 15 eutróficos).

\begin{tabular}{|c|c|c|c|c|c|c|}
\hline Variável & Grupos & Média & DP & $t$ & $p$ & $\begin{array}{c}\text { Correlação } \\
\text { com IMC } \\
\text { (Pearson) }\end{array}$ \\
\hline \multirow{2}{*}{ IMC } & Obeso & 26,0 & 4,0 & \multirow{2}{*}{9,39} & \multirow{2}{*}{$\leq 0,001$} & \multirow{2}{*}{1,00} \\
\hline & Eutrófico & 15,8 & 1,4 & & & \\
\hline Indicadores & Obeso & 2,8 & 2,0 & \multirow{2}{*}{0,48} & \multirow{2}{*}{0,64} & \multirow{2}{*}{0,09} \\
\hline Emocionais & Eutrófico & 2,5 & 1,8 & & & \\
\hline \multirow{2}{*}{ Itens Evolutivos } & Obeso & 19,3 & 5,1 & \multirow{2}{*}{$-0,11$} & \multirow{2}{*}{0,5} & \multirow{2}{*}{$-0,01$} \\
\hline & Eutrófico & 19,5 & 4,7 & & & \\
\hline \multirow{2}{*}{$\mathrm{R}$} & Obeso & 18,9 & 7,5 & \multirow{2}{*}{0,85} & \multirow{2}{*}{0,40} & \multirow{2}{*}{$-0,02$} \\
\hline & Eutrófico & 16,6 & 7,1 & & & \\
\hline \multirow{2}{*}{ RA } & Obeso & 0,7 & 1,0 & \multirow{2}{*}{$-0,20$} & \multirow{2}{*}{0,84} & \multirow{2}{*}{0,16} \\
\hline & Eutrófico & 0,8 & 0,9 & & & \\
\hline \multirow{2}{*}{ Rec } & Obeso & 0,3 & 0,5 & \multirow{2}{*}{0,00} & \multirow{2}{*}{1,00} & \multirow{2}{*}{0,23} \\
\hline & Eutrófico & 0,3 & 0,5 & & & \\
\hline \multirow{2}{*}{ Den } & Obeso & 0,2 & 0,6 & \multirow{2}{*}{$-0,32$} & \multirow{2}{*}{0,75} & \multirow{2}{*}{$-0,06$} \\
\hline & Eutrófico & 0,3 & 0,6 & & & \\
\hline \multirow{2}{*}{ TL médio } & Obeso & 19,3 & 12,0 & \multirow{2}{*}{3,05} & \multirow{2}{*}{$\leq 0,001$} & \multirow{2}{*}{$0,43 *$} \\
\hline & Eutrófico & 9,3 & 4,2 & & & \\
\hline \multirow{2}{*}{ TR médio } & Obeso & 30,5 & 11,2 & \multirow{2}{*}{2,18} & \multirow{2}{*}{0,04} & \multirow{2}{*}{$0,38^{*}$} \\
\hline & Eutrófico & 21,5 & 11,4 & & & \\
\hline G\% & Obeso & 42,2 & 20,9 & -065 & 052 & -0 - 01 \\
\hline & Eutrófico & 48,4 & 30,3 & & & \\
\hline
\end{tabular}




\begin{tabular}{|c|c|c|c|c|c|c|}
\hline \multirow{2}{*}{$\mathrm{D} \%$} & Obeso & 39,4 & 15,1 & \multirow{2}{*}{0,75} & \multirow{2}{*}{0,46} & \multirow{2}{*}{0,02} \\
\hline & Eutrófico & 33,9 & 23,9 & & & \\
\hline \multirow{2}{*}{$\mathrm{Dd} \%$} & Obeso & 17,9 & 10,1 & \multirow{2}{*}{0,03} & \multirow{2}{*}{0,97} & \multirow{2}{*}{$-0,03$} \\
\hline & Eutrófico & 17,7 & 11,5 & & & \\
\hline \multirow{2}{*}{$\mathrm{Dbl} \%$} & Obeso & 0,3 & 1,0 & \multirow{2}{*}{1,00} & \multirow{2}{*}{0,33} & \multirow{2}{*}{0,06} \\
\hline & Eutrófico & - & - & & & \\
\hline \multirow{2}{*}{$\mathrm{F} \%$} & Obeso & 23,3 & 15,8 & \multirow{2}{*}{$-0,03$} & \multirow{2}{*}{0,98} & \multirow{2}{*}{$-0,15$} \\
\hline & Eutrófico & 23,5 & 21,2 & & & \\
\hline \multirow{2}{*}{$\mathrm{F}+\%$} & Obeso & 69,1 & 21,3 & \multirow{2}{*}{$-0,66$} & \multirow{2}{*}{0,52} & \multirow{2}{*}{$-0,05$} \\
\hline & Eutrófico & 74,6 & 21,7 & & & \\
\hline \multirow{2}{*}{$\mathrm{F}+\operatorname{ext} \%$} & Obeso & 68,2 & 10,3 & \multirow{2}{*}{$-0,30$} & \multirow{2}{*}{0,77} & \multirow{2}{*}{$-0,03$} \\
\hline & Eutrófico & 69,5 & 14,0 & & & \\
\hline \multirow{2}{*}{$\mathrm{A} \%$} & Obeso & 64,7 & 17,2 & \multirow{2}{*}{$-1,18$} & \multirow{2}{*}{0,25} & \multirow{2}{*}{$-0,07$} \\
\hline & Eutrófico & 71,7 & 15,2 & & & \\
\hline \multirow{2}{*}{$\mathrm{H} \%$} & Obeso & 14,5 & 9,6 & -0.26 & 0.80 & $-0,13$ \\
\hline & Eutrófico & 15,6 & 12,8 & & & \\
\hline $\operatorname{Ban} \%$ & Obeso & 13,9 & 9,0 & 0.14 & 0.89 & 0.11 \\
\hline Ban $\%$ & Eutrófico & 13,5 & 6,4 & & & \\
\hline 3a Fórm & Obeso & 39,5 & 10,6 & 2.74 & 0.01 & 0.23 \\
\hline & Eutrófico & 30,6 & 6,7 & & & \\
\hline F Anoústia & Obeso & 4,7 & 6,0 & 0.03 & 0.98 & 0.03 \\
\hline & Eutrófico & 4,6 & 6,1 & & & \\
\hline SDO Geral & Obeso & 11,9 & 5,9 & -1.57 & 0,13 & $-0,34-2$ \\
\hline SDQ Geral & Eutrófico & 15,6 & 7,1 & $-1, J /$ & 0,15 & $-0,34$ \\
\hline Sintomas & Obeso & 4,1 & 2,5 & -0.49 & 062 & -0.15 \\
\hline emocionais & Eutrófico & 4,5 & 2,7 & & & \\
\hline Problemas de & Obeso & 2,4 & 2,0 & $-1,36$ & 0,18 & -0.28 \\
\hline conduta & Eutrófico & 3,5 & 2,3 & $-1,50$ & 0,18 & $-0,2 C$ \\
\hline Hineratividade & Obeso & 3,3 & 2,8 & -2.15 & 0.04 & $-0.32-y-2$ \\
\hline & Eutrófico & 5,3 & 2,5 & & & \\
\hline Problemas de & Obeso & 2,1 & 2,1 & -0.21 & 0,84 & $-0,20$ \\
\hline relacionamento & Eutrófico & 2,3 & 1,3 & & & \\
\hline Comportamento & Obeso & 8,5 & 1,8 & 0.58 & 0,57 & 0,07 \\
\hline pro-social & Eutrófico & 8,1 & 2,0 & & & \\
\hline
\end{tabular}

*Correlações estatisticamente significativas, $\operatorname{com} p \leq 0,05$.

Ao se considerar essa análise intragrupo do sexo masculino, observou-se diferenças estatisticamente significativas nos seguintes indicadores técnicos dos instrumentos avaliativos usados: a) no Rorschach: TLm ( $d$ de Cohen $=1,11)$, TRm médio $(d$ de Cohen $=0,8)$ e terceira Fórmula Afetiva $(d$ de Cohen $=1,0) ; \mathrm{b})$ no SDQ: na subescala Hiperatividade $(d$ de Cohen $=-0,75)$. Apesar da diferença estatisticamente 
significativa na fórmula da reatividade emocional do Rorschach, os valores encontrados resultam na mesma classificação clínica para as crianças (tipo ambigual), o que reduz a relevância desse achado específico. Com relação aos tempos de resposta ao Rorschach, os meninos com obesidade utilizaram maior TLm e TRm, precisando de mais tempo para reagir aos estímulos apresentados. O outro marcador foi relativo ao SDQ, onde os meninos eutróficos sinalizaram resultado médio superior na subescala hiperatividade, sugerindo maior movimentação corporal do que seus colegas com obesidade, segundo relato dos pais.

Já a análise das correlações neste grupo masculino de crianças foram estatisticamente significativas apenas para as variáveis do Rorschach TLm e TRm. Como essa correlação foi positiva, pode-se comentar que quanto maior o IMC, maior foi o tempo médio para reagir e para produzir interpretações ao Rorschach. Cabe destacar que tempos maiores de reação ao Rorschach tendem a indicar insegurança no contato e lentificação em processos associativos, o que pareceu ocorrer mais nos meninos com obesidade.

A Tabela 18 traz análises similares, realizadas com o grupo feminino de crianças $(\mathrm{n}=30)$.

Tabela 18: Resultados descritivos, comparação estatística das principais variáveis de cada instrumento avaliativo, e correlações com IMC no grupo feminino (15 com obesidade e 15 eutróficas).

\begin{tabular}{clccccc}
\hline Variável & Grupos & Média & DP & $t$ & $p$ & $\begin{array}{c}\text { Correlação } \\
\text { com IMC } \\
\text { (Pearson) }\end{array}$ \\
\hline IMC & Obeso & 25,1 & 3,3 & 11,59 & $\leq \mathbf{0 , 0 0 1}$ & 1,00 \\
& Eutrófico & 15,0 & 0,9 & & & \\
Indicadores & Obeso & 1,8 & 1,3 & $-1,07$ & 0,29 & $-0,13$ \\
Emocionais & Eutrófico & 2,3 & 1,5 & & & \\
\hline
\end{tabular}




\begin{tabular}{|c|c|c|c|c|c|c|}
\hline \multirow{2}{*}{ Itens Evolutivos } & Obeso & 19,2 & 4,7 & \multirow{2}{*}{$-0,49$} & \multirow{2}{*}{0,24} & \multirow{2}{*}{$-0,22$} \\
\hline & Eutrófico & 19,9 & 3,4 & & & \\
\hline \multirow{2}{*}{$\mathrm{R}$} & Obeso & 16,9 & 5,9 & \multirow{2}{*}{$-0,18$} & \multirow{2}{*}{0,86} & \multirow{2}{*}{$-0,14$} \\
\hline & Eutrófico & 17,3 & 8,1 & & & \\
\hline \multirow{2}{*}{ RA } & Obeso & 1,7 & 2,7 & \multirow{2}{*}{0,07} & \multirow{2}{*}{0,94} & \multirow{2}{*}{0,10} \\
\hline & Eutrófico & 1,7 & 2,1 & & & \\
\hline \multirow{2}{*}{ Rec } & Obeso & 0,1 & 0,5 & \multirow{2}{*}{$-0,28$} & \multirow{2}{*}{0,78} & \multirow{2}{*}{0,02} \\
\hline & Eutrófico & 0,2 & 0,8 & & & \\
\hline \multirow{2}{*}{ Den } & Obeso & 0,3 & 0,5 & \multirow{2}{*}{$-0,30$} & \multirow{2}{*}{0,77} & \multirow{2}{*}{$-0,03$} \\
\hline & Eutrófico & 0,3 & 0,7 & & & \\
\hline \multirow{2}{*}{ TL médio } & Obeso & 13,3 & 7,3 & \multirow{2}{*}{$-0,77$} & \multirow{2}{*}{0,45} & 012 \\
\hline & Eutrófico & 16,4 & 13,7 & & & $-0,12$ \\
\hline TR médio & Obeso & 31,6 & 13,0 & 092 & 037 & 024 \\
\hline I K medio & Eutrófico & 26,9 & 15,1 & 0,92 & 0,31 & 0,24 \\
\hline $\mathrm{G} \%$ & Obeso & 34,0 & 19,0 & 044 & 0.66 & 021 \\
\hline $4 \%$ & Eutrófico & 30,8 & 21,0 & 0,44 & 0,00 & 0,21 \\
\hline $\mathrm{D} \%$ & Obeso & 42,3 & 17,8 & -082 & 0.42 & -016 \\
\hline $\mathbf{D} \%$ & Eutrófico & 47,7 & 17,8 & $-0,82$ & 0,42 & $-0,10$ \\
\hline $\mathrm{Dd} \%$ & Obeso & 23,6 & 11,5 & 043 & 067 & -009 \\
\hline $\mathrm{Da} \%$ & Eutrófico & 21,5 & 15,3 & 0,43 & $0,0 /$ & $-0,09$ \\
\hline & Obeso & - & - & & & \\
\hline $\mathrm{Dbl} \%$ & Eutrófico & - & - & - & - & - \\
\hline & Eutrófico & - & - & & & \\
\hline EO & Obeso & 21,7 & 16,5 & & 033 & \\
\hline $\mathrm{F} \%$ & Eutrófico & 28,4 & 20,3 & $-0,99$ & 0,33 & $-0,20$ \\
\hline & Obeso & 78,5 & 29,3 & 042 & 068 & \\
\hline $\mathrm{F}+\%$ & Eutrófico & 73,5 & 33,1 & 0,42 & 0,08 & 0,17 \\
\hline Eteyt $\%$ & Obeso & 73,8 & 13,5 & 008 & 004 & 004 \\
\hline 1 TEXI 10 & Eutrófico & 74,3 & 19,5 & $-0,00$ & 0,54 & 0,04 \\
\hline $\mathrm{A} \%$ & Obeso & 53,1 & 16,1 & 160 & 012 & - $37 *$ \\
\hline A 10 & Eutrófico & 62,2 & 15,1 & $-1,00$ & 0,12 & (1) \\
\hline $\mathrm{HO}$ & Obeso & 28,7 & 15,1 & 141 & 017 & $037 *$ \\
\hline 1170 & Eutrófico & 20,7 & 15,8 & 1,41 & 0,11 & 0,5 \\
\hline Banor & Obeso & 17,2 & 11,3 & 034 & 073 & 004 \\
\hline Dant 70 & Eutrófico & 18,7 & 12,2 & $-0,34$ & 0,13 & 0,04 \\
\hline 3a Fórm & Obeso & 34,2 & 9,6 & 041 & 060 & $<0001$ \\
\hline Ja. гопा1. & Eutrófico & 32,9 & 8,2 & 0,41 & 0,0 & $=0,001$ \\
\hline F Anoústia & Obeso & 6,7 & 7,2 & 130 & 021 & 009 \\
\hline г. Angusura & Eutrófico & 3,9 & 4,3 & 1,30 & 0,21 & 0,09 \\
\hline SDO Geral & Obeso & 13,1 & 6,1 & 065 & 052 & 004 \\
\hline SDQ Geral & Eutrófico & 11,7 & 5,7 & $0,0 J$ & 0, & 0,04 \\
\hline Sintomas & Obeso & 5,4 & 2,4 & 104 & 0,31 & 0,11 \\
\hline emocionais & Eutrófico & 4,3 & 3,1 & 1,04 & 0,31 & 0,11 \\
\hline Problemas de & Obeso & 2,3 & 1,8 & 022 & 083 & -006 \\
\hline conduta & Eutrófico & 2,1 & 1,6 & $0, \angle 2$ & 0,03 & $-0,00$ \\
\hline
\end{tabular}




\begin{tabular}{cllllll}
\hline Hiperatividade & Obeso & 3,7 & 2,2 & \multirow{2}{*}{0,25} & 0,80 & $-0,10$ \\
& Eutrófico & 3,5 & 2,2 & & & \\
Problemas de & Obeso & 1,7 & 1,8 & $-0,11$ & 0,91 & 0,14 \\
relacionamento & Eutrófico & 1,8 & 1,5 & & & \\
Comportamento & Obeso & 8,4 & 1,4 & 0,72 & 0,47 & 0,17 \\
pro-social & Eutrófico & 7,8 & 2,9 & &
\end{tabular}

$\mathrm{Na}$ análise intragrupo para o sexo feminino, não foram identificadas diferenças estatisticamente significativas entre os resultados médios das crianças com obesidade e sem obesidade, nos diversos indicadores técnicos considerados. Ou seja, para as meninas o padrão de respostas aos vários instrumentos avaliativos aplicados não pareceu influenciado pela obesidade.

$\mathrm{Na}$ análise das correlações de seus resultados técnicos com o IMC foi possível identificar dois resultados estatisticamente significativos, para as variáveis A\% e $\mathrm{H} \%$ do Rorschach. Os achados apontaram moderada correlação positiva do H\% com IMC e associação negativa com A\%, sugerindo que o quanto maior o IMC das meninas, maior foi a tendência a produzir respostas de conteúdo humano e menos conteúdos animais. Ou seja, maior IMC pareceu se associar a maior interesse por contatos com as pessoas e menor espontaneidade e imaturidade. Mais uma vez é preciso lembrar que os achados com variáveis isoladas pouco significam do ponto de vista clínico em processos de avaliação psicológica, embora sejam explorações relevantes para se buscar compreender a dinâmica afetiva implicada em quadros de obesidade infantil.

Ainda no sentido de verificar possível influência da variável sexo sobre os resultados nos instrumentos avaliativos utilizados nesse trabalho, procurou-se examinar, para meninas e para meninos (análises intragrupo a partir do sexo), o número de indicadores emocionais (IE) presentes em seus DFH. Assim, para cada sexo, foram contadas as crianças que apresentaram ausência ou até um IE no desenho, as que 
tiveram dois IE no DFH e aquelas que produziram desenhos com três ou mais IE. Esses resultados podem ser visualizados na Figura 3, separando-se os casos com obesidade (15 para cada sexo) e sem obesidade (15 para cada sexo).

$$
\square \text { - } 1 \text { sinal } \square 2 \text { sinais } \quad \square \geq 3 \text { sinais }
$$

Meninas

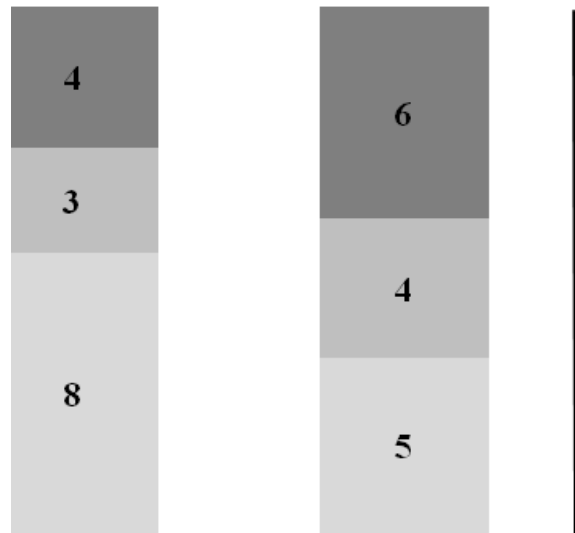

Grupo 1
Grupo 2
Meninos

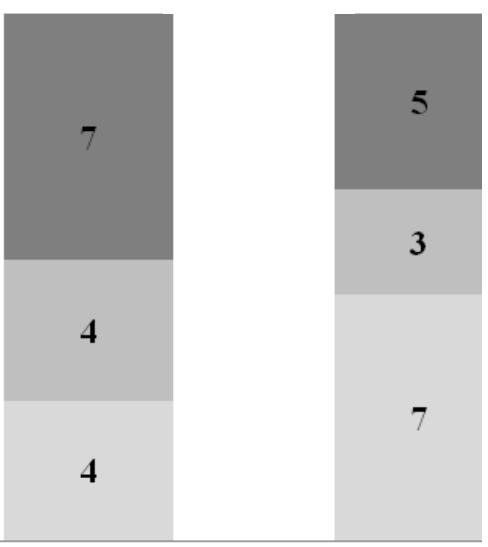

Grupo 1
Grupo 2

Figura 3: Distribuição das crianças a partir do sexo e do número de indicadores emocionais no DFH no grupo com obesidade (grupo 1) e sem obesidade (grupo 2).

A comparação estatística (teste Qui-quadrado) da distribuição dos casos nas variáveis consideradas apontou inexistir diferenças estatisticamente significativas entre as crianças subdivididas pelo número de IE presentes em seus DFH. Isso ocorreu tanto para o grupo feminino $\left(\chi^{2}=4,00, p=0,41\right)$, quanto no grupo masculino $\left(\chi^{2}=4,00\right.$, $p=0,26)$. Assim, pode-se inferir que possuir ou não obesidade, nesse grupo de crianças avaliadas, não pareceu interferir de modo estatisticamente significativo na quantidade de IE presentes em seus DFH, quando se realiza análise intragrupo para meninas e para meninos.

Por fim, foram realizadas análises específicas para avaliar eventual efeito da idade das crianças nos resultados. Optou-se por separá-las em dois grupos etários, a 
saber: a) sete a oito anos completos (13 crianças com obesidade e 14 crianças eutróficas), b) nove a 11 anos (17 crianças com obesidade e 16 eutróficas), comparando seus dados médios (teste $t$ de Student). Foram consideradas as variáveis principais dos instrumentos, tomadas em outras análises, ou seja, no DFH (Indicadores Emocionais e Evolutivos), no Rorschach (R, RA, Rec, Den, TL médio, TR médio, G\%, D\%, Dd\%, $\mathrm{Db} 1 \%, \mathrm{~F} \%, \mathrm{~F}+\%, \mathrm{~F}+\mathrm{ext} \%, \mathrm{~A} \%, \mathrm{H} \%, \mathrm{Ban} \%, 3 \mathrm{a}$. Fórm., e F. Angústia) e no SDQ (Pontuação Geral, Sintomas emocionais, Problemas de conduta, Hiperatividade, Problemas de relacionamento e Comportamento pro-social). Os resultados não revelaram quaisquer diferenças estatisticamente significativas entre as duas faixas etárias.

Numa nova tentativa analítica, comparou-se cada grupo etário específico de acordo com a classificação nutricional da criança (com e sem obesidade) e as variáveis dos testes psicológicos. A partir dessa análise inferencial, foram identificadas três diferenças estatisticamente significativas entre resultados médios das crianças com e sem obesidade no grupo mais jovem (crianças de sete e oito anos), a saber: tempo de reação médio (TRM) e a Fórmula da Angústia no Rorschach, além da escala de Hiperatividade no SDQ. O TRm foi significativamente $(t=2,328, p=0,028)$ mais elevado no grupo de crianças com obesidade $(34,0 \pm 13,3)$ do que no grupo de crianças eutróficas $(23,0 \pm 11,2)$. Já na Fórmula da Angústia, crianças com obesidade apresentaram significativamente $(t=2,365 ; p=0,026)$ valores mais elevados nesse indicador do Rorschach $(5,9 \pm 3,9)$ do que as crianças eutróficas $(2,6 \pm 3,5)$. E quanto à avaliação de Hiperatividade fornecida pelo SDQ, crianças com obesidade apresentaram resultados médios significativamente inferiores $(t=-2,492 ; p=0,020)$ nessa escala $(2,5 \pm 2,4)$, quando comparadas com crianças eutróficas $(5,1 \pm 2,8)$. Assim, entre as crianças com obesidade e menor idade indicadores sugestivos de maior tempo médio para responder aos 
estímulos do Rorschach e menos sinais de hiperatividade. A diferença identificada na Fórmula de Angústia do Rorschach deve ser relativizada, pois os valores apresentados pelas crianças foram reduzidos, não se constituindo efetivamente como indicador clínico de ansiedade.

Ao considerar para análise as crianças de nove 9 a 11 anos, a comparação dos resultados médios dos subgrupos com e sem obesidade revelou diferença estatisticamente significativa apenas na Terceira Fórmula Afetiva do Rorschach $(t=2,602 ; p=0,014)$. As crianças com obesidade tiveram valores significativamente mais altos $(39,5 \pm 9,3)$ quando comparadas com o grupo eutrófico $(31,7 \pm 7,7)$, embora a classificação final dessa fórmula seja a mesma para ambos os grupos (tipo ambigual).

Finalmente buscou-se comparar os grupos etários, com e sem obesidade, a partir do número de Indicadores Emocionais presentes no DFH. Esses resultados podem ser visualizados na Figura 4. 


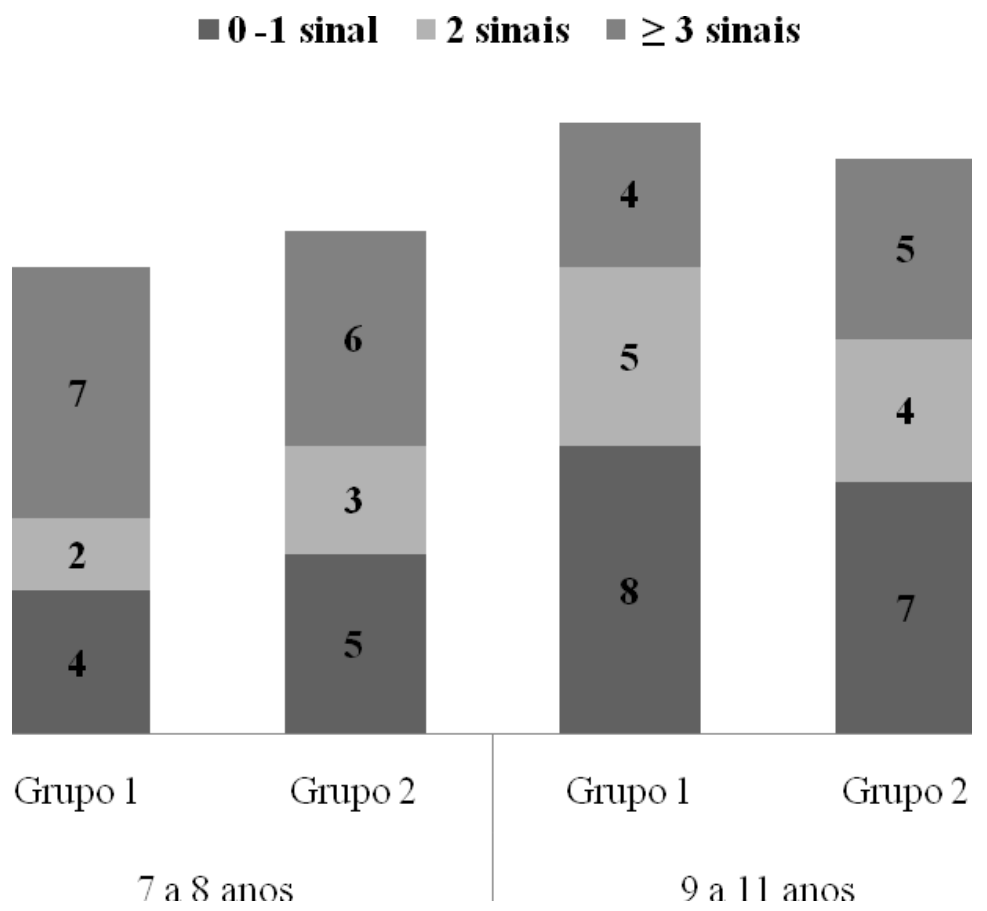

Figura 4: Distribuição das crianças com obesidade (Grupo 1) e sem obesidade (Grupo 2) de acordo com faixa etária e número de indicadores emocionais no DFH.

A comparação estatística (teste Qui-quadrado) da distribuição dos casos nas variáveis consideradas apontou inexistir diferenças estatisticamente significativas entre as crianças subdivididas pelo número de IE presentes em seus DFH. Isso ocorreu tanto para o grupo mais novo -7 a 8 anos $(\chi 2=0,351, p=0,839)$, quanto no grupo mais velho - 9 a 11 anos $\left(\chi^{2}=0,259, p=0,879\right)$. Assim, pode-se inferir que as faixas etárias aqui analisadas não pareceram interferir de modo estatisticamente significativo na quantidade de IE presentes em seus DFH, quando se realiza análise intragrupo. 


\subsection{Análise comparativa do Rorschach com grupo normativo}

Com relação ao Método de Rorschach torna-se relevante realizar breve comparação dos resultados aqui encontrados com aqueles apresentados por Fernandes (2010) e Raspantini (2010) para amostras normativas de seis a oito anos e de nove a 11 anos de idade, respectivamente. Com relação à produtividade, os resultados da amostra total do presente trabalho $(\mathrm{n}=60)$ parecem se aproximar dos achados dos dois estudos normativos, como pode ser visto na Figura 5.

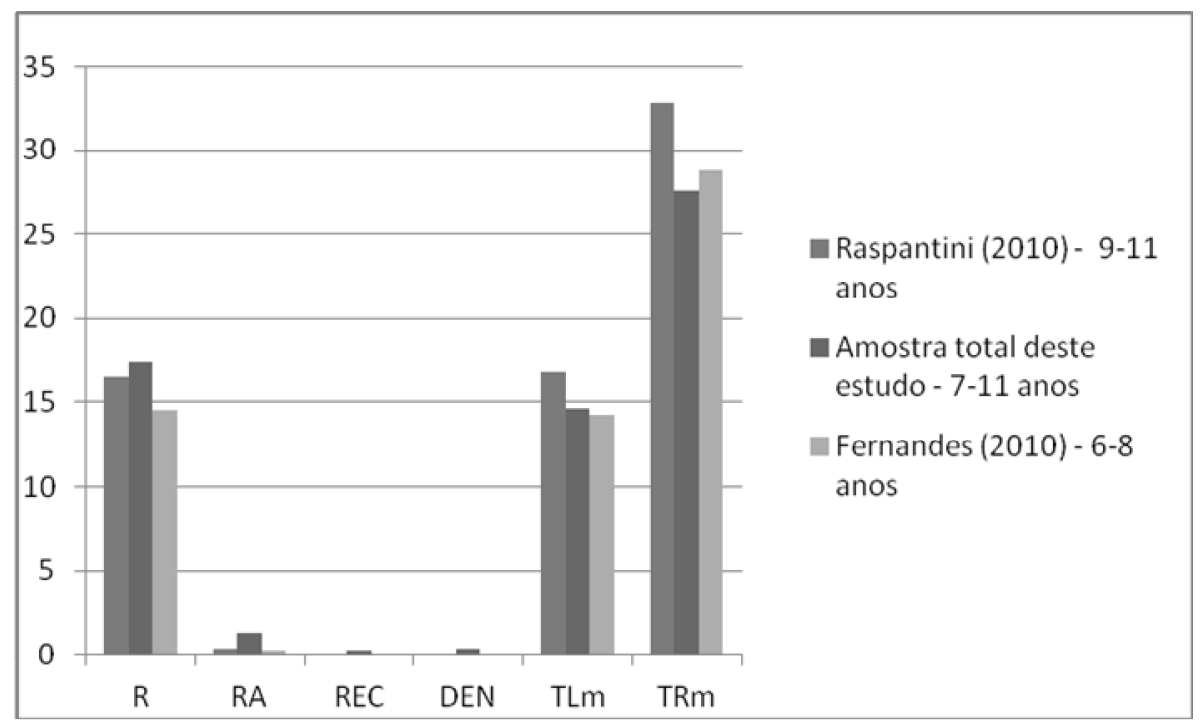

Figura 5: Distribuição dos resultados médios de produtividade no Rorschach do atual estudo $(n=60)$ em relação aos dados normativos de crianças.

Nota-se ligeiro aumento de RA nas crianças presentemente avaliadas, porém dada a baixa incidência desse indicador técnico, pouco pode ser depreendido a respeito. Pode-se visualizar que os participantes da atual amostra se mostraram levemente mais rápidos em seus processos associativos em relação aos dois estudos normativos, considerando o maior número de respostas em menor TRm. Tal diferença encontrada pode ser considerada pequena, porém é relevante refletir sobre sua possível associação 
ao contexto cotidiano de vida na contemporaneidade, onde há crescente valorização da agilidade e rapidez nas atividades e no ritmo de trabalho. Essa tendência foi vivenciada pela pesquisadora durante as aplicações, quando alguns participantes puderam verbalizar sua preocupação com o tempo, mesmo quando orientados a realizar a atividade livremente, sem controle temporal.

Referente aos modos de apreensão, os resultados aqui encontrados seguem a mesma tendência observada para a produtividade diante do Método de Rorschach. Os achados deste estudo localizam-se entre os resultados de Fernandes (2010) e Raspantini (2010). A Figura 6 demonstra a distribuição dos achados da amostra total $(n=60)$ em relação aos estudos normativos do Rorschach com crianças.

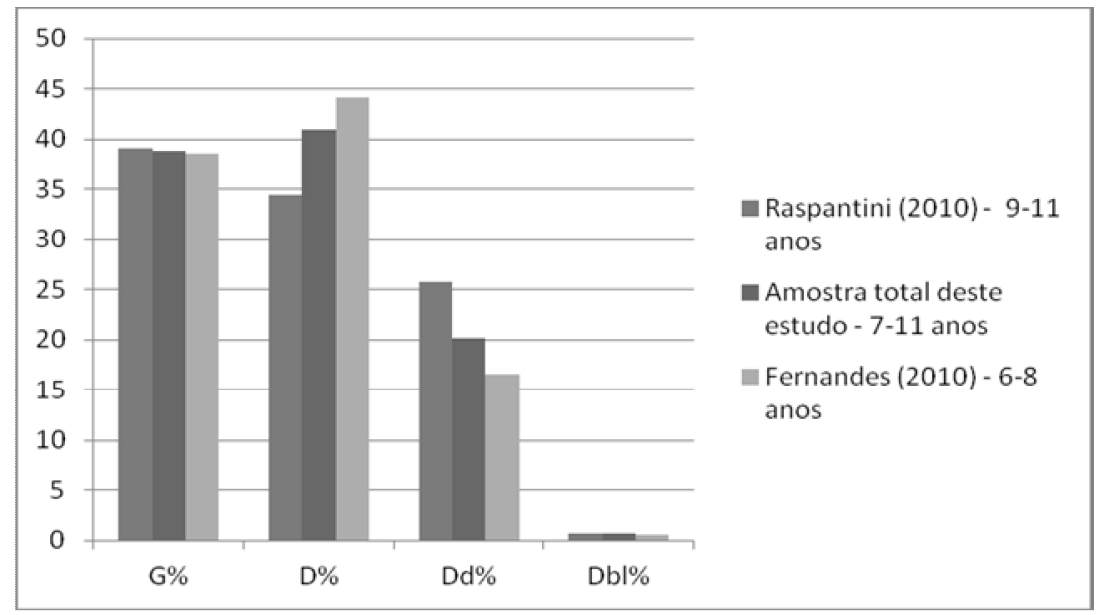

Figura 6: Distribuição dos resultados médios nos modos de apreensão do Rorschach do atual estudo (n=60) em relação aos dados normativos de crianças.

Os índices apontam grande similaridade entre os resultados das crianças presentemente avaliadas em comparação com aquelas dos estudos de padronização do Rorschach, no tocante à frequência de interpretação das áreas dos estímulos. $\mathrm{O}$ foco atencional das crianças volta-se aos elementos gerais e aos aspectos pregnantes de seus 
contextos ambientais, como expresso pelos indicadores $\mathrm{G} \%$ e $\mathrm{D} \%$, prioritários nas respostas das crianças.

A mesma aproximação entre os atuais achados da amostra geral de crianças em relação aos estudos normativos de Fernandes (2010) e Raspantini (2010) pode ser vista no tocante à distribuição dos conteúdos animais e humanos das respostas. Esses dados estão apresentados na Figura 7.

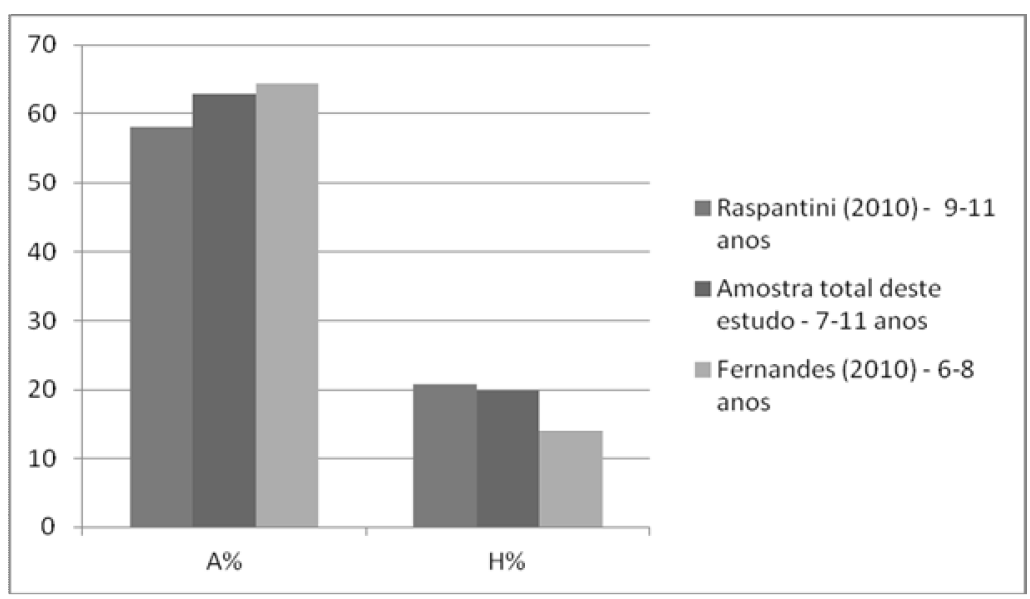

Figura 7: Distribuição dos resultados médios de conteúdos animais e humanos no Rorschach do atual estudo ( $n=60)$ em relação aos dados normativos de crianças.

É possível notar que as respostas de conteúdo animal ou humano constituem a maioria das interpretações oferecidas pelas crianças desse trabalho (médias: A\%=58,86; H\%=21,59), como também ocorreu nos estudos normativos do Rorschach com crianças. Observa-se, entretanto, que o aumento da idade parece favorecer a interpretação de respostas de conteúdos humanos em relação aos conteúdos animais. Pode-se pensar que o desenvolvimento de recursos psíquicos possibilite à criança mais velha identificar-se mais à figura humana, abrindo mão de pensamentos mais estereotipados e regressivos, como a identificação com animais. 
Por fim são apresentados os resultados das Fórmulas Afetivas identificadas no grupo atual $(n=60)$ e nos referenciais normativos. Esses dados podem ser visualizados na Figura 8.

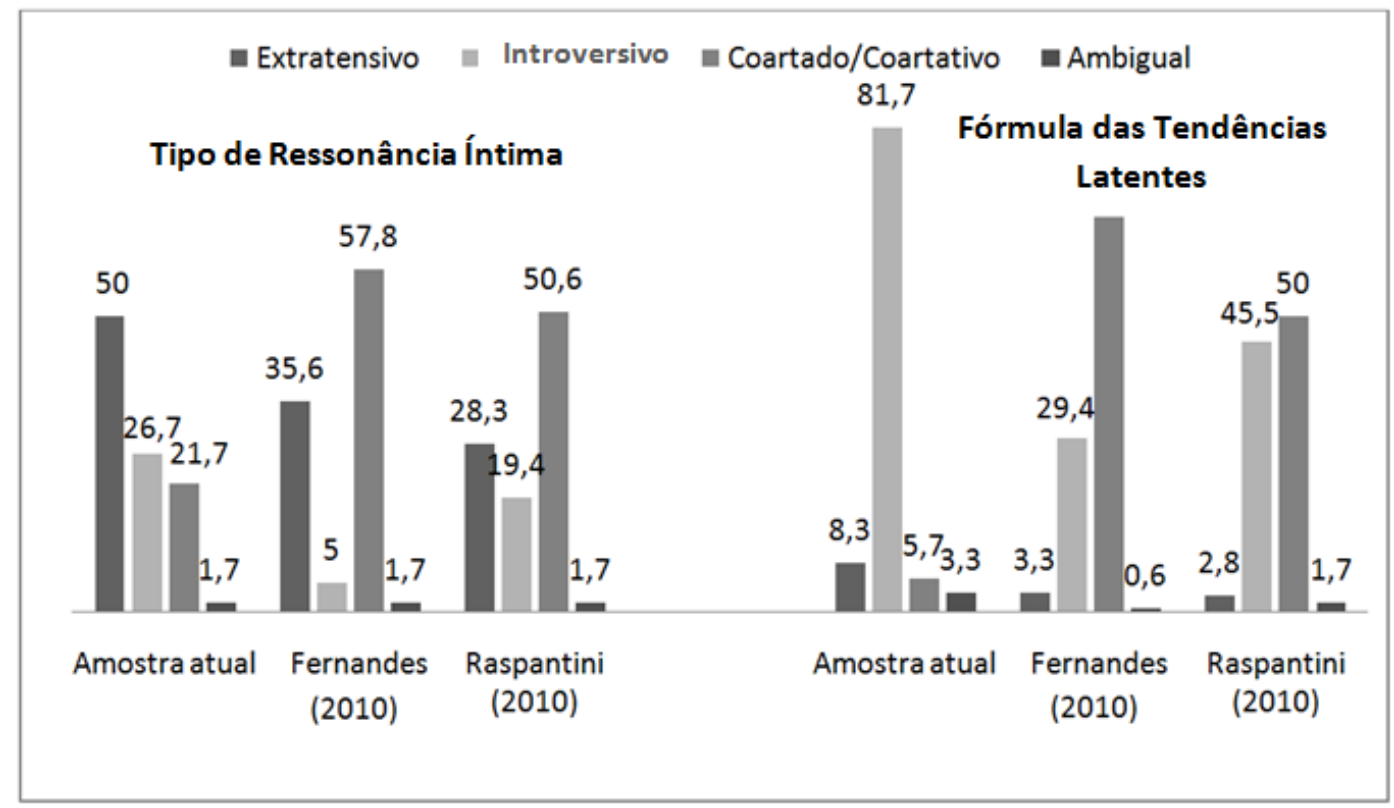

Figura 8: Distribuição de frequência (em porcentagem) dos casos nas fórmulas afetivas (TRI e TL) do Rorschach do atual estudo (n=60) em relação aos dados normativos de crianças.

Como é possível observar pela inspeção visual, existe considerável diferenciação entre os achados desses estudos. As crianças da amostra atual mostraram vivenciar a afetividade de maneira mais pronunciada, tanto no sentido da extratensividade quanto da introversividade (no caso do TRI, primeira fórmula afetiva), enquanto a maioria das crianças normativas apresentaram vivências mais inibidas (maioria de coartados e coartativos). Já nas tendências latentes (segunda fórmula afetiva), as crianças classificadas como introversivas no atual trabalho atingiram número muito superior de casos do que nos grupos normativos que, novamente, apresentaram predominantemente indicadores de inibição afetiva. 
Diante do exposto até o momento foi possível apresentar os resultados conforme os objetivos propostos ao presente estudo. Desta forma pôde-se caracterizar e comparar o padrão geral de respostas no Método de Rorschach e Desenho da Figura Humana (Koppitz, 1966) de crianças com obesidade em relação a crianças eutróficas, bem como indicadores de saúde mental a partir do Questionário de Capacidades e Dificuldades (SDQ). Da mesma forma, procurou-se comparar os resultados das crianças sob um olhar do significado clínico das variáveis, bem como verificar eventual influência do sexo e idade dos participantes em seus resultados nos instrumentos de avaliação psicológica. Pôde-se ainda testar a correlação entre os principais achados do Rorschach, DFH e SDQ com o índice de massa corporal das crianças, independentemente de grupos com classificação nutricional previamente estabelecida. Por fim, foi examinada a similaridade ou não dos resultados da presente amostra com os referenciais normativos do Rorschach, específicos para a faixa etária aqui avaliada. O conjunto dessas evidências passa, então, a ser explorado, numa perspectiva interpretativa reflexiva, no próximo tópico. 


\section{DISCUSSÃO}


Frente aos objetivos propostos para o presente estudo, foi possível levantar alguns dados relevantes referentes ao funcionamento psíquico de crianças obesas e eutróficas. As considerações a seguir têm a função de colaborar para a compreensão no campo científico da obesidade na infância a partir de perspectiva psicológica, com finalidade última de melhor cuidar das crianças acometidas de obesidade.

Primeiramente serão enfocados os resultados obtidos no Questionário de Capacidades e Dificuldades (SDQ), visando compreender a maneira como os pais e responsáveis percebem a criança em relação a sua saúde mental. De uma forma geral, pôde-se apreender que o conjunto das crianças foi majoritariamente percebido por seus responsáveis como adequados em termos desenvolvimentais. Tal achado pode ser considerado positivo e reafirmador dos critérios de inclusão e de exclusão utilizados no presente estudo, visto que os participantes foram selecionados por não apresentarem indicadores de transtornos ou graves dificuldades no desenvolvimento psicológico, podendo ser considerada similar ao esperado em termos da população infantil no Brasil.

Segundo a revisão de literatura realizada por Saur e Loureiro (2012), estudos de validade e fidedignidade do SDQ realizados no Brasil têm demonstrado bons índices psicométricos do instrumento, atestando seu adequado auxílio na identificação de problemas de saúde mental de crianças e adolescentes. Diante disso, pode-se dizer que os resultados no SDQ presentemente obtidos figuram como confiáveis e representativos de indicadores de saúde mental das crianças examinadas.

Em estudo sobre nível de saúde mental de crianças $(\mathrm{n}=143)$ de seis a 11 anos provenientes de escola pública de Ribeirão Preto, Cury e Golfeto (2003) usaram o SDQ respondido por pais/responsáveis. Seus dados indicaram que 45,8\% das crianças obtiveram altas pontuações no SDQ, alcançando a classificação clínica. Esses indicadores, em relação aos achados do presente estudo (onde 31,7\% da amostra foi 
considerada clínica, sendo 30,0\% no Grupo 1 e 33,3\% no Grupo 2), apontaram menor proporção de casos com indicadores de problemas na saúde mental nas crianças presentemente avaliadas. É possível pensar estes achados do ponto de vista da parcela amostral acessada, visto que nenhum dos dois estudos tinha intuito normativo, mas retratam diferentes parcelas de uma mesma população. Por outro lado, pode-se considerar o fator temporal como possível variável interveniente, o que exigira investigações de natureza longitudinal, ultrapassando os alcances dos atuais dados.

Com relação às análises do Desenho da Figura Humana (DFH), os resultados de comparação de médias dos dois principais indicadores, emocional e cognitivo, não evidenciaram diferenças estatisticamente significativas entre grupos de crianças com e sem obesidade. A amostra normativa de Hutz e Antoniazzi (1995), para a faixa etária equivalente a do presente estudo, obteve pontuação média igual a $17 \mathrm{em}$ Itens Evolutivos e 2,61 para Indicadores Emocionais. A análise comparativa dos dados brutos e dos percentis aqui encontrados em relação ao estudo normativo apontou resultados equivalentes para os Indicadores Emocionais e Itens Evolutivos, indicando sinais de desenvolvimento cognitivo e dificuldades emocionais próximas às esperadas para a faixa etária das crianças. Os atuais achados divergem das evidências derivadas do estudo de Azevedo (2003), cujos resultados apontam que os Indicadores "Figura Inclinada", "Omissão do Nariz" e "Braços Curtos" apareceram com maior frequência em crianças com obesidade. Mais uma vez, essas especificidades de dados empíricos devem ser tomadas em função da época e das características das amostras consideradas nos estudos, desafiando o campo de pesquisa a novas investigações para os devidos esclarecimentos.

Ao considerar os resultados obtidos no método de Rorschach, não foram identificadas diferenças estatisticamente significativas entre Grupo 1 e Grupo 2 nas 
variáveis relacionadas à produtividade ( $R, R A$, Recusa, Denegação). Contudo, o grupo de crianças com obesidade sinalizou necessitar de significativo maior tempo para produzir interpretações diante desse método projetivo, embora com similar número de respostas (diferença estatisticamente significativa em Soma do Tempo Total e TRm). Apesar dessa peculiaridade do Grupo 1, as médias encontradas nos indicadores de produtividade no Rorschach, em ambos os grupos, sugerem adequado padrão interpretativo aos cartões desse método de avaliação psicológica, sugerindo agilidade e bom funcionamento associativo-interpretativo nas crianças avaliadas.

A análise dos determinantes das respostas no Rorschach não sinalizou diferenças estatisticamente significativas entre os grupos. Houve apenas uma tendência à diferença estatisticamente significativa na variável Grande Cinestesia (K), porém com baixa incidência nos protocolos, o que relativiza seu significado geral. Os indicadores médios nesse método avaliativo permitem caracterizar as crianças como pouco vinculadas a determinantes formais para produzir suas respostas ao Rorschach. Porém quando recorreram aos contornos das manchas para interpretá-las, tiveram, no geral, adequado ajuste perceptivo e lógico em suas análises dos estímulos. Ambos os grupos utilizaram movimentos em suas respostas, bem como determinantes vinculados à cor, sugerindo sinais de envolvimento emocional e dinamismo psíquico em sua atividade interpretativa dos estímulos propostos.

A análise dos resultados médios de conteúdos e banalidades apresentados pelos dois grupos de crianças também demonstrou distribuição bastante semelhante. Foram identificadas apenas duas diferenças estatisticamente significativas entre as crianças com obesidade e aquelas eutróficas, a saber: a) conteúdo Simbólico (mais frequente nas crianças do Grupo 1); b) $3^{\text {a }}$ Fórmula Afetiva (com frequência superior no Grupo 1, embora classificadas na mesma faixa diagnóstica, como vivências ambiguais). Essas 
especificidades no padrão de respostas dos dois grupos de crianças devem ser relativizadas, pois ambas foram diminutas diante do conjunto de achados, bem como ocorreram em variáveis com reduzida incidência, diminuindo seu possível sentido interpretativo.

Foi identificada tendência à diferença estatisticamente significativa entre os grupos na variável A\%. Esse indicador mostrou-se mais frequente no Grupo 2, sugerindo tendência a maior conformismo e adaptação social nas crianças eutróficas. Porém, há que ser lembrado que esse grupo reagiu ao Rorschach com significativo menor tempo de resposta, de modo que a maior frequência de conteúdos animais pode estar associada a essa maior rapidez de reação, visto se tratar de um conteúdo, no geral, que exige menor elaboração por parte do respondente.

Tais achados médios parecem, a princípio, convergir com alguns dos estudos brasileiros acessados na literatura da área, tendo em conta a importância estabelecida às ressalvas culturais neste campo de estudo. O trabalho de Cardoso e Carvalho (2007), que estudou a personalidade a partir de traços específicos (lócus de controle e na ansiedade traço-estado) em 19 crianças de 10 a 12 anos que frequentavam um programa de cuidado à obesidade, e examinou seus resultados a partir dos levantamentos normativos dos instrumentos escolhidos, descreveram seus participantes como dentro da média populacional comparável. No presente estudo, os traços de personalidade avaliados também não apresentaram tendências específicas no grupo de crianças com obesidade.

Da mesma forma, o trabalho de Caetano, Carvalho e Galindo (2005) investigou lócus de controle, autoconceito, ansiedade, maturação cognitivo-emocional e problemas comportamentais em 27 crianças obesas e 27 crianças não obesas. Na análise dos resultados médios, os grupos não se diferenciaram em relação às variáveis estudadas. 
Foram verificados resultados indicativos de sofrimento psicológico em ambos os grupos de crianças desse trabalho, segundo os pesquisadores, não permitindo associar obesidade a problemas psicológicos ou comportamentais.

Ainda, o estudo de Carvalho (2001), estudou aspectos do funcionamento psicológico como a maturidade emocional, lócus de controle e ansiedade em préadolescentes obesos, não encontrando em seus resultados uma tendência específica quanto ao lócus de controle ser mais interno ou externo. A ansiedade, enquanto traço de personalidade, situou-se dentro do esperado do normativo para a maioria dos participantes. Com relação aos resultados do DFH os índices relativos à Escala Evolutiva e à Escala Emocional encontraram-se também dentro do esperado, em sua maior parte. Os resultados da autora sugerem que não existe diferença entre préadolescentes obesos e pré-adolescentes em geral, quanto às variáveis estudadas. Entretanto, uma ressalva é feita quanto à obesidade poder estar associada a dificuldades de elaboração de aspectos evolutivos e emocionais para alguns indivíduos.

Ao se considerar achados provenientes de alguns indicadores do Método de Rorschach, selecionados por seu sentido clínico, pôde-se analisar sua interação com os Índices Emocionais (IEs) do DFH. A análise da capacidade de organização lógica e dos mecanismos de defesa baseados na contenção formal de afetos, representada pelos indicadores $\mathrm{F} \%$, F+\% e F+ext\%, não sinalizou diferenças estatisticamente significativas entre as crianças com obesidade e as eutróficas em função dos IEs de seus desenhos. Este achado pode descrever capacidades semelhantes entre as crianças dos dois grupos aqui avaliados no manejo de angústias e afetos por meio de recursos racionais e lógicos.

No tocante aos indicadores relativos ao modo de funcionamento do afeto, houve mais casos de crianças com obesidade e estilo extratensivo no Tipo de Ressonância Íntima e nas Tendências Latentes, enquanto a maioria das crianças eutróficas evidenciou 
sinais de coartação afetiva ou estilo ambigual nas fórmulas vivenciais do Rorschach, ainda que o teste qui-quadrado não tenha apontado diferenças significativas entre esses grupos. Já a Terceira Fórmula Afetiva revelou tendência à inversão desses tipos afetivos nos casos, no sentido de mais crianças eutróficas desejarem expressar de maneira mais aberta sua afetividade, mas novamente sem diferenças significativas entre os grupos. $\mathrm{O}$ cruzamento dessas variáveis do Rorschach com a presença de Indicadores Emocionais do DFH também não revelou associações estatisticamente significativas, sugerindo similaridade nas vivências emocionais das crianças avaliadas, independentemente de sua condição clínica (obesidade ou não).

É interessante observar tais resultados em contraste com alguns estudos da literatura da área. Azevedo (2003) descreve a criança com obesidade como mais inibida na interação com seus afetos. Segundo esse estudo, a partir do Desenho da Figura Humana, a omissão do nariz estaria associada à conduta tímida e retraída, com ausência de agressividade manifesta e interesse social reduzido; a presença de braços curtos sinalizaria tendência ao retraimento, ao fechamento sobre si e à inibição de impulsos; e o desenho inclinado estaria associado a insegurança, instabilidade emocional. Em contrapartida, os atuais resultados concordam com os achados de Braet (2005), que descreve escores mais altos em impulsividade e fatores de externalização (maior responsividade a estímulos externos, como cheiros e imagens, em detrimento de sensações internas como saciedade) como traços de personalidade em crianças com obesidade.

Poder-se-ia pensar nesse conjunto de resultados empíricos a partir da teoria do desenvolvimento da libido (Abraham, 1924). Nessa concepção, é possível pensar a fase oral (estágio canibalesco) do desenvolvimento pulsional como dividida em duas etapas, uma primeira ligada ao ato de sugar, e a subsequente relacionada à atividade de morder. 
O autor apresenta o morder como relacionado originalmente aos impulsos sádicos, caracterizando os dentes como primeiro instrumento de dano ao mundo exterior. Assim, se relacionarmos a obesidade, em algum nível, à atividade alimentar, pode-se pensar que a ingestão do alimento, sua mastigação e incorporação ao corpo (destruição do objeto) poderia se vincular a manifestações, dentre outros processos, da agressividade da criança. Neste sentido, a criança com obesidade poderia encontrar forma de vazão de afetos agressivos e vivências ambivalentes do objeto de amor na atividade alimentar, o que, até certo ponto, favoreceria compreender maior número de casos de extratensividade nos estilos de vivência emocional das crianças com obesidade. Logicamente a constituição da personalidade é muito complexa e dependente de inúmeras variáveis e vivências, mas o argumento proposto visa a apenas hipotetizar que o estilo de vivência emocional possa se relacionar, de alguma maneira, com a ingestão alimentar aumentada, existente em alguns casos de obesidade. Essa hipótese, no entanto, exigiria investigação específica, ultrapassando os atuais achados.

Ao lado da questão de similaridades ou não entre características de personalidade de crianças com obesidade e eutróficas, é relevante considerar como o grupo de casos presentemente examinado se posiciona frente ao esperado no desenvolvimento típico para sua faixa etária, como apontado nos parâmetros normativos do método de Rorschach. Conforme foi possível observar, as crianças deste estudo (como um todo) apresentaram índices mais elevados de extratensividade e menor inibição afetiva do que os grupos normativos (Fernandes, 2010; Raspantini, 2010). É possível pensar que a distância temporal de cinco anos entre os estudos pode representar um espaço de tempo significativo para mudanças, visto o desenvolvimento acelerado da tecnologia e as práticas de estimulação precoce das crianças para a prática de atividades diversas. Esta hipótese leva em consideração argumentos apresentados no trabalho de 
Marafon e Papadopoulos (2015), onde apontam sinais de menor inibição afetiva e controle de impulsos das crianças na atualidade, associados a sobrecarga de estimulação ambiental.

Referente a indicadores do Rorschach relativos aos recursos individuais de contenção lógica do afeto $(\mathrm{FC}: \mathrm{CF}+\mathrm{C})$ e da angústia $(\mathrm{FE}: \mathrm{EF}+\mathrm{E})$, encontrou-se diferença significativa entre os grupos com obesidade e eutrófico. Houve mais casos de crianças com obesidade que sinalizaram adequados recursos de contenção dos impulsos $(\mathrm{FC}>\mathrm{CF}+\mathrm{C})$ e de angústia $(\mathrm{FE}>\mathrm{EF}+\mathrm{E})$, comparativamente ao grupo de crianças sem obesidade, entre os casos sem dificuldades emocionais (até dois IEs no DFH).

Frente a esses achados e às considerações teóricas prévias, é possível pensar que, em determinadas circunstâncias, a criança com obesidade pode encontrar em seu manejo afetivo alguma contenção da impulsividade por meio de sua expressão concreta (ingestão alimentar, ganho de peso), em que o próprio corpo funcionar como continente afetivo. Ainda que seja um recurso desenvolvimental menos elaborado, a contenção corporal de necessidades afetivas pode exercer papel importante para alívio de vivências emocionais. Essa diretriz interpretativa, embora ousada, parece interessante ao estimular reflexão sobre possíveis intervenções com as crianças com obesidade, no sentido de estimular sua contenção de afetos por meio de processos de simbolização, de caráter mais abstrato (possivelmente de ordem lógica, cognitiva) para realizar a função de continência, em lugar do recurso de ordem concreta (corporal), possivelmente utilizado em casos com estilo afetivo do tipo extratensivo.

Ao tomar para análise as variáveis do Rorschach relacionadas à proporção dos determinantes movimento $(\mathrm{K}: \mathrm{kan}+\mathrm{kob}+\mathrm{kp})$, nas respostas dos dois conjuntos de crianças, notou-se similaridade entre os grupos. Houve predomínio das pequenas cinestesias nos protocolos, resultado adequado para a faixa etária. A ausência de 
diferenças estatisticamente significativas entre Grupo 1 e Grupo 2 também ocorreu com os dados referentes a Fórmula da Angústia, com baixos valores percentuais. Esses dois indicadores do Rorschach também não mostraram relação com o número de sinais emocionais do DFH. Assim, esses achados apontaram que as crianças de ambos os grupos acompanham os sinais encontrados na população de referência.

A análise dos relacionamentos interpessoais avaliada pela proporção de $(\mathrm{H}: \mathrm{Hd})$ do Rorschach também não revelou diferença estatisticamente significativa entre os grupos, ainda que as crianças com obesidade apresentaram frequência ligeiramente maior de interpretações humanas totais em relação às parciais. A figura humana total estaria relacionada a integridade no processo de identificação com a representação humana e, consequentemente, indicaria recursos mais favoráveis para as relações interpessoais. No entanto, cumpre destacar que esses dados não mostraram interação estatisticamente significativa com os Indicadores Emocionais do DFH.

Ainda como forma alternativa de análise dos atuais dados, a correlação entre o Índice de Massa Corporal e as médias de algumas das principais variáveis dos instrumentos de avaliação psicológica utilizados não evidenciou diferenças estatisticamente significativas entre G1 e G2. Como exceção está o tempo médio para a produção de respostas, que se mostrou significativamente maior nas crianças com IMC mais elevado.

A hipótese do sexo como variável influente nos resultados de crianças com obesidade e eutróficas foi examinada por diferentes estratégias técnicas. Os dados gerais, independente do peso da criança, mostraram que meninas apresentaram mais Respostas Adicionais (RA) que os meninos, enquanto estes apresentaram maior frequência de respostas Globais (G\%) como modo de apreensão, sendo que as meninas evidenciaram certa tendência $(p=0,09)$ a apresentarem mais respostas de Detalhe $(\mathrm{D} \%)$. 
Em relação ao conteúdo, os meninos apresentaram mais conteúdos animais (A\%) e menos conteúdos Humanos $(\mathrm{H} \%)$ do que as meninas. Estes achados podem ser pensados, como propõe Koppitz (1966), como indicadores de especificidades no desenvolvimento infantil nessa faixa etária avaliada, uma vez que meninas podem apresentar amadurecimento cognitivo superior ao de meninos entre sete e nove anos, o que tende a se alterar nos anos posteriores de vida.

Das análises realizadas ainda com a variável sexo, foi possível identificar diferença estatisticamente significativa entre crianças com obesidade e eutróficas na escala Hiperatividade do SDQ, ao se considerar apenas o subgrupo masculino. Encontrou-se que meninos eutróficos foram percebidos como mais hiperativos por seus pais e/ou responsáveis em relação aos meninos com obesidade. Poder-se-ia pensar, portanto, que meninos que mais se movimentam (pontuação alta em hiperatividade) sinalizaram IMC compatível com o esperado para sua idade, o que parece compreensível em termos gerais (por uma questão de gastos energéticos).

No entanto, essas associações entre variáveis clínicas não devem ser olhadas de modo simplista. Como argumentam Stivanin, Scheuer e Assumpção Jr. (2008), o comportamento hiperativo se associa à idade, já que na medida em que as crianças vão adquirindo mais recursos expressivos passam a necessitar menos da atividade motora para se comunicarem, controlando melhor seus atos motores. Outra forma possível para se tentar compreender a menor hiperatividade em meninos obesos, seria entender o seu estilo de comportamento alimentar como uma estratégia expressiva relevante de suas necessidades, recorrendo menos às formas motoras para se comunicar. Esse caminho interpretativo consideraria, então, a obesidade como maneira encontrada pela criança para se expressar/comunicar. 
No entanto, esse resultado contraria achados de White, Nicholls, Christie, Cole e Viner (2012). Esses pesquisadores descreveram a hiperatividade infantil como preditora de obesidade em idades posteriores, inclusive relacionando-a com a dificuldade da contenção de impulsos.

Ao tomar para análise especificidades de resultados encontrados no grupo feminino aqui avaliado, pode-se destacar o tipo de conteúdo prevalente no Rorschach de crianças com e sem obesidade. O grupo das meninas com obesidade apresentou significativamente mais interpretações de conteúdos humanos que seus pares eutróficos, enquanto este grupo apresentou significativamente mais conteúdos animais que o grupo de meninas com obesidade. A identificação com a figura animal pode se associar a imaturidade no desenvolvimento, expressões de ordem mais primitiva, como também a conformismo e estereotipia na forma de pensar. Assim, poder-se-ia pensar que as meninas sem obesidade sinalizaram mais indicadores de imaturidade e conformismo em seu desenvolvimento. Mais uma vez, esse resultado segue direção divergente do encontrado por Cobreros (2008). Ao avaliar crianças com obesidade e crianças diabéticas, classificadas como "doenças crônicas", encontrou, como elementos comuns nesses casos, escores sugestivos de intelectualidade deficitária e pensamento concreto, com lentidão na aprendizagem e nos processos de compreensão.

É interessante notar que, tanto no grupo masculino quanto no grupo feminino, ao comparar crianças com e sem obesidade, surgiram algumas marcas específicas em sua capacidade de elaboração cognitiva e afetiva. Assim podem ser compreendidos os sinais de imaturidade na coordenação afetiva e de hiperatividade dos meninos eutróficos, bem como o conteúdo destacado na interpretação do Rorschach em meninas eutróficas, também associado à imaturidade. Estas particularidades dos subgrupos de crianças, ainda que sob necessidade de cautela interpretativa e reserva devido ao reduzido número 
de indicadores, podem contribuir para a idéia de que a obesidade ou ganho de peso pode estar servindo, de maneira pouco adaptativa, visto que pode acarretar diversas complicações físicas, como recurso interno para lidar com angústias e afetos e, possivelmente, colaborar para o desenvolvimento mais positivo da criança de sete a 11 anos.

Se considerada essa explanação interpretativa, ainda deve ser tomada com ressalvas no sentido de estar voltada para a faixa etária avaliada. Isso porque, como mostram outros trabalhos (Incledon, Wake \& Hay, 2011), a adolescência parece ser uma fase em que a própria obesidade e sobrepeso podem servir como variável de sofrimento psíquico ao jovem, sobretudo no âmbito social.

Além disso, quando observamos o quadro da frequência dos Indicadores Emocionais do DFH segundo o sexo, é possível observar que meninos com obesidade apresentaram mais sinais de problemas emocionais do que as meninas com obesidade, ainda que a comparação entre grupos não tenha mostrado diferenças estatisticamente significativas. Este dado, entretanto, não acompanha tendência identificada na literatura científica da área, onde frequentemente o sexo feminino é apontado como mais vulnerável a problemas emocionais, sobretudo ansiedade e depressão (Cornette, 2008; De Niet \& Naiman, 2011; Fabricatore \& Wadden, 2004; Harriger \& Thompson, 2012; Incledon, Wake \& Hay, 2011; Rees, Oliver, Woodman \& Thomas, 2011; Wardle \& Cooke, 2005). Talvez isso se deva às faixas etárias diferentes consideradas nos vários estudos que, em sua maioria, envolveram também adolescentes.

No presente trabalho também não foram identificadas diferenças estatisticamente entre os subgrupos etários aqui considerados (sete a oito anos X nove a 11 anos). Diante desses achados e das considerações prévias da literatura científica, pode-se argumentar no sentido que a idade pode passar a ser uma variável importante a 
partir da adolescência, não sendo tão relevante em idades mais jovens. Neste sentido, a réplica deste trabalho com uma faixa etária mais velha poderia ser de grande valor para a compreensão da obesidade, a partir da vertente da organização psíquica e possibilidades de expressão de afetos e angústias.

A fim de ampliar a presente discussão, é interessante apresentar dados do Sistema de Vigilância Alimentar Nutricional (SISVAN, 2015) que revelam a proporção anual da classificação nutricional por idade, nos diferentes estados do Brasil. Segundo esse órgão, no ano de 2015, a distribuição nutricional das crianças do Estado de São Paulo, na faixa etária de sete a 10 anos, foi a seguinte: 1,6\% com magreza acentuada; $2,1 \%$ de com magreza; $59,9 \%$ com eutrofia; $18,1 \%$ com sobrepeso; $11,8 \%$ com obesidade; 6,6\% com obesidade grave. Este dado revela que, pelos critérios de inclusão e de exclusão do atual estudo, de antemão seriam excluídos $21,7 \%$ da população de referência no processo inicial de seleção dos participantes. Além disso, há que se comentar que a população eutrófica representaria apenas $60,0 \%$ da população. Desse modo, a amostra de conveniência composta tende a não representar a diversidade de casos existentes na população, o que representa relevante limite a ser comentado nesse momento reflexivo sobre os achados.

Diante dessas considerações, podem ser menos surpreendentes as diferenças identificadas entre os atuais resultados e evidências da literatura científica da área, circunscrevendo algumas particularidades encontradas como possíveis especificidades amostrais desse estudo. Apesar desse limite técnico, os achados atuais foram enriquecedores para a compreensão da obesidade em crianças, uma vez que apontaram normalidade na maioria das variáveis relativas ao funcionamento lógico e afetivo, acompanhando referenciais normativos da faixa etária estudada. Este comentário se faz importante na medida em que há uma tendência geral e socialmente compartilhada de 
aproximar a eutrofia à saúde mental e normalidade, enquanto a obesidade seria, por princípio, associada a indicadores de dificuldades emocionais ou cognitivas. Nenhuma dessas direções interpretativas pode ser sustentada pelos atuais achados.

Com base nessa linha interpretativa faz-se possível pensar que cada indivíduo encontra maneiras ou recursos, em cada fase de seu desenvolvimento, auxiliares para expressar suas angústias internas e equilibrar seu psiquismo. Essas diferentes estratégias expressivas do mundo interno podem resultar em desfechos desenvolvimentais bastante variados, alguns inclusive menos adaptativos e de risco à saúde, como no caso da obesidade.

A possibilidade de reconhecer o ganho de peso como uma alternativa para lidar com elementos internos pode servir para reconhecer a eventual funcionalidade dessa estratégia defensiva naquele indivíduo e, a partir desse reconhecimento, considerar outros recursos, mais adaptativos, que poderiam ser estimulados e apoiados para substituir o caminho da ingestão alimentar/ganho de peso. Essa reflexão poderia auxiliar a criança com obesidade a receber cuidados multidisciplinares mais indicados a suas necessidades de desenvolvimento, não apenas focados em questões de dieta alimentar. Pode-se inclusive aqui arriscar a hipótese de que estimular a redução do peso sem considerar a função que a obesidade exerce naquele determinado psiquismo pode dificultar o próprio equilíbrio psíquico infantil, o que merece a devida investigação específica em trabalhos futuros. 
6. CONSIDERAÇÕES FINAIS 
Frente aos achados do presente trabalho é possível notar que os resultados das crianças avaliadas, independentemente de sua condição clínica (com ou sem obesidade), acompanharam de forma bastante próxima os padrões esperados para sua faixa etária, conferindo a elas indicadores de adequado desenvolvimento psíquico. Assim, pode-se inferir que, em termos desenvolvimentais e estruturais, as crianças com obesidade se encontram com mesmos potenciais e recursos que seus pares, dentro das informações disponíveis pelos instrumentos de avaliação psicológica aqui utilizados. Não foi possível identificar características específicas de personalidade diretamente associadas com obesidade infantil, a partir do grupo avaliado.

Como possível contribuição reflexiva derivada desse trabalho, poder-se-ia pensar a obesidade como recurso psíquico encontrado por crianças para lidar com seus afetos e necessidades psíquicas, embora pouco adaptativo, ocupando espaço importante e digno de reconhecimento na forma de sua organização e equilíbrio psíquico. Esta possibilidade se faz importante na medida em que o olhar multidisciplinar que se dedica aos cuidados dos quadros de obesidade poderia se beneficiar ao considerar o pilar do psiquismo como aspecto igualmente fundamental na determinação de propostas interventivas. Nesse sentido, estratégias de intervenção que auxiliem o desenvolvimento de processos de abstração na expressão afetiva, que atendam as necessidades afetivas infantis, podem favorecer desfechos mais adaptativos e que contemplem a integralidade de seu desenvolvimento.

Diante do exposto até o momento, pode-se comentar que os objetivos propostos para o presente trabalho foram alcançados. Os resultados aqui apresentados fornecem evidências empíricas relevantes sobre características da organização e funcionamento psíquico de crianças com e sem obesidade, possibilitando compreender algumas especificidades do desenvolvimento infantil e da complexidade inerente aos quadros da 
obesidade nessa faixa etária. Foram propostas hipóteses compreensivas sobre os achados, bem como seus limites interpretativos, com sugestões para futuras investigações científicas nesse complexo tema. 


\section{REFERENCIAS ${ }^{1}$}

${ }^{1}$ De acordo com padrão APA - American Psychological Association, adaptado pelo Sistema Integrado de Bibliotecas - USP. 
Abraham, K. (1924). Breve estudo do desenvolvimento da libido visto à luz das perturbações mentais. In: Teoria Psicanalítica da Libido (C. M. Oticica, trad., pp. 81-160). Rio de Janeiro: Imago (Trabalho original publicado em 1924).

Angelini, A. L., Alves, I. C. B., Custódio, E. M., Duarte, W. F. \& Duarte, J. L. M. (1999). Matrizes Progressivas Coloridas de Raven: Escala Especial. Manual. São Paulo: CETEPP.

Anzieu, D. (1986). Os métodos projetivos (5 $5^{\mathrm{a}}$ ed.). Rio de Janeiro: Campus LTDA.

Araújo, M. F. (2007). Estratégias de diagnóstico e avaliação psicológica. Psicologia: teoria e prática, 9(2), 126-141.ISSN 1516-3687.

Arteche, A. X. (2006). Indicadores emocionais do desenho da figura humana: Construção e validação de uma escala infantil. Tese de Doutorado, Universidade Federal do Rio Grande do Sul, Porto Alegre, Rio Grande do Sul.

Azevedo, M. A. S. B. (2003). A criança obesa: um estudo exploratório da personalidade através do desenho da figura humana e dos indicadores emocionais de Koppitz. Boletim de psicologia, 53(118), 49-72.

Azoulay, C., Emmanuelli, M., Rausch de Traubenberg, N., Corroyer, D., Rozencwajg, P. \& Savina, Y. (2007). Les données normatives françaises du Rorschach à l'adolescence et chez Le jeune adulte. Psychologie Clinique et Projective, 13, 371-409.

Baum, A. \& Posluszny, D. M. (1999). Health Psychology: mapping biobehavioral contributions to health and illness. Annual Reviews Psychology, 50, 137-163.

Braet, C. (2005). Psychological profile to become and to stay obese. International Journal of Obesity (London), 29(Suppl 2), S19-S23.

Brasil. Ministério do Planejamento, Orçamento e Gestão, Instituto Brasileiro de Geografia e Estatística, Pesquisa de orçamentos familiares 2008-2009. Antropometria e Estado Nutricional de Crianças, adolescentes e adultos no Brasil. Rio de Janeiro: IBGE; 2010.

Calderón, C., Forns, M. \& Varea, V. (2010). Implicación de la ansiedad y la depresión en los trastornos de alimentación de jóvenes con obesidad, Nutrición Hospitalaria; 25(4), 641-647.

Capitão C. G., Scortegagna, S. A. \& Baptista, M. N. (2005). Importância da Avaliação Psicológica na Saúde. Avaliação Psicológica, 4(1), 75-82. 
Cardoso, L. K. O. \& Carvalho, A. M. P. (2007). Avaliação psicológica de crianças acompanhadas em programa de atenção multiprofissional à obesidade. InterfaceComunicação, Saúde, Educação, 11(22), 297-312.

Carvalho, A. M. P. (2001). Maturidade emocional, lócus de controle e ansiedade em pré- adolescentes. Paidéia (Ribeirão Preto), 11(20), 39-47.

Carvalho, A. M. P., Cataneo, C., Galindo, E. M. C., \& Malfará, C. T. (2005). Auto conceito e imagem corporal em crianças obesas. Paidéia (Ribeirão Preto), 15(30), 131-139. ISSN 0103-863X

Cataneo, C., Carvalho, A. M. P., \& Galindo, E. M. C. (2005). Obesidade e aspectos psicológicos: maturidade emocional, auto-conceito, lócus de controle e ansiedade. Psicologia: Reflexão e Crítica, 18(1), 39-46. ISSN 0102-7972

Chagnon, J. Y. (2014). Histoire et développements contemporains de l'école de Paris. Em S. R. Pasian [et al.]. (Organizadores), VII Congresso da Associação Brasileira de Rorschach e Métodos Projetivos. Ribeirão Preto, São Paulo.

Cobreros, R. R. (2008). Desarrollo evolutivo, personalidad y nivel de adaptación de un grupo de menores obesos. Apuntes de Psicología, 26 (3), 411-426.

Cornette, R. (2008). The Emotional Impact of Obesity on Children.Worldviews on Evidence-Based Nursing, 5(3), 136-141.

Cruz, R. M. (2004). Parecer e laudo. In: Cruz, R. M., Alchieri, C., Sardá Jr., J. J. (2002/2004). Avaliação e medidas psicológicas: produção do conhecimento e da intervenção profissional. São Paulo: Casa do Psicólogo.

Cunha, J. A.(2007). Psicodiagnóstico-V. (5ª ed.). Porto Alegre: Artmed.

Cury, C. R., Golfeto, J. H. (2003). Strengths and difficulties questionnaire (SDQ): a study of school children in RibeirãoPreto. Revista Brasileira de Psiquiatria. 25(3), $139-45$.

Cury-Jacquemin, R. P. (2012). Padrões normativos do Psicodiagnóstico de Rorschach em adolescentes de 12 a 14 anos. Tese de mestrado, Universidade de São Paulo, Ribeirão Preto, SP, Brasil.

De Niet, J. E., Naiman, D. I. (2011). Psychosocial aspects of childhood obesity.Minerva Pediatrica. 63(6), 491-505.

Dreyfus, M. (1993). Psychological approach to obesity in children and adolescents in a multidisciplinary consultation. Annales de Pediatrie (Paris), 40(5), 305-312. 
Fabricatore, A. N. \& Wadden, T. A. (2004). Psychological aspects of obesity. Clinics in Dermatology, 22(4), 332-337.

Fensterseifer, L. \& Werlang, B. S. G. (2008). Apontamentos sobre o status científico das técnicas projetivas. In: Villemor-Amaral, A. E., Werlang, B.S.G. orgs (2008). Atualizações em Métodos Projetivos para Avaliação Psicológica (pp. 15- 33). São Paulo: Casa do Psicólogo.

Fernandes, S. (2010). O Psicodiagnóstico de Rorschach em crianças de seis a oito anos. Dissertação de mestrado não publicada, Faculdade de Filosofia Ciências e Letras de Ribeirão Preto, Universidade de São Paulo, São Paulo, Brasil.

Ferreira, V. A. \& Magalhães, R. (2006). Obesidade no Brasil: Tendências Atuais. Revista Portuguesa de Saúde Pública, 24(2), 71-81.

Fleitlich, B., Cortazar, P. G. \& Goodman, R. (2000). Questionário de Capacidades e Dificuldades (SDQ). Revista Infanto (de Neuropsiquiatria da Infância e da Adolescência), 8, 44-50.

Gonçalves, S., Silva, D., \& Antunes, H. (2012).Psychosocial correlates of overweight and obesity in infancy. Journal of Human Growth and Development; 22(2), 179186.

Goodenough, F. L. (1951). Test de inteligencia infantil por medio del debujo de la figura humana (M. L. F Cabanera, trad.). Buenos Aires: Paidos.

Goodman, R. (1997). The Strengths and Difficulties Questionnaire: A Research Note. Journal of Child Psychology and Psychiatry, 38: 581-586.

Guo, S. S., Wu, W., Chumlea, W. C \& Roche, A. F. (2001). Predicting overweight and obesity in adulthood from body mass index values in childhood and adolescence. Obesity Research, 9(4), 239S-243S.

Hammer, E. F., (1991). Aplicações clínicas dos desenhos projetivos. São Paulo: Casa do Psicólogo.

Handelzalts, J. E., Yael Ben-Artzy-Cohen, Y. (2014). The Draw-A-Person Test and Body Image. Rorschachiana: Journal of the International Society for the Rorschach 35, 3-22.

Harriger, J. A., \& Thompson, J. K. (2012). Psychological consequences of obesity: weight bias and body image in overweight and obese youth. International Review of Psychiatry, 24(3), 247-253, doi: 10.3109/09540261.2012.678817. 
Hartmann, A. S., Czaja, J., Rief, W., \& Hilbert, A. (2010). Personality and psychopathology in children with and without loss of control over eating. Comprehensive Psychiatry, 51(6), 572-578.

Herzberg, E. \& Mattar, A. (2008). Instrumentos clínicos utilizados no Departamento de Psicologia Clínica da USP: 10 anos depois. Boletim de Psicologia, 58 (128), 39-54.

Hesketh, K. D., Campbell, K. J. (2010). Interventions to Prevent Obesity in 0-5 Year Olds: An Updated Systematic Review of the Literature. Obesity, 18(1), pp. 27S$35 \mathrm{~S}$.

Hilbert, A., Rief, W., Tuschen-Caffier, B., de Zwaan, M. \& Czaja, J. (2009). Loss of control eating and psychological maintenance in children: an ecological momentary assessment study. Behavioral Research and Therapy; 47(1), 26-33.

Hutz, C. S. \& Bandeira, D. R. (1995). Avaliação psicológica com o desenho da figura humana: Técnica ou intuição? Temas em Psicologia, 3, 35-41.

Hutz, C., \& Antoniazzi, A. (1995). O desenvolvimento do Desenho da Figura Humana em crianças de 5 a 15 anos. Normas para avaliação. Psicologia: Reflexão e Crítica, 8, 3-18.

Incledon, E., Wake, M., \& Hay M. (2011). Psychological predictors of adiposity: systematic review of longitudinal studies. International Journal of Pediatric Obesity, 6(2-2), e1-11, doi: 10.3109/17477166.2010.549491.

Jardim-Maran, M. L. S. (2011). O psicodiagnóstico de Rorschach em adolescentes: Normas e evidências de validade. Tese de doutorado, Universidade de São Paulo, Ribeirão Preto, SP, Brasil.

Jardim-Maran, M. L. C., Pasian, S. R., \& Okino, E. T. K. (2015). Normative Study of Rorschach (Parisian School) for Brazilian Adolescents. Paidéia (RibeirãoPreto), 25(62), 333-342.ISSN 1982-4327.

Kitamura, J. M., Delvan, J. S., Schlösser, A. \& Lançoni-Jr., A.C., (2013). Sintomas depressivos, indicadores emocionais e nível de maturidade mental em crianças com obesidade. Psicologia.com.pt, 1, 1-15.

Kobayashi, C., (2015). Os indicadores Emocionais de Koppitz no Desenho de Figura Humana de crianças de São Paulo. Tese de Doutorado, Instituto de Psicologia, Universidade de São Paulo. 
Koppitz, E. M. (1966). Emotional indicators on human figure drawings of children: A validation study. Journal of Clinical Psychology, 22, 313-315.

Landis J. R., Koch G. G., (1977). The measurement of observer agreement for categorical data.Biometrics; 33: 159-174.

Li, Y. P., Ma, G. S., Schouten, E. G., Hu, X. Q., Cui, Z. H., Wang, D., \& Kok, F. J. (2007). Report on childhood obesity in China (5) body weight, body dissatisfaction, and depression symptoms of Chinese children aged 9-10 years. Biomedical and Environmental Sciences, 20(1), 11-18.

Lilienfeld, S., Wood, J. \& Garb, H. (2000).The scientific status of projective techniques. Psychological Science in Public Interest, 1(2), 27-66.

Loureiro, S. R. \& Romaro, R. A. (1985). A utilização das técnicas projetivas, Bateria de Grafismo de Hammer e Desiderativo como instrumentos de diagnóstico: estudo preliminar. Arquivos Brasileiros de Psicologia, 37(3), 132-41.

Luiz, A. M. A. G., Gorayeb, R., \& Liberatore Júnior, R. R. (2010). Avaliação de depressão, problemas de comportamento e competência social em crianças obesas. Estudos de Psicologia (Campinas), 27(1), 41-48.

Marafon, G. \& Papadopoulos, C. R. (2015). Atenção: Modalidades atencionais e a problematizaçãodo diagnóstico de TDAH. Revista Educação Online, 18, jan-mai $2015,58-75$.

McCullough, N., Muldoon, O., \& Dempster, M. (2009). Self-perception in overweight and obese children: a cross-sectional study. Child: Care, Health and Development, 35(3), 357-364, doi: 10.1111/j.1365-2214.2008.00924.x.

Melo, M. E. (2011). Diagnóstico da Obesidade Infantil. Abeso - Associação Brasileira para o Estudo da Obesidade e da Síndrome Metabólica. Recuperado em 22 fevereiro, 2013, de http://www.abeso.org.br/pdf/Artigo\%20\%20Obesidade\%20Infantil\%20Diagnostico\%20fev\%202011.pdf.

Mériaux, B. G., Berg, M. \& Hellström, A. L. (2010). Everyday experiences of life, body and well-being in children with overweight. Scandinavian Journal of Caring Science, 24(1), 14-23.

Ministério da Saúde. Conselho Nacional de Saúde. Resolução No 196, de 10 de Outubro de 1996. Recuperado em 22 fevereiro, 2013, de http:// conselho.saude.gov.br/docs/resoluçoes/reso196.doc. 
Mishima, F. K. T., \& Barbieri, V. (2009).O brincar criativo e a obesidade infantil. Estudos de Psicologia (Natal),14(3), 249-255.

Nascimento, M., Gomes, M. C. \& Pasian, S. R. (no prelo). Estrutura fatorial das Matrizes Progressivas Coloridas de Raven. Psico USF, 21(2).

Ocampo, M. L. S. \& Arzeno, M. E. G. (1994). O processo psicodiagnóstico. In: Ocampo, M. L. S., Arzeno, M. E. G., Piccolo, E. G. \& colaboradores. (1994). $O$ processo psicodiagnóstico e as técnicasprojetivas (pp. 11-19) ( $7^{\mathrm{a}}$ ed.). São Paulo: Martins Fontes.

Ogden, C. L., Carroll, M. D., Kit, B. K., \& Flegal K. M. (2014). Prevalence of childhood and adult obesity in the United States, 2011-2012. Journal of the American Medical Association, 311(8), 806-814.

Organização Mundial da Saúde (2007). Curvas de crescimento para crianças de 05 a 19 anos. Recuperado em 10 de agosto de 2015, a partir do web-site: http://www.who.int/growthref/en/.

Pasian, S. R., Loureiro, S. (2010). Reflexões sobre princípios e padrões normativos do Rorschach. In: Pasian, S. R. (Org.). Avanços do Rorschach no Brasil. São Paulo: Casa do Psicólogo.

Public Health England, United Kingdom Government (2012). Recuperado em 20 de junho, 2014, a partir do web-site: http://www.noo.org.uk/NOO_about_obesity/adult_obesity/international.

Puder, J. J. \& Munsch, S. (2010). Psychological correlates of childhood obesity. International Journal of Obesity (London), 34(2), S37-43.

Raspantini, R. L. (2010). O Psicodiagnóstico de Rorschach em crianças de nove a 11 anos: Normas e evidências de validade. Dissertação de mestrado não publicada, Faculdade de Filosofia Ciências e Letras de Ribeirão Preto, Universidade de São Paulo, São Paulo, Brasil.

Rausch de Traubenberg, N. (1998). A prática do Rorschach. São Paulo: Vetor.

Rees, R., Oliver, K.,Woodman, J. \& Thomas, J. (2011). The views of young children in the UK about obesity, body size, shape and weight: a systematic review. BMC Public Health, 11:188, pp. 1-12.

Romo, L., Coëffec, A., \& Guilmin-Crepon, S. (2012). Évaluation de la personnalité, de la motivation au changement et des facteurs familiaux présents chez des jeunes suivis pour obésité. Revue Psychiatrique, 170(9), 649-653. 
Rosa, H. R. e Alves, I. C. B., (2014). Estudo normativo do Teste Goodenough-Harris em crianças na cidade de São Paulo. Boletim Academia Paulista de Psicologia, 34(87), 336-351.

Rosa, H. R. (2006). Teste Goodenough-Harris e indicadores maturacionais de Koppitz para o desenho da figura humana: estudo normativo para crianças de São Paulo. Tese de Doutorado, Instituto de Psicologia, Universidade de São Paulo.

Saur, A. M., \& Loureiro, S. R. (2012). Qualidades psicométricas do Questionário de Capacidades e Dificuldades: revisão da literatura. Estudos de Psicologia, 29(4), 619-629.

Saur, A. M., Pasian, S. R. \& Loureiro, S. R. (2010). Desenho da Figura Humana e avaliação da imagem corporal. Psicologia em Estudo, 15(3), 497-507.

Sistema de Vigilância Alimentar Nutricional - SISVAN (2015). Recuperado em 15 de outubro de 2015 a partir do web-site: http://dabsistemas.saude.gov.br/sistemas/sisvan/relatorios_publicos/relatorios.php.

Shin, N. Y., \& Shin, M. S. (2008). Body dissatisfaction, self-esteem, and depression in obese Korean children. Journal of Pediatrics, 152(4), 502-506.

Sisto, F. (2006). O Desenho da Figura Humana - Escala Sisto. São Paulo: Vetor

Sociedade Brasileira de Pediatria (2009). Avaliação nutricional da criança e do adolescente - Manual de Orientação / Sociedade Brasileira de Pediatria. Departamento de Nutrologia. - São Paulo: Sociedade Brasileira de Pediatria. 112 p. (pp.42-46)

Stivanin, L., Scheuer, C. I. e Assumpção Jr., F. B. (2008). SDQ (Strengthsand Difficulties Questionnaire): identificação de características comportamentais de crianças leitoras. Psicologia: Teoria e Pesquisa, v.24(4).

Sun, S. S., Liang, R., Huang, T. T-K., Daniels, S. R., Arslanian, S., Liu, K., Grave, G. D., \& Siervogel, R. M. (2008). Childhood Obesity Predicts Adult Metabolic Syndrome: The Fels Longitudinal Study. TheJournal of Pediatrics, 152(2),191-200.

Urbina, S. (2007). Fundamentos da testagem psicológica. Porto Alegre: Artmed.

Villemor-Amaral, A. E. \& Pasqualini-Casado, L. (2006). A cientificidade das técnicas projetivas em debate. Psico-USF, 11(2), 185-193. 
Vollrath, M. E., Hampson S. E., \& Juliusson, P. B. (2012). Children and eating. Personality and gender are associated with obesogenic food consumption and overweight in 6- to 12-year-olds. Appetite,58(3):1113-1117, doi: 10.1016/j.appet.2012.02.056.

Wardle, J., \& Cooke, L. (2005). The impact of obesity on psychological well-being. Best Practice \& Research: Clinical Endocrinology \& Metabolism,19(3), 421-440.

Weiner, I. B. (2000). Using the Rorschach properly in practice and research. Journal of Clinical Psychology, 56(3), 435-438.

Weiner, I. B. (1991). Editor's note: interscorer agreement in Rorschach research. Journal of Personality Assessment, 56, 1.

Weschler, S. (2003). O desenho da figura humana: Avaliação do desenvolvimento cognitivo de crianças brasileiras. Campinas: LAMP/PUC.

White, B., Nicholls, D., Christie, D., Cole, T. J., \& Viner, R. M. (2012). Childhood psychological function and obesity risk across the lifecourse: findings from the 1970 British Cohort Study. International Journey of Obesity (London),36(4), 511516.

World Health Organization. (2012). Obesity and overweight. Fact sheet $\mathrm{N}^{\circ} 311$. Recuperado em 27 fevereiro, 2013, a partir do web-site: http://www.who.int/mediacentre/factsheets/fs311/en/.

World Health Organization.(n.d.). Childhood overweight and obesity. Recuperado em 04 de abril, 2014, a partir do web-site: http://www.who.int/dietphysicalactivity/childhood/en/.

Yazigi, L. (2010). Fundamentação teórica do Método de Rorschach. In: Pasian, S.R., org. (2010). Avanços do Rorschach no Brasil (pp.7-30). São Paulo: Casa do Psicólogo.

Young-Hyman, D., Tanofsky-Kraff M., Yanovski, S. Z., Keil, M., Cohen, M. L., Peyrot, M., \& Yanovski, J. A. (2006). Psychological status and weight-related distress in overweight or at-risk-for-overweight children. Obesity (Silver Spring), 14(12), 2249-2258.

Zeller, M. H., Saelens, B. E., Roehrig, H., Kirk, S., \& Daniels, S. R. (2004). Psychological adjustment of obese youth presenting for weight management treatment. Obesity Research, 12(10), 1576-1586. 
ANEXOS 
ANEXO 1: Tabelas com curvas de crescimento (OMS, 2007) utilizadas na classificação do Índice de Massa Corporal das crianças neste estudo.

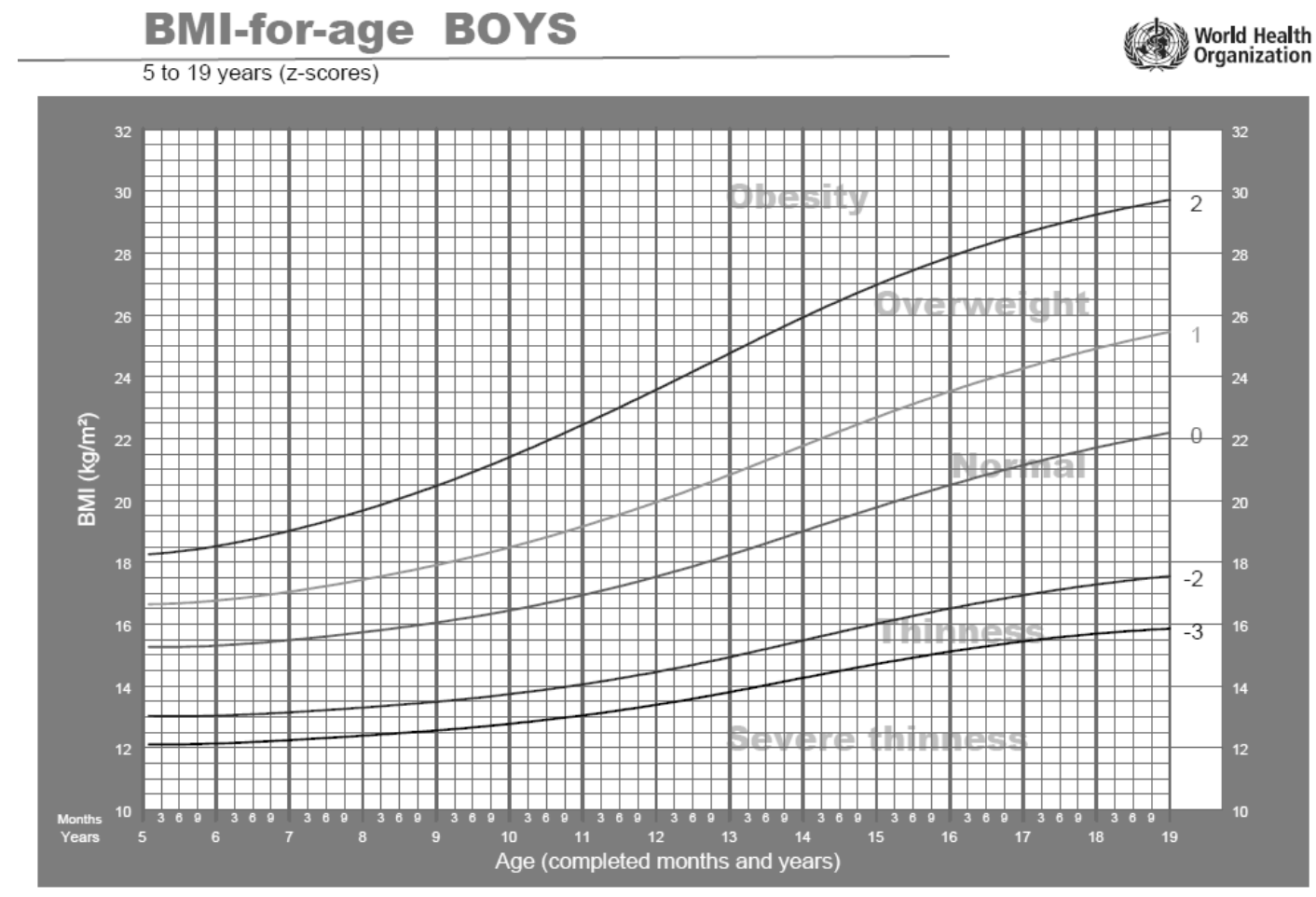

BMI-for-age GIRLS

2007 WHO Reference

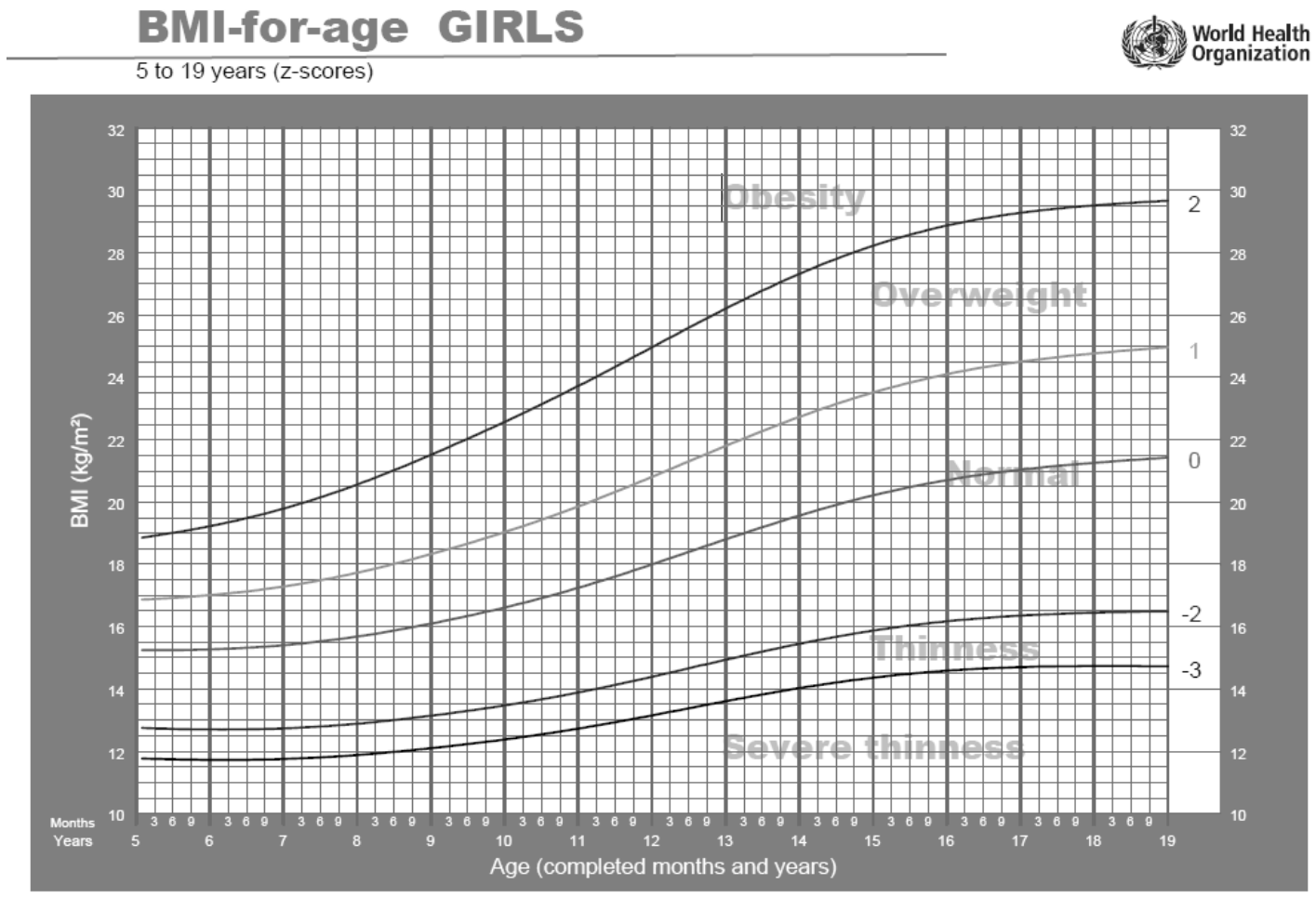

2007 WHO Reference 
ANEXO 2:Cópia do comprovante de exame e aceite do projeto de pesquisa pelo Comitê de Ética em Pesquisa com Seres Humanos da Faculdade de Filosofia, Ciências e Letras de Ribeirão Preto da Universidade de São

\section{Universidade de São Paulo Faculdade de Filosofia, Ciências e Letras de Ribeirão Preto Comitê de Ética em Pesquisa}

Campus de Ribeirão Preto

Of.CEtP/FFCLRP-USP/088-vjmc

Ribeirão Preto, 05 de novembro de 2013

Prezada Pesquisadora,

Comunicamos a V. Sa. que o projeto de pesquisa intitulado "INVESTIGAÇÃo dA ImAgem CoRPORAL E DinÂMICA PSíquiCA NA OBESIDADE INFANTIL" fOi analisado pelo Comitê de Ética em Pesquisa da FFCLRP-USP, em sua $125^{\text {a }}$ Reunião Ordinária, realizada em 31.10.2013, e enquadrado na categoria: APROVADO (CAAE n. $\left.{ }^{\circ} 21650813.2 .0000 .5407\right)$.

Solicitamos que eventuais modificações ou emendas ao projeto de pesquisa sejam apresentadas ao CEP, de forma sucinta, identificando a parte do projeto a ser modificada e suas justificativas, e que relatórios parciais e final sejam entregues, via Plataforma Brasil, conforme os itens X.1.3.d e XI.2.d, da Res. CNS n $466 / 2012$.

Atenciosamente,

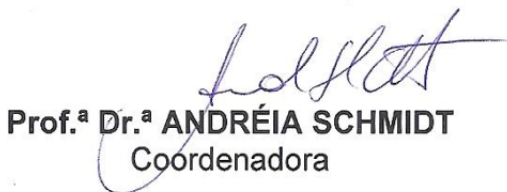

À Senhora

Carmem Gil Coury

Programa de Pós-graduação em Psicologia da FFCLRP USP

$\mathrm{C} / \mathrm{C}$ :

Profa. Dra. Sônia Regina Pasian

Departamento de Psicologia da FFCLRP USP

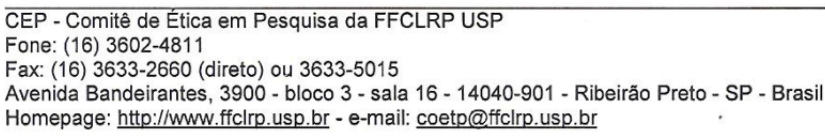

Homepage: http://www.ffclrp.usp.br - e-mail: coetp@ffclrp.usp.br

Paulo. 
ANEXO 3: Cópia do comprovante de exame e aceite do projeto de pesquisa pelo pela Secretaria Municipal de Saúde de Ribeirão Preto.

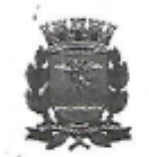

\title{
Prefeitura Municipal de Ribeirão Preto
}

Estado de São Paulo - Secretaria Municipal da Saúde

Of. $n^{2} 3877 / 13$

CAAP-fcp

Ribeirão Preto, 06 de setembro de 2013.

\author{
Prezada Orientadora, \\ Prof ${ }^{2}$. Dr ${ }^{\mathrm{d}}$. Sonia Regina Pasiana \\ Prezada pesquisadora \\ Carmen Gil Coury
}

A Diretora do Departamento de Atençāo à Saúde das Pessoas - Ilka Barbosa Pegoraro, a Enfermeira Responsável pelo Ambulatório de Nutrologia do Núcleo de Gestão Assistencial - Luciana Rigotto Parada Redigolo, bem como o Gerente do Núcleo de Gestão Assistencial - Carlos Eduardo de Oliveira ; manifestaram a concordância para a coleta de dados do projeto de pesquisa "INVESTIGAÇÃO DA IMAGEM CORPORAL E DINÂMICA PSIQQUICA NA OBESIDADE INFANTIL", nas dependências desta Secretaria da Saúde.

Conforme despachos no Processo Administrativo 0220130504404.

Como o seu campo de pesquisa se trata de Unidades de Saúde, ressaltamos que vossa senhoria se apresente à coordenaçăo destas com antecedência para agendamento da pesquisa, tendo em vista as rotinas destes estabelecimentos de saúde.

Informo que a pesquisa somente poderá iniciar quando obtiver a aprovaçãa do Comitê de Ética em Pesquisa da instituição proponente e a concordância da SMS-RP como instituição coparticipante.

Cordialmente,

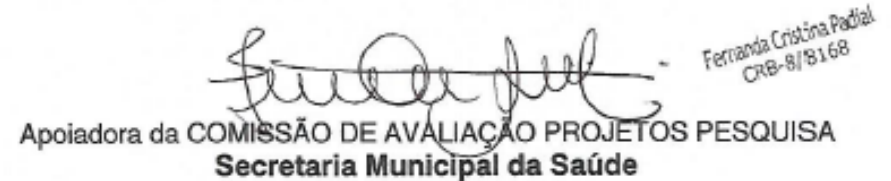

Secretaria Municipal da Saúde 
ANEXO 4: Tabela com resultados percentílicos dos estudos normativos de Fernandes (2010) e Raspantini (2010) utilizados para classificação das variáveis deste estudo.

\section{REFERÊNCIAS NORMATIVAS DO MÉTODO DE RORSCHACH PARA CRIANÇAS}

Suélen Fernandes (2011) - crianças de 6 a 8 anos

\begin{tabular}{|c|c|c|c|c|c|}
\hline Variável & Média & DP & P40 & P50 & P60 \\
\hline R & 14,5 & 4,2 & 13 & 13 & 14 \\
\hline G & 41,5 & 19,3 & 33,3 & 36,4 & 44,0 \\
\hline D & 44,8 & 16,6 & 41,7 & 46,2 & 50,0 \\
\hline Dd & 13,0 & 11,6 & 8,8 & 10,6 & 14,3 \\
\hline Db1 & 0,7 & 2,3 & 0 & 0 & 0 \\
\hline F\% & 66,4 & 16,0 & 64,3 & 68,3 & 72,4 \\
\hline F+\% & 76,6 & 16,4 & 72,7 & 78,1 & 83,3 \\
\hline F+ext\% & 76,0 & 14,0 & 72,7 & 76,5 & 81,8 \\
\hline A\% & 64,9 & 17,9 & 60,1 & 65,7 & 70,0 \\
\hline H\% & 13,9 & 12,1 & 9,1 & 12,5 & 15,5 \\
\hline Ban\% & 17,8 & 9,1 & 15,2 & 17,6 & 20,0 \\
\hline
\end{tabular}

Renata Raspantini (2011) - crianças de 9 a 11 anos

\begin{tabular}{|c|c|c|c|c|c|}
\hline Variável & Média & DP & P40 & P50 & P60 \\
\hline R & 16,5 & 7,5 & 13 & 14 & 16 \\
\hline G & 44,0 & 21,4 & 38,5 & 42,9 & 46,2 \\
\hline D & 33,0 & 15,6 & 29,9 & 33,3 & 37,5 \\
\hline Dd & 22,6 & 14,3 & 17,6 & 19,7 & 25,0 \\
\hline Db1 & 0,5 & 1,6 & 0 & 0 & 0 \\
\hline F\% & 63,0 & 16,5 & 60,0 & 65,7 & 69,1 \\
\hline F+\% & 76,0 & 17,2 & 73,1 & 77,8 & 81,8 \\
\hline F+ext\% & 75,7 & 15,1 & 75,0 & 77,8 & 81,8 \\
\hline A\% & 58,3 & 16,6 & 53,8 & 57,1 & 61,5 \\
\hline H\% & 21,1 & 13,2 & 15,8 & 19,7 & 23,5 \\
\hline Ban\% & 22,4 & 10,8 & 18,2 & 20,0 & 23,5 \\
\hline
\end{tabular}


APÊNDICE A: Carta de Apresentação do projeto para dirigentes dos estabelecimentos de saúde, para acordo de coleta de dados.

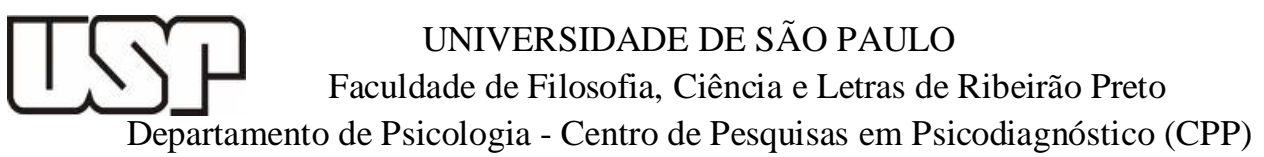

CARTA DE APRESENTAÇÃO

Estamos desenvolvendo uma pesquisa em Ribeirão Preto (SP), intitulada: "Investigação da Imagem Corporal e Dinâmica Psíquica na Obesidade Infantil". Enfocamos este tema em função do crescente aumento da obesidade em crianças brasileiras e a necessidade de novos conhecimentos a respeito, de modo a favorecer estratégias de cuidados com esses indivíduos. Essa pesquisa tem por objetivo conhecer características de personalidade de crianças obesas e com peso normal, de sete a onze anos, por meio de um processo de avaliação psicológica. Esse trabalho será desenvolvido sob responsabilidade da psicóloga Carmem Gil Coury, aluna de Mestrado em Psicologia na Faculdade de Filosofia, Ciências e Letras de Ribeirão Preto (FFCLRP) da Universidade de São Paulo (USP), e da Profa. Dra. Sonia Regina Pasian, professora do Departamento de Psicologia desta mesma Faculdade.

Essa pesquisa estudará crianças que, juntamente com seus responsáveis, buscaram tratamento especializado para a obesidade em instituições de saúde, bem como crianças com peso normal, na mesma faixa etária. Esta instituição foi identificada como uma possível colaboradora do estudo e, sendo assim, gostaríamos de contar com sua autorização para realizar a pesquisa nesse estabelecimento sob sua responsabilidade.

Nossa atuação dar-se-á da seguinte forma: a pesquisadora acessará as crianças da referida faixa etária, diagnosticadas pelo serviço como obesas, a partir dos prontuários médicos. Em momento de suas consultas regulares no serviço de saúde, a pesquisadora procurará cada criança e seu respectivo responsável para explicar o projeto de pesquisa e fornecer, aos que se mostrarem interessados, o Termo de Consentimento Livre e Esclarecido e um questionário dirigido aos pais (a respeito de informações sobre desenvolvimento da criança).

Em seguida, a pesquisadora combinará com o responsável um horário para a realização da avaliação psicológicacom a criança, a ser realizada na própria instituição de saúde. Nesse contato, que durará cerca de 60 minutos, a pesquisadora fará uma breve conversa com cada participante e aplicará instrumentos de avaliação psicológica. O risco de participação no estudo é considerado mínimo, sendo que envolve apenas respostas (de crianças e seus responsáveis) a métodos avaliativos da Psicologia, implicando em atividades de desenhar e interpretar figuras em cartões. As informações são confidenciais e somente serão utilizadas para investigação científica, sem nenhuma identificação das pessoas que as forneceram.

A cooperação de seu estabelecimento será muito valiosa e imprescindível para que os objetivos desse estudo sejam alcançados. Participar do estudo será uma contribuição voluntária, sem oferecer qualquer pagamento pelas atividades realizadas. A colaboração nessa pesquisa poderá ser uma forma de contribuir para a construção de conhecimentos a respeito de algumas das características envolvidas na obesidade infantil, auxiliando na criação e aperfeiçoamento de intervenções e tratamentos voltados a essas crianças.Desde já, agradecemos a atenção dispensada.

Cordialmente,

\section{CARMEM GIL COURY}

Prof. Dra. SONIA REGINA PASIAN

Departamento de Psicologia- FFCLRP - USP - Av. Bandeirantes, 3900 - Monte Alegre

Fone: (16) 3602-3785 /Fax: (16) 3602-4835

E-mail:srpasian@ffclrp.usp.br 


\section{DECLARAÇÃO DE CONSENTIMENTO DA INSTITUIÇÃO DE SAÚDE}

PARA A PESQUISA

Eu, $\mathrm{RG}$ abaixo assinado, na função de da Instituição , declaro estar

de acordo com a realização do projeto de pesquisa anteriormente referido, aceitando que seja utilizado o banco de dados desta Instituição a fim de buscar as informações necessárias à identificação de eventuais alunos voluntários para a mesma. Autorizo também que a psicóloga responsável pelo projeto entre em contato com essas crianças, nos ambientes do serviço, para lhes propor o trabalho e, aos que consentirem, realizar a pesquisa em espaço da instituição (individualmente).

Diante do exposto, assino o presente termo, enquanto representante da Instituição, declarando o consentimento livre e esclarecido para esta pesquisa.

Ribeirão Preto, ......... de .......................... de 2013

Cidade e data

Assinatura e carimbo do Representante Institucional 
APÊNDICE B: Termo de Consentimento Livre e Esclarecido (TCLE) para pais elou responsáveis das crianças do Grupo 1.

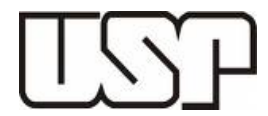

UNIVERSIDADE DE SÃO PAULO

Faculdade de Filosofia, Ciência e Letras de Ribeirão Preto

Departamento de Psicologia - Centro de Pesquisas em Psicodiagnóstico (CPP)

\section{TERMO DE CONSENTIMENTO LIVRE E ESCLARECIDO}

Estamos desenvolvendo uma pesquisa em Ribeirão Preto (SP), intitulada: "Investigação da Imagem Corporal e Dinâmica Psíquica na Obesidade Infantil”. Enfocamos este tema em função do crescente aumento da obesidade em crianças brasileiras e a necessidade de novos conhecimentos a respeito, de modo a favorecer estratégias de cuidados com esses indivíduos. Essa pesquisa tem por objetivo conhecer características de personalidade de crianças obesas e com peso normal, de sete a onze anos, por meio de um processo de avaliação psicológica. Esse trabalho será desenvolvido pela psicóloga Carmem Gil Coury, aluna de Mestrado em Psicologia na Faculdade de Filosofia, Ciências e Letras de Ribeirão Preto (FFCLRP) da Universidade de São Paulo (USP), e da Profa. Dra. Sonia Regina Pasian, professora do Departamento de Psicologia desta mesma Faculdade.

Essa pesquisa estudará crianças entre sete e onze anos que buscaram tratamento especializado para a obesidade em instituições de saúde, bem como crianças com peso normal, na mesma faixa etária. Assim, gostaríamos de convidar seu filho(a) a participar dessa pesquisa. Será combinado, com os responsáveis que concordarem com a participação da criança, um horário conveniente para as atividades que serão realizadas no próprio serviço de saúde, tendo duração aproximada de 60 minutos. As crianças que concordarem em participar do estudo realizarão, com a pesquisadora, três tarefas: um exercício de raciocínio, uma atividade de desenho e uma tarefa de interpretar cartões com manchas de tinta, para conhecer o modo de pensar e de vivenciar emoções dessas crianças. Será solicitado aos responsáveis que concordarem com a participação da criança o preenchimento de um questionário sobre o desenvolvimento de seu filho(a).

Uma das vias deste Termo é destinada ao responsável, e a outra deverá ser devolvida à pesquisadora. A aceitação ou não da participação na pesquisa, bem como desistência em qualquer etapa do processo não trará qualquer risco ou prejuízo ao tratamento da criança e em sua relação com o serviço de saúde. O risco de participação no estudo é considerado mínimo, sendo que envolve apenas respostas (de crianças e seus responsáveis) a procedimentos utilizados na Psicologia, exigindo apenas o tempo e atenção às atividades. As informações coletadas nesse estudo são confidenciais e somente serão utilizadas para a investigação científica. Os resultados desse trabalho deverão ser divulgados em espaços de comunicação científica, sempre protegendo a identidade dos participantes.

Assim, a sua colaboração e da criança por quem o senhor(a) é responsável é de grande valor para que este estudo seja possível. A participação é voluntária, de forma que não serão oferecidos pagamentos ou recompensas, bem como não há custos nessa sua colaboração. Além disso, caso sejam identificadas quaisquer dificuldades psicológicas, a pesquisadora cuidará de orientar os responsáveis e auxiliar o encaminhamento da criança, quando adequado, a atendimentos psicológicos específicos na rede de saúde de sua cidade.

A colaboração a essa pesquisa, ainda que não lhe traga benefícios diretos,poderá contribuir para a construção de conhecimentos a respeito de algumas das características envolvidas na obesidade infantil, auxiliando na criação e aperfeiçoamento de intervenções e tratamentos voltados a estas crianças. Agradecemos desde já sua colaboraçãoe permanecemos disponíveis para possíveis dúvidas e novas informações, em qualquer momento.

Cordialmente, 
Carmem Gil Coury

Pesquisadora - CRP: 06/ 114166

$\mathrm{Eu}$,
Profa. Dra. Sonia Regina Pasian

Orientadora - CRP: 06/24.018-0

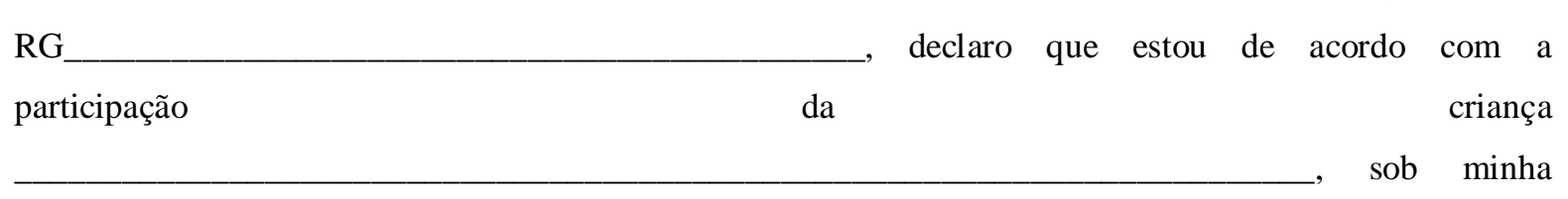

responsabilidade, como voluntário no projeto de pesquisa "Investigação da Imagem Corporal e Dinâmica Psíquica na Obesidade Infantil”, desenvolvido pela psicóloga CARMEM GIL COURY e pela Profa. Dra. Sonia Regina Pasian, assim como estou ciente de que os registros relativos a esse trabalho serão utilizados como material de trabalho científico e poderão ser divulgados em congressos e publicados em revistas ou livros especializados, resguardando-se o devido sigilo quanto a nossa identificação.

Ribeirão Preto, de de 201_.

(Assinatura do responsável pela criança)

\section{Observação:}

-Em caso de dúvidas referentes a essa pesquisa, entre em contato com o Departamento de Psicologia da FFCLRP-USP e esclareça-se conosco pelo telefone: (16) 3602.3785ou pelo email:srpasian@ ffclrp.usp.br, ou fale diretamente com Carmem Gil Coury, pelo telefone celular (16) 97123599 .

- Em caso de informações éticassobre a pesquisa, entrar em contato com:

Comitê de Ética em Pesquisa da Faculdade de Filosofia, Ciências e Letras de Ribeirão Preto - USP

Avenida Bandeirantes, 3900 - bloco 3 - sala 16 - 14040-901 - Ribeirão Preto - SP - Brasil

Fone: (16) 3602-4811 / Fax: (16) 3633-2660

E-mail: coetp@ ffclrp.usp.br 
APÊNDICE C: Termo de Consentimento Livre e Esclarecido (TCLE) para pais elou responsáveis das crianças do Grupo 2.

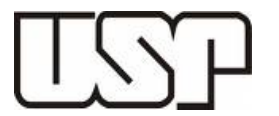

UNIVERSIDADE DE SÃO PAULO

Faculdade de Filosofia, Ciência e Letras de Ribeirão Preto

Departamento de Psicologia - Centro de Pesquisas em Psicodiagnóstico (CPP)

TERMO DE CONSENTIMENTO LIVRE E ESCLARECIDO

Estamos desenvolvendo uma pesquisa em Ribeirão Preto (SP), intitulada: "Investigação da Imagem Corporal e Dinâmica Psíquica na Obesidade Infantil". Enfocamos este tema em função do crescente aumento da obesidade em crianças brasileiras e a necessidade de novos conhecimentos a respeito, de modo a favorecer estratégias de cuidados com esses indivíduos. Essa pesquisa tem por objetivo conhecer características de personalidade de crianças obesas e com peso normal, de sete a onze anos, por meio de um processo de avaliação psicológica. Esse trabalho será desenvolvido pela psicóloga Carmem Gil Coury, aluna de Mestrado em Psicologia na Faculdade de Filosofia, Ciências e Letras de Ribeirão Preto (FFCLRP) da Universidade de São Paulo (USP), e da Profa. Dra. Sonia Regina Pasian, professora do Departamento de Psicologia desta mesma Faculdade.

Essa pesquisa estudará crianças entre sete e onze anos que buscaram tratamento especializado para a obesidade em instituições de saúde, bem como crianças com peso normal, na mesma faixa etária, em instituições de ensino fundamental. Assim, gostaríamos de convidar seu filho(a) a participar dessa pesquisa. Será combinado, com os responsáveis que concordarem com a participação da criança, um horário conveniente para as atividades, com autorização também dos professores.A atividade será realizada na própria escola, tendo duração aproximada de 60 minutos. As crianças que concordarem em participar do estudo realizarão, com a pesquisadora, três tarefas: um exercício de raciocínio, uma atividade de desenho e uma tarefa de interpretar cartões com manchas de tinta, para conhecer o modo de pensar e de vivenciar emoções dessas crianças. Será solicitado aos responsáveis que concordarem com a participação da criança o preenchimento de um questionário sobre o desenvolvimento de seu filho(a).

Uma das vias deste Termo é destinada ao responsável, e a outra deverá ser devolvida à pesquisadora. A aceitação ou não da participação na pesquisa, bem como desistência em qualquer etapa do processo não trará qualquer risco ou prejuízo ao ensino da criança e em sua relação com a escola. O risco de participação no estudo é considerado mínimo, sendo que envolve apenas respostas (de crianças e seus responsáveis) a procedimentos utilizados na Psicologia, exigindo apenas o tempo e atenção às atividades. As informações coletadas nesse estudo são confidenciais e somente serão utilizadas para a investigação científica. Os resultados desse trabalho deverão ser divulgados em espaços de comunicação científica, sempre protegendo a identidade dos participantes.

Assim, a sua colaboração e da criança por quem o senhor(a) é responsável é de grande valor para que este estudo seja possível. A participação é voluntária, de forma que não serão oferecidos pagamentos ou recompensas, bem como não há custos nessa sua colaboração. Além disso, caso sejam identificadas quaisquer dificuldades psicológicas, a pesquisadora cuidará de orientar os responsáveis e auxiliar o encaminhamento da criança, quando adequado, a atendimentos psicológicos específicos na rede de saúde de sua cidade.

A colaboração a essa pesquisa, ainda que não lhe traga benefícios diretos, poderá contribuir para a construção de conhecimentos a respeito de algumas das características envolvidas na obesidade infantil, auxiliando na criação e aperfeiçoamento de intervenções e tratamentos voltados a estas crianças. Agradecemos desde já sua colaboraçãoe permanecemos disponíveispara possíveis dúvidas e novas informações, em qualquer momento.

Cordialmente, 
Carmem Gil Coury

Pesquisadora - CRP: 06/ 114166

$\mathrm{Eu}$,

\section{Profa. Dra. Sonia Regina Pasian}

Orientadora - CRP: 06/24.018-0

$\mathrm{RG}_{\text {_Lação }}$
participaçaro que estou de acordo com a

responsabilidade, como voluntário no projeto de pesquisa "Investigação da Imagem Corporal e Dinâmica Psíquica na Obesidade Infantil”, desenvolvido pela psicóloga CARMEM GIL COURY e pela Profa. Dra. Sonia Regina Pasian, assim como estou ciente de que os registros relativos a esse trabalho serão utilizados como material de trabalho científico e poderão ser divulgados em congressos e publicados em revistas ou livros especializados, resguardando-se o devido sigilo quanto a nossa identificação.

Ribeirão Preto, de de 201

(Assinatura do responsável pela criança)

\section{Observação:}

-Em caso de dúvidas referentes a essa pesquisa, entre em contato com o Departamento de Psicologia da FFCLRP-USP e esclareça-se conosco pelo telefone: (16) 3602.3785ou pelo e-mail: srpasian@ffclrp.usp.br, ou fale diretamente com Carmem Gil Coury, pelo telefone celular (16) 97123599.

- Em caso de informações éticas sobre a pesquisa, entrar em contato com:

Comitê de Ética em Pesquisa da Faculdade de Filosofia, Ciências e Letras de Ribeirão Preto - USP

Avenida Bandeirantes, 3900 - bloco 3 - sala 16 - 14040-901 - Ribeirão Preto - SP - Brasil

Fone: (16) 3602-4811 / Fax: (16) 3633-2660

E-mail: coetp@ ffclrp.usp.br 
APÊNDICE D: Termo de Assentimento para voluntários da pesquisa (Grupo 1 e Grupo2).

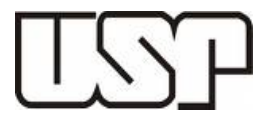

UNIVERSIDADE DE SÃO PAULO

Faculdade de Filosofia, Ciência e Letras de Ribeirão Preto

Departamento de Psicologia - Centro de Pesquisas em Psicodiagnóstico (CPP)

TERMO DE CONSENTIMENTO LIVRE E ESCLARECIDO

Gostaria de convidar você a participar como voluntário(a) da pesquisa "INVESTIGAÇÃO DA IMAGEM CORPORAL E DINÂMICA PSÍQUICA NA OBESIDADE INFANTIL”. Esse estudo quer entender melhor como a criança que está acima do peso organiza seus pensamentos e sentimentos, em relação àquela que está com o peso normal. Será que existe alguma diferença?

Estudar esse assunto pode nos ajudar a compreender a obesidade na criança e favorecer formas de ajudá-las a para perder peso, já que estar acima do peso pode trazer dificuldades de saúde, principalmente mais tarde, na idade adulta. Você pode nos ajudar com esse trabalho, motivo do atual convite para participar dessa pesquisa.

Vou lhe propor algumas atividades para fazer comigo, depois da concordância e autorização de seus pais ou responsáveis. Faremos quatro atividades, envolvendo desenhos, opiniões sobre figuras mostradas em cartões, exercícios de raciocínio e atividade de montagem a partir de quadrículos coloridos, o que deve demorar em torno de uma hora. Caso você se canse ou tenha dúvidas, podemos parar para descansar e você pode me perguntar o que desejar sobre as atividades. Como você está participando voluntariamente, pode desistir também, sem qualquer problema.

Para participar deste estudo, o responsável por você deverá autorizar e assinar um termo de consentimento. Ele também poderá interromper a sua participação se assim quiser. Como estamos querendo ajudar a aumentar o conhecimento sobre a obesidade infantil, precisamos dividir os nossos resultados com as outras pessoas que cuidam destas crianças! Por isso, quando o trabalho estiver pronto, escreveremos para revistas dos profissionais da saúde, divulgando esses achados. Mas não se preocupe, as suas informações pessoais, que deixam saber quem você é, serão guardadas adequadamente, mantendo sua identidade protegida.

Este estudo tem risco mínimo, o que significa que seriam os mesmos riscos ao fazermos nossas atividades do dia a dia, como conversar, estudar, realizar atividades escolares.

Os seus dados ficarão arquivados com o pesquisador responsável por um período de cinco anos, e após esse tempo serão destruídos, também para a proteção da sua identidade. Este termo de assentimento foi impresso em duas vias, sendo que uma cópia será guardada por mim, a pesquisadora responsável, e a outra ficará com você.

$\mathrm{Eu}$, fui informado(a) dos objetivos do presente estudo de maneira clara e detalhada e esclareci minhas dúvidas, declarando aceitar participar como voluntário no projeto de pesquisa "Investigação da Imagem Corporal e Dinâmica Psíquica na 
Obesidade Infantil”, desenvolvido pela psicóloga CARMEM GIL COURY e pela Profa. Dra. Sonia Regina Pasian, assim como estou ciente de que os registros relativos a esse trabalho serão utilizados como material de trabalho científico e poderão ser divulgados em congressos e publicados em revistas ou livros especializados, resguardando-se o devido sigilo quanto a minha identificação.

Ribeirão Preto, de de 201

(Assinatura da pesquisadora responsável)

(Assinatura do voluntário)

\section{Observação:}

-Em caso de dúvidas referentes a essa pesquisa, entre em contato com o Departamento de Psicologia da FFCLRP-USP e esclareça-se conosco pelo telefone: (16) 3602.3785ou pelo e-mail: srpasian@ffclrp.usp.br, ou fale diretamente com Carmem Gil Coury, pelo telefone celular (16) 97123599.

- Em caso de informações éticas sobre a pesquisa, entrar em contato com: Comitê de Ética em Pesquisa da Faculdade de Filosofia, Ciências e Letras de Ribeirão Preto - USP Avenida Bandeirantes, 3900 - bloco 3 - sala 16 - 14040-901 - Ribeirão Preto - SP - Brasil

Fone: (16) 3602-4811 / Fax: (16) 3633-2660

E-mail: coetp@ ffclrp.usp.br 